\title{
Socioeconomic status, lifestyle and the risk of cancer of lung, breast, colon and stomach
}

Citation for published version (APA):

van Loon, A. J. M. (1997). Socioeconomic status, lifestyle and the risk of cancer of lung, breast, colon and stomach. [Doctoral Thesis, Maastricht University]. Universitaire Pers Maastricht.

https://doi.org/10.26481/dis.19970411al

Document status and date:

Published: 01/01/1997

DOI:

10.26481/dis.19970411al

Document Version:

Publisher's PDF, also known as Version of record

\section{Please check the document version of this publication:}

- A submitted manuscript is the version of the article upon submission and before peer-review. There can be important differences between the submitted version and the official published version of record.

People interested in the research are advised to contact the author for the final version of the publication, or visit the DOI to the publisher's website.

- The final author version and the galley proof are versions of the publication after peer review.

- The final published version features the final layout of the paper including the volume, issue and page numbers.

Link to publication

\footnotetext{
General rights rights.

- You may freely distribute the URL identifying the publication in the public portal. please follow below link for the End User Agreement:

www.umlib.nl/taverne-license

Take down policy

If you believe that this document breaches copyright please contact us at:

repository@maastrichtuniversity.nl

providing details and we will investigate your claim.
}

Copyright and moral rights for the publications made accessible in the public portal are retained by the authors and/or other copyright owners and it is a condition of accessing publications that users recognise and abide by the legal requirements associated with these

- Users may download and print one copy of any publication from the public portal for the purpose of private study or research.

- You may not further distribute the material or use it for any profit-making activity or commercial gain

If the publication is distributed under the terms of Article $25 \mathrm{fa}$ of the Dutch Copyright Act, indicated by the "Taverne" license above, 
SOCIOECONOMIC STATUS, LIFESTYLE AND THE RISK OF CANCER OF LUNG, BREAST, COLON AND STOMACH 
CIP-DATA KONINKLIJKE BIBLIOTHEEK, DEN HAAG

(C) Van Loon, Adriana Johanna Maria

Socioeconomic status, lifestyle and the risk of cancer of lung, breast, colon and stomach / Adriana Johanna Maria van Loon. - [S.I.s.s.n.] Thesis Universiteit Maastricht. - With summary in Dutch.

ISBN $90-74130-20-8$

NUGI 757

Subject headings: socioeconomic status - cancer - lifestyle - working conditions.

Tekening omslag: Hay Wijnhoven, Nijmegen. Ets/Aquatint.

Produktie: Datawyse | Universitaire Pers Maastricht. 
SOCIOECONOMIC STATUS, LIFESTYLE AND THE RISK OF CANCER OF

\section{LUNG, BREAST, COLON AND STOMACH}

\section{PROEFSCHRIFT}

ter verkrijging van de graad van doctor aan de Universiteit Maastricht,

op gezag van de Rector Magnificus, Prof. mr. M.J. Cohen volgens het besluit van het College van Dekanen, in het openbaar te verdedigen op 11 april 1997 om 14.00 uur

door 
Promotores:

Co-promotor:

Beoordelingscommissie:
Prof. dr. ir. P.A. van den Brandt

Prof. dr. F. Sturmans

Dr. ir. R.A. Bausch-Goldbohm

Prof. dr. ir. W.H.M. Saris (voorzitter)

Prof. dr. M.J. Drop

Prof. dr. L.J. Gunning-Scheepers (Universiteit van Amsterdam)

Prof. dr. J.A. Knottnerus

Prof. dr. J.P. Mackenbach (Erasmus Universiteit Rotterdam) 


\section{CONTENTS}

1. Introduction

2. Differences in cancer incidence and mortality among socio-economic groups Scan J Soc Med 1995; 23: 110-120.

3. Lung cancer: is there an association with socioeconomic status in The Netherlands? $J$ Epidemiol Comm Health 1995; 49: 65-69.

4. Socioeconomic status and breast cancer incidence: A prospective cohort study. Int J Epidemiol 1994; 23: 899-905.

5. Socioeconomic status and colon cancer incidence: A prospective cohort study. Br J Cancer 1995; 71: 882-887.

6. Socioeconomic status and stomach cancer incidence: results from the Netherlands Cohort Study. Submitted.

7. Occupational exposure to carcinogens and lung cancer risk: results from the Netherlands Cohort Study. Submitted.

8. Socioeconomic status and lung cancer incidence in men in the Netheriands: is there a role for occupational exposure? J Epidemiol Comm Health. accepted

9. Socioeconomic status, physical activity at work and colon cancer incidence: results from the Netherlands Cohort Study.

10. General discussion

Summary

Samenvatting

Dankwoord

Authors 
Voor mijn ouders 
Chapter 1

INTRODUCTION 


\section{Background}

Differences in cancer risk between socioeconomic groups thave been reported very often. Earlier research in affluent countries showed that different types of cancer (lung, ${ }^{1}$ stomach, ${ }^{2}$ cervix ${ }^{3}$ ) more frequently occur among people with a low socioeconomic status, whereas other types of cancer (breast, ${ }^{4}$ colon $^{5}$ ) occur more often among people in the higher socioeconomic status categories. Most of these studies have been conducted in the United Kingdom, the United States of America and Italy. Until now, there has been no study on socioeconomic status (SES) and cancer risk conducted in the Netherlands. In most articles about SES and cancer the authors speculate about possible explanations for their findings. Remarkably little research has been done on the evaluation of possible explanations in simultaneous analyses. Therefore, research is warranted to study the association between SES and cancer risk, in which possible explanations for this association are explicitly tested.

Socioeconomic health differences are one of the classical themes in public health research. ${ }^{6}$ It was assumed that after the introduction of the so-called welfare state, socioeconomic health differences would disappear or at least diminish to a negligible extent. ${ }^{6}$ Unfortunately, this was not the case. In the Netherlands, this conclusion led to the initiation of a research programme about socioeconomic health differences for the years 1989-1993. The objectives of this research programme were a quantification of the extent of socioeconomic health differences in the occurrence of various health problems in the Netherlands, the explanation of socioeconomic health differences in the Netherlands and the evaluation and development of strategies for the diminishing of socioeconomic health differences. ${ }^{6}$ As part of this research programme the present study was started on the association between socioeconomic status and cancer, within a prospective cohort study on diet and cancer.

\section{Conceptualization and operationalization of socioeconomic status}

From a sociological point of view SES is defined as the position of people in the social stratification with the accompanied prestige or social standing. ${ }^{*}$ An elaboration of this concept can be unidimensional or multidimensional. According to Marx, the social inequality is unidimensional and ownership of the means of production is the fundamental dimension of stratification. ${ }^{7}$ Weber started from the assumption of three dimensions of inequality: economic position, political power and social status. ${ }^{8}$ The most frequently used measures of SES are based on Weber's view of three separate but linked dimensions of SES. ${ }^{-}$Therefore, in the present research project on SES and cancer is also chosen for a multidimensional starting point. The three dimensions of SES are often operationalized by means of education (material and symbolic resources), occupation (economic and symbolic resources) and income (material and economic resources). This operationalization does not include political power. However, this aspect is less important in demacracies like the Netherlands. ${ }^{10}$

\section{Possible explanations for the association between SES and health}

Generally speaking, people with a higher SES are healthier compared with people with a lower SES. The life expectancy of people within the higher SES categories is also longer. ${ }^{11}$ For these findings four different explanations were proposed in the so-called "Black 
Report", which was written by a Working Group on Inequalities in Health, set up in 1977 in the United Kingdom. ${ }^{12}$ These four explanations were the artefact explanation, which emphasizes the incorrectness of measurement of SES; the natural or social selection theory; which assumes that those in better health are more likely to be upwardly mobile and those in worse health dowriwardly; the materialist explanation, which points at social class differences in health linked to aspects of living (e.g. poor housing) and aspects of working (heavy work, exposure to harmful agents); and the cultural or lifestyle explanation, which assumes that differences in health might be caused by differences in lifestyle (e. g. smoking habits, eating habits), associated with SES.

\section{Associations between SES and cancer}

As starting point for developing hypotheses concerning the association between SES and cancer risk, we used the four possible explanations for socioeconomic health differences derived from the Black Report. As aiready mentioned, the kind of association between SES and cancer risk is not the same when the different individual cancer sites are compared. This observation does not support the artefact explanation nor the natural or social selection theory. The materialist explanation and the cultural or lifestyle explanation are both possible explanations for the differences in cancer incidence among the SES categories. Starting from the latter two explanations, the association between SES and cancer risk runs through lifestyle characteristics and/or aspects of working and living. To test whether these factors are an explanation for the association between SES and cancer, we consider them as intermediate factors. Besides these intermediate factors, there are also aspects like age and family history of cancer which will confound the association between SES and cancer. These confounders will also be considered in the analyses.

\section{Aims of the study}

The aims of this study are to investigate in a prospective study whether there is an association between SES and lung, breast, colon and stomach cancer risk in the Netherlands, and whether these associations can be attributed to lifestyle and working conditions. The choice of these four tumour sites is based on the proposed association with SES and on the relatively high incidence of these cancers in the Netheriands. Possible explanations for these potential associations are explicitly tested through multivariate analyses. For each tumour site specific hypotheses are formulated based on the literature. An extensive description of the literature is given in chapter 2 . Briefly, it is hypothesized that people with a lower SES have a higher risk of lung cancer. "Moreover, this higher risk of lung cancer in the lower SES categories may be due to differences in smoking habits between the SES categories, ${ }^{13}$ differences in dietary habits, ${ }^{14}$ and differences in working conditions ${ }^{t 5}$ (exposure to carcinogenic agents during work). The hypothesis with regard to breast cancer runs as follows: women with a higher SES have a higher risk of breast cancer ${ }^{4}$ and this higher risk may be due to differences in the distribution of reproductive factors. "For colon cancer the hypothesis is that people with a higher SES have a higher risk. ${ }^{5}$ This higher risk of colon cancer in the higher SES categories may be due to differences in alcohol intake ${ }_{1}^{17}$ dietary habits, ${ }^{14}$ reproductive factors, ${ }^{16}$ and/or differences in working conditions (physical activity at work). Finally, people with a lower SES are expected to have a higher risk of stomach cancer, ${ }^{2}$ and this higher risk may be due to differences in dietary habits, ${ }^{14}$ smoking habits, ${ }^{13}$ and alcohol intake. ${ }^{17}$ 


\section{The Netherlands Cohort Study}

The association between SES and cancer and the role of lifestyle and working conditions in explaining possible associations are investigated in the Netherlands Cohort Study (NLCS) on diet and cancer. ${ }^{19}$ This is a prospective cohort study that started in 1986 among 58,279 men and 62,573 women aged 55-69 years at the beginning of the study. Data on highest level of education for the individual and for his or her partiner, job history, dietary habits, smoking habits and other potential risk factors for cancer were collected by means of a self-administered questionnaire. Therefore, this prospective study includes most of the relevant information for studying the association between SES and different types of cancer and the role of lifestyle aspects and working conditions simultaneously. Unfortunately, there was no information available on living conditions.

Follow-up for incident cancer has been established by record linkage with all regional cancer registries in the Netherlands and with a national pathology register. For the first analyses information was used from the period between September 1986 through December 1989 (3.3 years of follow-up). Later on, the analyses could be conducted with data gathered after 4.3 years of follow-Up. SES was operationalized by means of highest attained level of education and occupational history, two of the recommended measures of SES. ${ }^{9}$ Information about the occupation was coded according to occupational group and required training (EGP score), ${ }^{10}$ and according to social standing (U\&S score). ${ }^{10}$

\section{Outline of the thesis}

In chapter 2 the literature on SES and cancer risk at different sites is reviewed. This review is restricted to studies conducted in affluent countries, after 1970. Only studies using income, education and/or occupation as SES indicators are included. Associations between SES and lung, breast, colon and stomach cancer are described in chapter 3, 4, 5 and 6 , together with the role of lifestyle factors in explaining these associations. In chapter 7 the construction of a coding system to assess the probability of exposure to carcinogens at work is described. Moreover, the association between this probability of exposure to carcinogens and lung cancer risk is presented in this chapter. In chapter 8 this coding system is used to find out whether exposure to carcinogens can explain the association between SES and lung cancer. Chapter 9 describes the construction of a coding system for physical activity at work and the role of physical activity at work in explaining the association between SES and colon cancer. Finally "chapter 10 contains a general discussion of our findings.

\section{REFERENCES}

1. Leon DA. Longitudinal study. Social distribution of cancer, 1971-1975 (OPCS Series LS No. 3). London: HMSO, 1988.

2. Pukkala $E_{1}$ Teppo L. Socioeconomic status and education as risk determinants of gastrointestinal cancer. Prew Med 1986;15:127-138.

3. Parazinni F. La Vecchia C, Negri E, Maggi M. Oral contraceptive use and irvasive cenvical cancer. Int $J$ Epidemiol 1990;19:259-263.

4. Rimpela $\mathrm{AH}_{3}$. Pukkala E. Cancers of affluence: positive social class gradient and rising incidence trend in some cancer forms. Soc Soi Med 1987;24:601-606.

5. Ferraroni M, Negri E. La Vecchila C, D'Avanzo B. Franceschi S. Socioeconomic indicators, tobacco and alcohol in the aetiology of digestive tract neoplasms. Int $J$ Epidemiol 1989:18:556-562 
6. Mackenbach JP. Ongezonde verschillen. Over sociale stratificatie en gezondheld in Nedertand. Assen: Van Gorcum, 1994.

7. Schuyt CUM. Maatschappelike ongelijkheid. Een sociologische interpretatie. Economisch Statistische Berichten 1987:72:195:198.

8. Giddens E, Sociology (2nd edition). Cambridge, Polity Press, 1993.

9. Liberatos P, Link BG, Kelsey JL. The measurement of social elass in epidemiology. Epidemial Rer 1988; 10:87-121.

10. Van Berkel-Van Schaik AB, Tax B. Naar een standaard operationalisatie van sociaal-economische status woor epidemiologisch en sociaal-medisch onderzoek. Saciaal-economische gezondheidsverschillen nr 6 . Den Haag DOP, 1990.

11. Van de Water HPA, Boshuizen HC, Perenboom RJM. Health expectancy in the Netherlands 1983-1990. Eur J Public Health 1996;6:21-28.

12. Black D, Morris JN, Smith C, Townsend P. The Black Report. London: Penguin Books, 1990.

13. Rosen $M$, Hanning $M$, Wall $S$. Changing smoking habits in Sweden: towards better health, but not for all. Int J Epidemiol 1990;19:316-322.

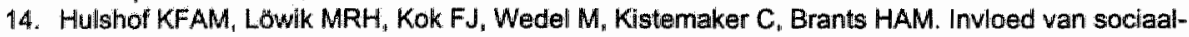
economische status op voeding en andere levensstilffactoren. In: Mackenbach JP, ed. Sociaal-economische gezondheidsverschillen onderzocht.Deel III. Den Haag: DOP, 1991.

15. Jockel $\mathrm{KH}$, Ahrens $\mathrm{W}$, Wichmann HE et al. Occupational and environmental hazards associated with liung cancer. Int J Epidemiol 1992;21:202-213.

16. Jacobsen BK, Lund $E$. Level of education, use of oral contraceptives and reproductive factors: The Tromso Study. Int I Epidemiol 1990;19:967-970.

17. Kromhout $D$, Doornbos $G$, Hoffmans MDAF. Voedselkeuze, leekwijze en sterfte in relatie tot opleiding. $T$ Soc Gezondheidsz 1988;66:345-348.

18. Ballard-Barbasi R, Schatzkin $A$, Albanes $D$ et al, Physical activity and risk of large bowel cancer in the Framingham study. Cancer Res 1990;50:3610-3613.

19. Van den Brandt PA, Goldbohm RA, Van "it Veer $P$, Volovics $A$, Hermus RJJ, Sturmans F. A large-scale prospective cohort study on diet and cancer in the Netherlands. J Clin Epidemiol 1990;43:285-295. 
Chapter 2

DIFFERENCES IN CANCER INCIDENCE AND MORTALITY

AMONG SOCIOECONOMIC GROUPS

A. Jeanne M. van Loon, Johannes Brug, R. Alexandra Goldbohm, Piet A. van den Brandt 


\section{ABSTRACT}

Objectives - In this article studies on the association between socioeconomic status (SES) and risk for cancer at different sites are reviewed.

Methods - The review is restricted to studies conducted in affiuent societies, after 1970. Only studies using income, education and/or occupation as SES indicators are included. Results - A more or less consistent positive association between SES and cancer risk was found for colon and breast cancer. More or less consistent inverse associations were found for lung, stomach, oropharyngeal and esophageal cancer. Inconsistent associations were reported for cancer of the rectum and pancreas. Possible explanations for SES differences in cancer risk are discussed with special emphasis on lifestyle variables related to cancer risk.

Conclusions - It is concluded that it is still unclear whether the reported associations can be (partially) attributed to lifestyle related risk factors for cancer such as smoking, nutritional habits, drinking habits and reproductive factors. 


\section{INTRODUCTION}

Health differences between socioeconomic groups in industrialized countries have been reported frequently in the last decades. ${ }^{1,2}$ Because of an increase in the general standard of living it was expected that such health differences would have been diminished.

Nevertheless, there are indications that the health gap between socioeconomic groups has not disappeared in affluent countries. ${ }^{3.4}$ These health differences can become apparent through differences in life expectancy, perceived health status, anthropometric characteristics (birth weight, adult body height) and in differences in incidence and mortality of various chronic diseases, for example coronary heart disease and cancer..$^{2,5}$

In this article studies conducted since 1970 on differences in cancer incidence and mortality between various socioeconomic groups are reviewed in which education, occupation and income are used as socioeconomic status (SES) indicators. The diversity of methods used in these studies makes a formal statistical overview impossible. Therefore, the results of the reviewed studies are compared in a qualitative matter. The year 1970 was chosen because literature on research on SES differences in cancer risk conducted before approximately 1970 has been reviewed before. ${ }^{5}$ This review is restricted to the three SES indicators mentioned because they are recommended as the most valid and reliable by various authorities and are the most widely used in epidemiologic research. ${ }^{7}$

Although SES is associated with risk for various cancer sites, it is not supposed to be a direct risk factor. SES is commonly regarded as a proxy for differences in lifestyle variables that have been identified as possible risk factors for cancer, e.g. smoking, nutritional habits, reproductive factors, occupational exposure to carcinogens etc. "Therefore, the possibility of explaining differences in cancer incidence and mortality between SES groups through differences in lifestyle is discussed.

\section{SOCIOECONOMIC STATUS}

Socioeconomic status is usually operationalized through occupation, education and/or income. There are different scales to measure these three indicators of SES. The most complex indicator to measure is occupation. The earliest classification system widely used in epidemiologic research, which is based on occupation as SES indicator, is the British Registrar General's scale, which includes five social classes, based on the occupation of the head of household. ${ }^{7}$ Nevertheless, each social class represents a very broad range of occupations $^{9}$ and the accuracy of classification is not always satisfactory. ${ }^{10}$

Other problems when using occupational status as SES indicator have to do with differences in occupational classification between jobs ulsually carried out by women and jobs usually carried out by men ${ }^{10,11}$ how to classify persons without formal occupation, such as large groups of women with no formal employment, students and pensioners, and how to classify people who have changed jobs or have more than one job at the same time. Furthermore, occupation can be classified according to different categorizations: an exposure-based categorization, a prestige-based categorization or an economic-based categorization. $^{12}$ 
Highest level of education is a characteristic that is easily obtainable and recordable. It applies to every adult individual and in individuals it is stable over time ${ }^{53}$ Measurement of educational level can be based on number of years at school, academic degrees or special certificates. Number of years at school is the most commonly used measure of education, but certification is found to be more influential in determining prestige. ${ }^{14}$ The fact that (level of) education is stable over time has also negative implications, since it can mask important changes in individual circumstances after education is finished..$^{13}$ Inclusion of information on additional courses can probably correct this disadvantage. Another disadvantage of using education as a measure of SES is that people of higher age generally have a lower average level of education due to the gradually rising level of education in the last decades (cohort effect)..$^{7.15}$

Measurement of the third indicator of SES, income, gives several problems. There is no uniform definition, it is unstable over time, age-dependent and questionnaire items on income are often not or incompletely answered, ${ }^{7.12}$ Part of these objections also apply to occupation and education, but not as strong as for income. Another problem is that of comparability across households of different size. To overcome this problem, one can use the poverty index, which relates total familly income to family size. ${ }^{7}$

\section{METHODS}

In this article literature concerning studies on the association between SES and cancer risk conducted since 1970 is reviewed. In order to find relevant publications the MEDLINE computerized database from the Index Medicus was used. Initial keywords for the MEDLINE search were SOCIOECONOMIC AND CANCER. Also strongly related or similar keywords like education, Occupation and income, and TUMOR and NEOPLASMS were checked in various combinations. Furthermore, all references in the publications seiected through MEDLINE were checked for relevant articles and reports not included in the MEDLINE selection. Finally, the Dutch literature database on socioeconomic health differences, located in Rotterdam, the Netherlands, was searched for literature on SES and cancer risk.

Publications had to meet the following criteria in order to be included in this review:

A) Studies must have been conducted after 1970;

B) The published studies must have been conducted in affluent societies;

C) The studies must have used education, occupation andior income as indicators for SES. Furthermore, studies focussing primarily on occupation related exposure and not using occupation as SES indicator; were also excluded from this review.

\section{SOCIOECONOMIC STATUS AND CANCER}

\section{Stomach cancer}

The results of the thirteen reviewed studies ${ }^{16-27}$ on stomach cancer risk and SES are summarized in table 1. An inverse association between SES and stomach cancer risk was found consistently. Relative risks (high versus low SES) between 0.24 and 1.09 were reported. Two of the eight reviewed studies on SES and stomach cancer incidence were adjusted for possible lifestyle related risk factors. ${ }^{18,19} \mathrm{~A}$ case-control study conducted in italy 
adjusted for smoking status, and for alcohol and coffee consumption, ${ }^{18}$ while a case-control study conducted in New Zealand adjusted only for smoking status. ${ }^{\text {" }}$ Both studies found inverse associations after adjustment comparable to the unadjusted results in the same studies. Five studies on SES and stomach cancer mortality were reviewed. ${ }^{24-27}$ Inverse associations with SES were found in all studies " one study reporting a significant association. ${ }^{24}$

\section{Colon cancer}

The studies on SES and colon cancer risk are presented in table 2. A rather consistent positive association between SES and colon cancer risk was found ${ }^{16-19,21-26,28-31}$ allthough more studies found a significant positive association with occupation ${ }^{24 \cdot 23,28,30}$ compared to education. ${ }^{22}$ Two studies used income as SES indicator; one reported a non-significant inverse association for both men and women ${ }^{16}$ and in the second study no association was found. "Relative risks between 0.87 and 2.16 were reported for high versus low SES. Two studies made adjustments for possibly lifestyle related risk factors, namely smoking, coffee and alcohol consumption ${ }^{18}$ and smoking. ${ }^{46}$ Five studies on SES and colon cancer mortality were reviewed. ${ }^{24-26,31}$ The results on the association between SES and colon cancer mortality are similar to the results for colon cancer incidence.

\section{Other cancers of the digestive tract}

A consistent inverse association was found between SES and oropharyngeal cancer. Five of the six case-control studies on the relation between SES and the incidence of oropharyngeal cancer showed a modest to strong inverse association. ${ }^{18,32-35}$ The sixth study used a crosssectional design ${ }^{16}$ and took pharyngeal cancer separately into account. It showed inconsistent and non-significant results. Between the case-control studies there are great differences in strength of the association; odds ratios of high SES versus low SES vary from 0.16 to 0.61 . In four studies ${ }^{16,16,33,34}$ the researchers controlled for lifestyle variables like smoking and/or alcohol consumption. The results of these adjustments are not consistent. In one case-control study an unadjusted significant inverse relation between SES and oropharyngeal cancer changed after adjustment for smoking, alcohol consumption, age, race, marital status, geographic area, tooth loss and denture problems into a non-significant inverse association. ${ }^{33}$ In another case-control study a significant inverse association (OR $=0.16$ ) did not really change after adjustment for smoking and alcohol consumption (OR $=0.19),{ }^{28}$ and in a cross-sectional study adjustment for smoking did not influence the results for pharyngeal cancer. ${ }^{16}$ Elwood ef al. ${ }^{34}$ reported only adjusted results for cancer of the mouth and pharynx separately. After adjustment for age, sex, alcohol and cigarette consumption, marital status, dental care and history of tuberculosis, they found a non-significant inverse association between occupational status and cancer of the mouth ( $O R=0.66)$ and a significant inverse association between SES and cancer of the pharynx $(\mathrm{OR}=0.46)$.

Although there was no clear relation between various SES indicators and the incidence or mortality of esophageal cancer in a cross-sectional study design ${ }_{0}{ }^{16,24,25}$ one case-control study in Italy ${ }^{18}$ and cohort studies in Finland ${ }^{22}$ and Sweden ${ }^{21}$ showed a significant, inverse association between SES (education and occupation) and incidence of esophageal cancer. It seems that there was no difference in the relation between esophageal cancer and the three SES-indicators. In all studies adjustment was made for age and sex. Ferraroni et al. also adjusted for marital status, smoking, coffee and alcohol consumption. This adjustment 


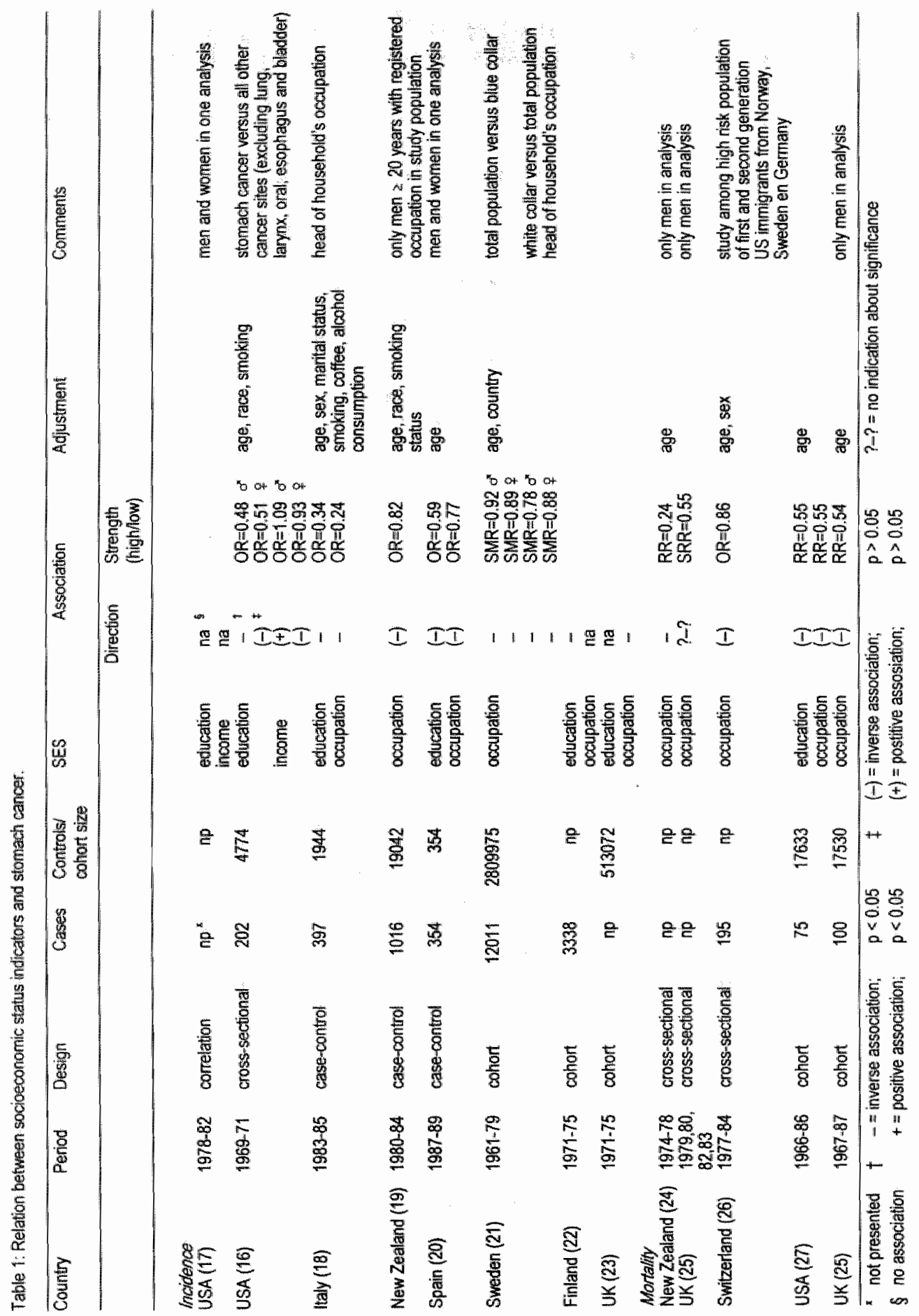




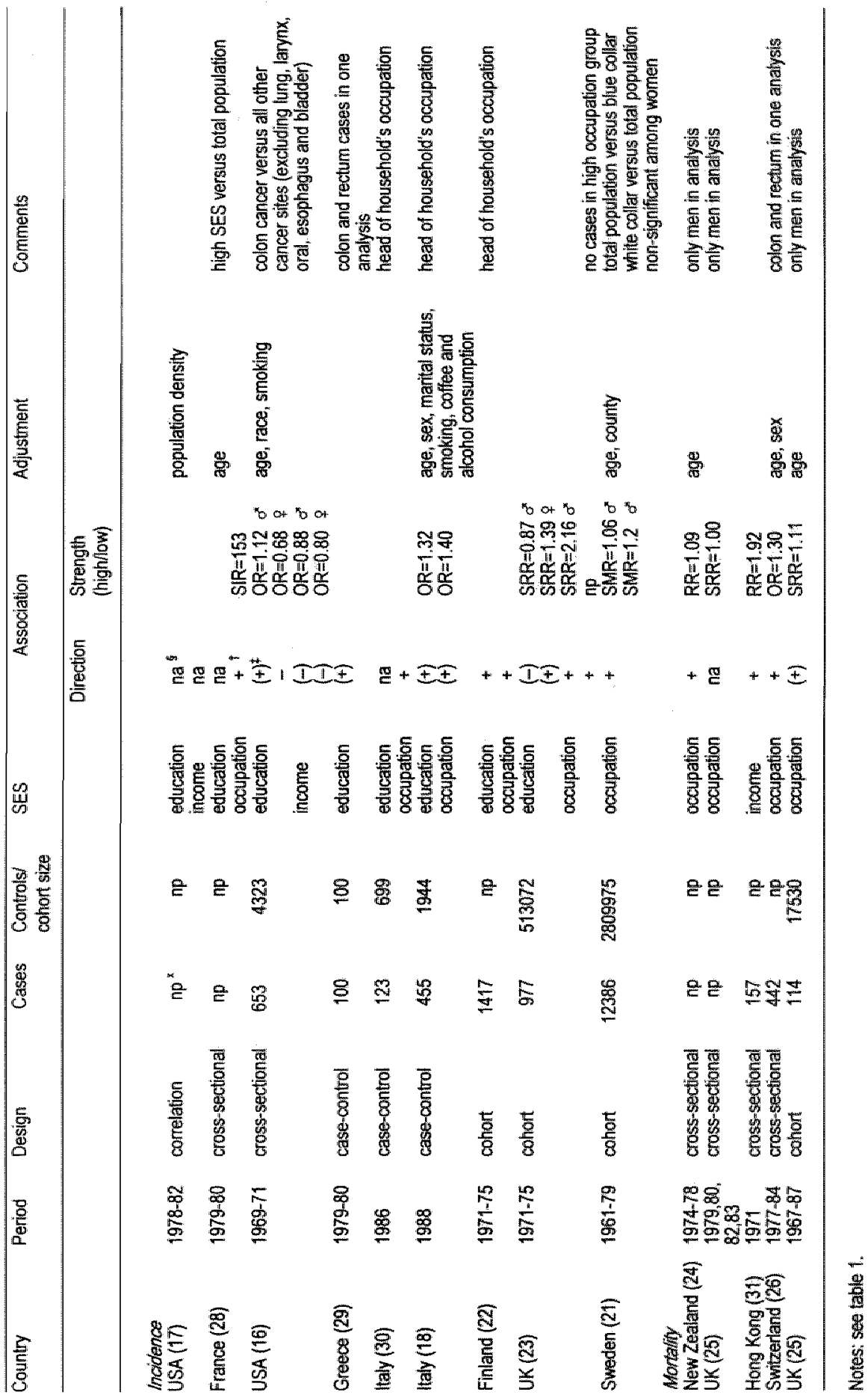


did not make a real difference in the associations between esophageal cancer and education or social class, although there was a significant positive association between the risk of esophageal cancer and smoking habits or total alcohol consumption. ${ }^{\text {"s }}$

The association between SES and pancreatic cancer risk is not clear. Four studies on pancreatic cancer incidence were reviewed. ${ }^{18,21,22,38}$ One study found a non-significant positive association with income, ${ }^{3}$ and one study found a non-significant inverse association with education." Of the five studies on SES and pancreatic cancer mortality. two found non-significant inverse associations. ${ }^{24,25}$ The remaining studies on SES and pancreatic cancer risk did not find significant results and did not present information on the direction of the associations found. ${ }^{25,28}$

A rather consistent inverse association between SES and liver cancer risk was found. Of the four studies on liver cancer incidence, ${ }^{18 ; 24-23}$ two found a significant inverse association with education and/or occupation. ${ }^{18,22}$ Nevertheless, a cohort study conducted in Sweden found a higher liver cancer incidence among white collar workers in comparison with the general population, among men. ${ }^{21}$ Three studies evaluating the association between SES and liver cancer mortality all found inverse associations, significant results were found in three studies. ${ }^{2428}$

The association between SES and rectal cancer risk is not clear. Nine studies on SES and rectal cancer incidence were reviewed..$^{16-18,21-23,26-30}$ Four studies found an inverse association, ${ }^{16,18,33,40}$ three of these reported statistically significant results. ${ }^{18,23,30}$ In all studies reporting inverse associations occupation was used as SES indicator. One of these studies also found a significant inverse association between rectal cancer incidence and education. ${ }^{48}$ The studies reporting significant associations were two case-control studies conducted in Italy, ${ }^{40,30}$ and a cohort study conducted in the U.K. ${ }^{23}$

A cross-sectional study conducted in the US reported non-significant positive associations between SES and rectal cancer incidence, with occupation and income as SES indicators, for income only among women. ${ }^{16}$ Five studies did not report associations between SES and rectal cancer incidence ${ }^{17,21,22,28,29}$ Except for a case-control study conducted in Italy, where adjustment was made for alcohol and coffee consumption, ${ }^{18}$ no studies were found where the association between SES and rectal cancer incidence was adjusted for possible lifestyle related risk factors. Five studies on SES and rectal cancer mortality were rewlewed ${ }^{2423,34}$ with comparable results as were found for rectal cancer incidence.

\section{Lung cancer}

The reviewed studies on SES and lung cancer risk showed a consistent inverse association between lung cancer incidence or mortality and SES. Seven studies on SES and lung cancer incidence were reviewed. All studies on SES and lung cancer found an inverse (age adjusted) association for men $16,17,21,23,37,39$ independent of study design, both for educational level and occupation, with relative risks of the highest versus the lowest categories varying from 0.4 to 0.9 . In five studies results were presented for women separately. ${ }^{16,21,23,33,39}$ A cross-sectional study ${ }^{16}$ showed a significant inverse association between lung cancer incidence and education among women $(O R=0.6)$ and a case-control study also showed significant associations with an OR of 0.5 for highest versus lowest occupational class and an $O R$ of 0.7 for highest versus lowest education. ${ }^{39}$ Another case-control study with lifetime non-smokers or former smokers showed no association. ${ }^{38}$ The two cohort studies with 
information on SES and lung cancer risk for women ${ }^{21,23}$ showed relative risks of lung cancer close to 0.9 , comparing the highest versus lowest SES. Only one study design incorporated smoking, the most important risk factor for lung cancer, as control variable, ${ }^{15}$ which did not make any real difference in the inverse association between SES and lung cancer incidence. All studies on SES and lung cancer mortality showed a significant inverse association. ${ }^{24-26}$

\section{Breast cancer}

Table 3 summarizes the reviewed studies on breast cancer and SES. Although almost all of the twelve studies on SES and breast cancer incidence reported a positive association, there are differences in significance and magnitude: relative risks of the highest versus the lowest category varied from 1.0 to 2.5 . These differences in results are probably due to differences in the use of control variables, because in almost all studies that included age as the only confounding variable, significant positive associations were found, with relative rates varying from to 1.2 to 2.5 . Only one study examined the relation between SES and breast cancer mortality. It showed a non-significant positive association. ${ }^{26}$

\section{DISCUSSION AND CONCLUSIONS}

In this review consistent positive associations between the three SES indicators and breast cancer risk were reported, and more or less consistent positive associations with SES were reported for colon cancer. Consistent inverse assoclations between SES and cancer risk were found for lung, stomach and oropharyngeal cancer, while more or less consistent inverse associations were found for liver and esophageal cancer. Inconsistent associations with SES were found for rectum and pancreatic cancer. The associations seem to be largely independent of which SES indicator is used and the country where the study was conducted. Only for cancer of the colon most significant associations were found with occupation as SES indicator.

We restricted this review to studies conducted in industrialized countries. The differences in SES in developing countries are of a different magnitude. Furthermore, the problems of malnutrition, contaminated drinking water, poor living conditions, etc. related to extreme poverty in some of these countries and vast differences in lifestyle compared to affluent societies, makes the comparison of associations between SES and cancer risk in these countries to the associations found in industrialized countries difficult. This restriction to industrialized countries reduces the possibility of interaction according to study region. Another restriction was made for studies conducted before 1970. A review on SES and cancer risk by Logan summarizes the literature on studies conducted before approximately 1970, reporting comparable results. ${ }^{B}$

In this review different search strategies were used to select relevant publications.

The initial literature search was done through MEDLINE. Some information is available on the effectiveness of MEDLINE searches. In a review study on food supplements and their efficacy, conducted in 1991, MEDLINE search provided a little less than $50 \%$ of all relevant publications included in the review. ${ }^{48}$ Comparable results were published by Dickersin and by Hofmans. ${ }^{49,50}$ In our study a smaller part of the publications reviewed were selected through MEDLINE, because of the small number of studies focussing primarily on differences 


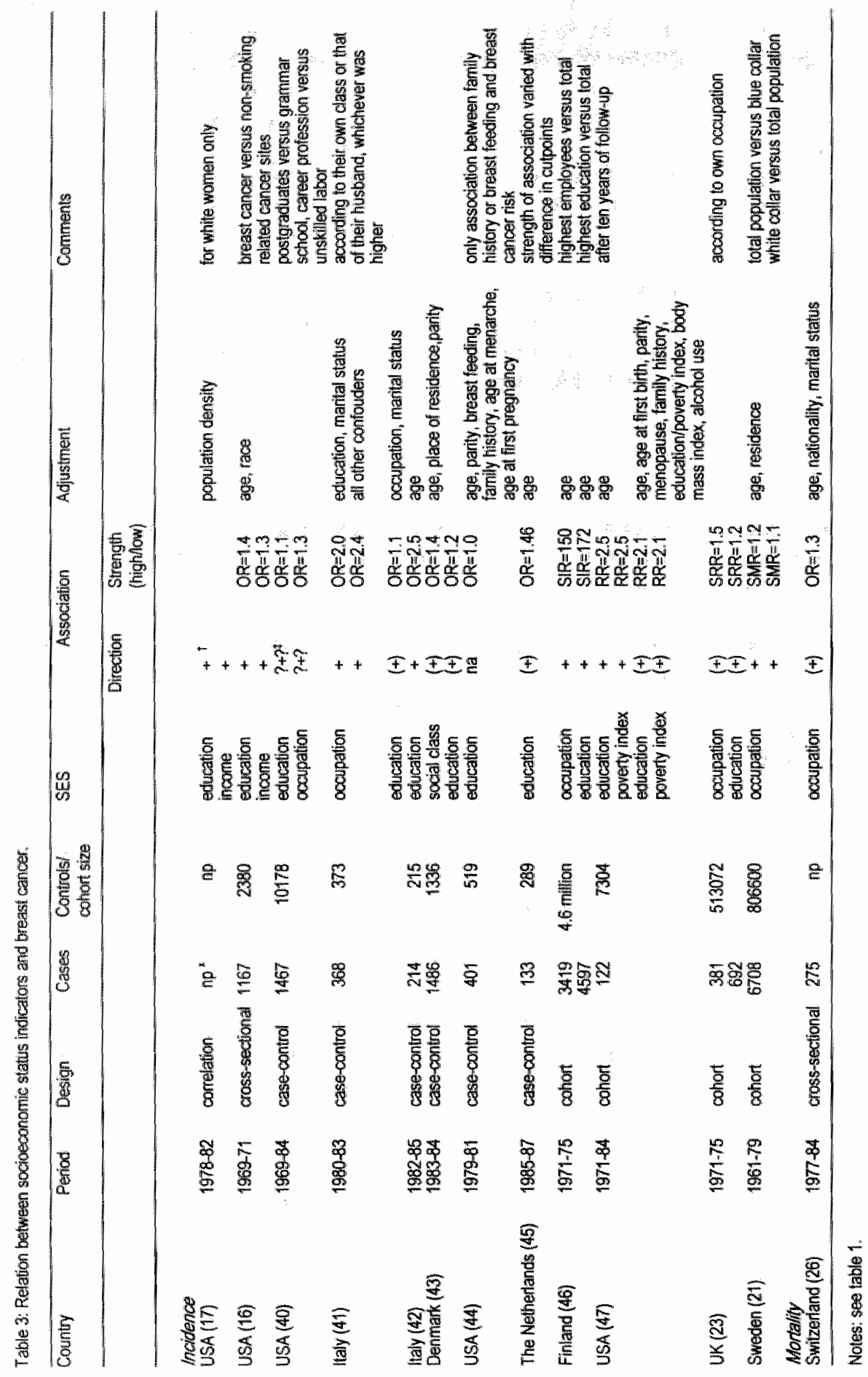


in cancer risk according to SES. Studies included in this revlew, where the association between SES and cancer risk was a secondary subject of study, were mainly selected through checking of references of the articles found through the first search.

Publication bias is a possible problem in every review article. Studies with negative results might have less chance to be submitted or published. In this review, publications where the association between SES and cancer risk was a secondary object of investigation were also included. It seems reasonable to assume that publication bias in relation to the association between SES and cancer risk will be less important in these studies. The associations found in these studies are in accordance with those found in studies focussing primarily on SES and cancer risk. Therefore, we conclude that the general directions of the associations presented in this review are not likely to be severely influenced by publication bilas.

Although occupational status, education and income show differences in strength with other health indicators, ${ }^{54,52}$ the patterns of associations are broadly the same. Therefore, the choice of indicators can be determined by the availability of information. In the second paragraph of this article different problems when using occupation, education and income as indicators of SES have been mentioned. Most of the studies reviewed did not pay attention to these issues. When occupation is used as SES indicator, study populations are often restricted to men.

The association between cancer risk and SES is not the same when the different individual cancer sites are compared. This finding does not support the hypothesis that lower SES groups have a generally higher susceptibility for cancer. Explanations for the relation between SES and cancer point at measurement artefacts, natural or social selection, a materialist explanation and lifestyle risk factor differences between SES groups. ${ }^{23,53,54}$ The artefact explanation emphasizes the (in)correctiness of measurement of social class. The occupation-based classification of SES can give misleading results. The proportion of semi and unskilled work is diminishing, because part of it has been taken over by machines, and as a result people that enter the workforce move into skilled or white collar jobs. Therefore, a higher incidence or mortality of cancer in the lowest SES groups may be a result of the higher average age. ${ }^{53}$ The same problems can arise when SES is conceptualized by education or income. Standardization or stratification for age can overcome this problem. Most of the studies in this review were adjusted for age, hence the associations between SES and the incidence or mortality of the different cancer sites cannot be considered as an artefact.

The natural or social selection theory assumes that those in better health are more likely to be upwardly mobile and those in worse health downwardly. ${ }^{12,63}$ The influence of cancer incidence or mortality on social mobility will probably not play an important role because most types of cancer are diagnosed at a later age. ${ }^{55}$ Therefore this explanation is probably more important in research on general health and SES.

The materialist explanation points at social class differences in health linked to aspects of living (the distribution of income and wealth, poverty, access to education, poor housing) and aspects of working (heavy work, noise, exposure to carcinogenic agents). ${ }^{53}$ Various authors suggest that occupational exposure to carcinogenic agents might be an important risk factor for the cancer sites inversely associated with SES. ${ }^{56,57}$ Positive associations between SES and cancer can not be explained by exposure to carcinogenic agents but 
differences in physical activity during work might lead to positive associations with some types of cancer.

Another possible explanation for the differences in cancer risk between SES groups might be differences in lifestyle variables that are related to cancer risk between these groups.

Differences between SES groups in variables like smoking habits, diet, alcohol intake, and parity between SES groups have been reported frequently in affluent societies. However, only very few studies on differences in cancer risk between SES groups have attempted tc study whether the differences found could be attributed to differences in lifestyle related risk factors. Furthermore, it has to be kept in mind that differences might exist in the relation between SES indicators and lifestyle aspects between age-groups and between countries.

Differences in smoking prevalence are thought to be largely responsible for the difference in lung, mouth, pharynx and esophageal cancer risk between SES groups. ${ }^{24,26}$ Smoking ha been found to be more prevalent among lower SES groups in most affluent countries ${ }^{96,60,61}$ and this difference might even be growing in some countries. ${ }^{60-62}$ Strange enough, there is only one study that included smoking habits in the analysis of the relation between SES and lung cancer ${ }^{* 6}$ and surprisingly, this did not change the association between SES and lung cancer.

There is evidence that a higher alcohol consumption might be a risk factor for cancer sites of the upper digestive tract..$^{34,35,63}$ Furthermore, it has been suggested that there is also a relation between alcohol consumption and rectum, liver and/or breast cancer ${ }^{58,64-68}$ The relation between SES and alcohol consumption is not clear. ${ }^{58}$ Studies in the Netherlands reported a higher percentage of total abstainers among the lowest SES-groups. ${ }^{59,69}$ But data on the relation between SES and excessive alcohol consumption do not show unequivocal results. ${ }^{69.71}$ So, there is no clear evidence that differences in alcohol consumption between SES groups can be responsible for part of the associations found between SES and cancer risk. In some studies, differences in nutritional habits between the SES groups have been suggested to be a possible explanation for the differences in cancer risk. ${ }^{22,2 \theta, 39}$ Surprisingly, no studies were found in which the associations between SES and cancer risk were adjusted for possible dietary risk factors, with an exception for alcohol and coffee consumption. ${ }^{18}$ In general " diets high in fat, and obesity, caused by a positive energy balance over an extended period of time, are considered to increase cance risk at various sites. ${ }^{72,73}$ In contrast, diets high in (fresh) fruit and vegetables and dietary fiber are considered protective for various cancer sites. ${ }^{72,74}$ Especially the preventive effect of fruits and vegetables for cancers of the digestive tract, and cancers of the respiratory system is supported by strong and extensive epidemiological evidence. ${ }^{74}$ Dietary fiber may be protective especially for colorectal cancer. ${ }^{75}$ Food consumption research in different countries suggest that diets of higher SES groups are in better concurrence with dietary guidelines for cancer prevention. Subjects of upper SES categories eat generally more frui and vegetables and dietary fiber, and less fat and energy ${ }^{59,68.76,77}$ and might have a lower intake of mitrites and nitrosamines. ${ }^{77}$

The positive association between SES and colon cancer risk found in this review is not in agreement with the more protective diet generally found among higher SES groups. Because physical activity has consistently been shown to be inversely related to colon cancer risk ${ }_{n}^{78.79}$ the positive association may be attributable to the higher levels of physical 
activity, which is more prevalent in lower occupations. For stomach cancer and cancer of the esophagus the inverse association found between cancer risk and SES is in agreement with the more protective diet generally found among subjects of higher SES. The more protective diet found among higher SES groups is not in accordance with the higher breast cancer risk among women of higher SES. Nulliparity, late age at first birth, and late age at menopause are thought to be more important risk factors ${ }^{80,81}$ and these risk factors are more prevalent among women of higher SES. ${ }^{82}$

It can be concluded that differences in lifestyle factors between SES groups could be partly responsible for the differences in cancer risk between these groups. It is therefore surprising that in most situdies there was not much attention given to the adjustment for lifestyle variables, when the relation between SES and cancer was studied. Only very few studies were found on SES and cancer risk where adjustment for lifestyle variables was made and even fewer used techniques to compare the relation between SES and cancer incidence (or mortality) with and without adjustment for lifestyle variables. Furthermore, in most of the studies there is hardly any information on how lifestyle variables were measured. So no information was available on possible misclassifications of lifestyle variables. Misclassification, of course, can potentially give invalid results. In concliusion, additional research is necessary to study whether differences in cancer risk between SES groups could be attributable to lifestyle differences.

In the Netherlands a prospective cohort study was started in 1986, on diet, other lifestyle

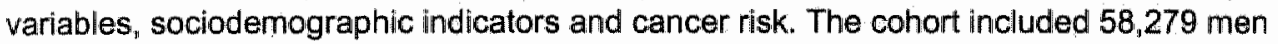
and 62,573 women aged 55-69 years at the start of the study. The data were gathered by means of a self-administered questionnaire on lifestyle factors (smoking habits, alcohol consumption, dietary habits), sociodemographic indicators (age, marital status, place of residence, education, work history) and other possible risk factors for cancer (family history of cancer, precancerous lesions).$^{83}$ By means of record linkage to cancer registries and a pathology register, the incident cancer cases in the cohort are identified. ${ }^{\text {a4 }}$ This information will be used to study the association between SES and the incidence of lung, breast, colon and rectal cancer, with and without adjustment for possible relevant lifestyle variables, to gain more insight into the association between SES and cancer.

\section{REFERENCES}

1. Ajach P. Curtis S. Social inequalities in self-reported morbidity.: Interpretation and comparison of data from Britain and France. Soc Sci Med 1990;31:267-274.

2. Mackenbach JP. Socio-economic health differences in the Netherlands; a review of empirical findings. Soc Soi Med 1992:34:213-226.

3. Marmot MG, Kogevinas M, Elston MA. Socialleconomic status and disease. Ann Rev Publ Health 1987 ; 8:111-135.

4. Kirchgassler KU. Health and social inequities in the Federal Republlic of Germany. Soc Scl Med 1990; $31: 249-256$.

5. Pipemo A, Di Orio F. Social differences in health and utilization of health services in Italy. Soc Sci $\mathrm{Med}$ $1990,31: 305-312$

6. Logan WPD. Cancer mortality by occupation and social class, 1851-1971. Lyon: International Agency for Research on Cancer. London, 1982.

7. Liberatos $P$, Link BG, Kelsey JL. The measurement of sociall class in epidemiology "Epidamiol RQv 1988 ; $10: 87-121$. 


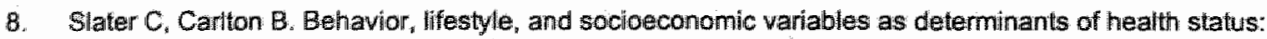
Implications for health policy development. Am J Prev Med 1985:1:25-33.

9. Jones $1 G$, Cameron D. Social class analysis - an embarrassment to epidemiology. Comm Med 1984;6: $37-46$.

10. Osborn AF. Morris TC. The rationale for a composite index of social class and its evaluation. Br J Sociol $1979,30: 39-60$.

11. McDowall M. Measuring women's occupational mortality. Population Trends $1983 / 84 ; 34: 25-29$.

12. Van Berkel-Van Schaik AB, Tax B. Naar een stendaardoperationalisatie van sociaal-economische status voor epidemiologisch en sociaal-medisch onderzoek. Sociaal-economische gezondheidsverschillen mi. 6. Den Haag: DOP, 1990.

13. Zurayk $\mathrm{H}$, Halabi $\mathrm{S}$, Deeb M. Measures of social class based on education for use in health studies in developing countries. J Epidemiol Community Health 1987:41:173-179.

14. Faia MA. Selection by certification: a neglected variable in stratification research. Am J Social 1981;86: $1093-1111$.

15. Deelnota ouderen. Gegevens over ouderen. Aanzet tot een sociale kaart. "s-Gravenhage, 1990.

16. Williams RR, Horm JW. Association of cancer sites with tobacco and alcohol consumption and socioeconomic status of patients: interview study from the third national cancer survey. I Natl Cancer Inst 1977,58:525-547.

17. Baquet CR, Horm JW, Gibbs T, Greenwald P. Socioeconomic factors and cancer incidence among blacks and whites. J Natl Cancer Inst 1991;83:551-557.

18. Ferraroni $M_{1}$ Negri $E_{1}$ La Vecchia CL, D'Avanzo B, Franceschi S. Socioeconomic indicators, tobacco and alcohol in the aetiology of digestive tract neoplasms. Int $J$ Epidemiol 1989;18:556-562.

19. Dockerty JD, Marshall S, Fraser J. Pearce N. Stomach cancer in New Zealland: time trends, ethnic group differences and a cancer registry-based case-control study. Int I Epidemiol 1991;20:45-53.

20. Gonzalez CA, Sanz JM, Marcos G. Dietary factors and stomach cancer in Spain: a multi-centre case control study. Int $J$ Cancer 1991;49:513-519.

21. Vägero D, Persson G. Occurrence of cancer in socioeconomic groups in Sweden. Scand J Soc Med $1986 ; 14: 151-160$.

22. Pukkala $E_{,}$Teppo L. Socioeconomic status and education as risk determinants of gastrointestinal cancer. Prew Med 1986:15:127-138.

23. Leon DA. Longitudinal study. Social distribution af cancer, 1971-1975 (OPCS Series LS No. 3). London, HMSO, 1988.

24. Pearce NE, Howard JIK Occupation, sociall class and male cancer mortality in New Zealand, 1974-78. Int J Epidemiol 1986;15:456-462.

25. Davey Smith G, Leon D, Shipley MJ, Rose G. Socioeconomic differentials in cancer among men. Int $u$ Epidemiol 1991;20:339-345.

26. Levi F, La Vecchia CL, Cong-Te V. Socio-economic groups and cancer: Risk at death in the Swiss canton of Vaud. Int J Epidemiol 1988;17:711-717.

27. Kneller R, McLauglin JK, Bjelke E, at al. A cohort study of stomach cancer in a high-ristk American population. Cancer 1991;68:672-678.

28. Faivre J, Bedenne L, Boutron MC, Milan C, Collonges R, Arveux P. Epidemiological evidence for distinquishing subsites of colorectal cancer. J Epidemiol Community Health 1989;43:356-361.

29. Papadimitriou C, Day N, Tzonou A, Gerovassilis F, Manousos D. Trichopoulos D. Biosocial correlates of colorrectal cancer in Greece. Int J Epidemiol 1984:13:155-159.

30. Bidoli E, Franceschi S. Talamini R, Barra S, La Vecchia C. Food consumption and cancer of the colon and rectum in North-eastern Italy. Int $J$ Cencer 1992;50:223-229.

31. Crowther JS, Drasar BS, Hill M MJ, et al. Faecal sterolds and bacteria and large bowel cancer in Hong Kong by socio-economic groups. Br J Cancer 1976;34:191-198.

32. Kabat GC, Wynder EL. Type of alcoholic beverage and oral cancer, Int J Cancer 1989;43:190-194.

33. Greenberg RS, Haber MJ "Clark WS et. al. The relation of socioeconomic status to oral and pharyngeal cancer Epidemial 1991;2:194-200.

34. Elwood JM, Pearson JCG, Skippen DH, Jackson SM. Alcohol, smoking, social and occupational factors in the aetiology of cancer of the oral cavity, pharynx and larynx. Int $J$ Cancer 1984;34;603-612.

35. La Vecchia $C$, Negri E, D'Avanzo B, Boyle P, Franceschi S. Dietary indicators of oral and pharyngeal cancer. Int J Epidemiol 1991;20:39-44.

36. Falk RT, Pickle W, Fontham ET, Correa P, Fraumeni JF. Life-style risk factors for pancreatic cancer in Loulsiana: a case control study. Am J Epidemiol 1988;128:324-336.

37. Teppo L. Cancer incidence by living area, social class and occupation. Scand J Work Environ Health 1984:10:361-366. 
38. Wynder EL, Stellman SD. Comparatiwe epidemiology of tobacco-related cancers. Cancer Res 1977,37 : $4608-4622$.

39. Alavanja MCR, Brownson RC, Boice JD, Hock E. Preexisting lung disease and lung cancer among nonsmoking women. Am J Epidemiol 1992;136:623-632,

40. Harris RE, Wynder EL. Breast cancer and alcohol consumption. A studiy in weak associations. JAMA 1988:259:2867-2871.

41. Talamini $R_{n}$ La Vecchia $C_{n}$ Decarli $A_{\text {, }}$ et al. Social factors, diet and breast cancer in a northern Italian population. Br J Cancer 1984;49:723-729.

42. Marubini $E_{\text {, Decarli }} \mathrm{A}_{\text {, Costa }} \mathrm{A}_{*}$ et all. The relationship of dietary intake and serum levels of retinal and beta-carotene with breast cancer. Results of a case-control study. Cancer 1988;61:173-180.

43. Ewertz M. Risk of breast cancer in relation to social factors in Denmark. Acta Oncol 1988;27:787-792.

44. Harris RE. Zang EA. Wynder EL. Oral contraceptives and breast cancer risk: a case-control study. Int J Epidemiol 1990;19:240-246.

45. Van 't Veer P. Dekker JM, Lamers JWL, et al. Consumption of fermented milk products and breast cancer: a case-control study in the Netherlands. Cancer Res $1989 ; 49: 4020-4023$.

46. Rimpela AH, Pukkala El. Cancers of affluence: positive social class gradient and rising incidence trend in some cancer forms. Soc Sci Med 1987;24:601-606.

47. Carter $\mathrm{CL}$, Jones DY, Schatzkin A, Brinton LA. A prospective study of reproductive, familial and socioeconomic risk factors for breast cancer using the NHANES I data. Publ Hea/th Rep 1989;104:45-50.

48. Kleijnen J, Knipschild P. Searching the literature with on-fine computer databases: In: Kleijnen J. Food supplements and their efficacy (thesis). Maastricht: University of Limburg. 1991.

49. Dickersin $K_{n}$ Hewitt P. Mutch $L$, Chalmers I, Chalmers TC. Perusing the literature: comparison of MEDLINE searching with a perinatal database. Controlled Clin Trials 1985;6:306-317.

50. Hofmans EA. De opbrengst van een MEDLINE search. De toegankelijkheid van onderzoek naar de effectiviteit van acupunctuur II. Huisarts en Wetenschap 1990;33:103-106.

51. Abramson $\mathrm{JH}$, Gofin $\mathrm{R}$, Habib J Pridan $\mathrm{H}$, Gofin J. Indicators of social class. A comparative appraisal of measures for use in epidemiological studies. Soc Sci Med 1982;16:1739-1746.

52. Syme SL, Berkman LF. Social class, susceptibility and sickness. Am J Epidemiol 1976;104:1-8.

53. Blane D. An assessment of the Black report's explanations of health inequalities. Soc Health illness $1985 ; 7: 423-445$.

54. Epstein SS, Swartz JB. Fallacies of lifestyle cancer theories. Nature 1981;289:127-130.

55. Dix $D$. Cohen $P$. On the role of aging in cancer incidence. $J$ Theor Biol $1980 ; 83: 163$.

56. Pastorino U, Berrino F, Gervasio A. Pesenti V, Riboli E, Crasignani P. Proportion of lung cancer due to occupational exposure. Int $J$ Cancer 1984;33:231-237.

57. Hall NEL, Rosenman KD. Cancer by industry: analysis of a population-based cancer registry with an emphasis on blue-collar workers. Am J Ind Med 1991:19:145-159.

58. Knibbe RA, Lemmens PH. Korrelate des alcoholkonsums in cler Schweiz, Deutschland und den Niederlanden. Drogalcohol 1987;11:27-41.

59. Hulshof KFAM, Löwik MRH, Kok FJ, Wedel $M_{1}$ Kistemaker $C$, Brants HAM. invloed van sociaaleconomische status op voeding en andere levenssijlfactoren. In: Mackenbach JP ed.

Sociaal-economische gezondheidswerschillen onderzocht. Deel ill. Den Haag: DOP 1991.

60. Sterling TD. Weinkam JJ. Smoking patterns by occupation, industry, sex, and race. Arch Environ Health 1978;37:313-317.

61. Rosén $M_{3}$ Hanning $M_{*}$, Wall $S$. Changing smoking habits in Sweden: towards better health, but not for all. Int J Epidemiol 1990:19:316-322.

62. Weinkam J.J. Sterling TD. Changes in smoking characteristics by type of employment from 1970 to 1979/80. Am J Ind Med 1987;11:539-561.

63. Choi SY. Kahyo H. Effect of cigarette smoking and alcohol consumption in the etiology of cancers of the digestive tract. Int J Cancer 1991:62:381-386.

54. Doll R. Symposium on 'diet and cancer'. An overview of the epidemiological evidence linking diet and cancer. Proceedings of the Nutrition Society 1990:49:119-131.

65. Longnecker MP, Berlin JA, Orza MJ. Chalmers TC. A meta-analysis of alcohol consumption in relation to risk of breast cancer. JAMA 1988;260:652-656.

66. Freudentheim JL, Graham S, Marshall JR, Haughey BP, Wilkinson G. Lifetime alcohol intake and risk of rectal cancer in western New York. Nutr Cancer 1990:13:101-109.

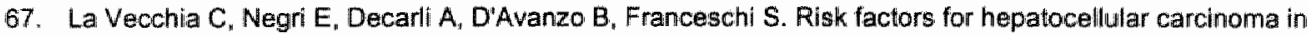
Northern Italy. Int I Cancer 1988;42:872-876.

68. Kune GA, Vitetta L. Alcohol consumption and the etiology of colorectal cancer: a review of the scientific ewidence from 1957 to 1991. Nutr Cancer 1992;18:97-111. 
69. Kromhout D, Doornbos G, Hoffmans MDAF. Voedselkeuze, leefwijze en sterite in relatie tot opleiding. T Soc Gezondheidsz 1988;66:345-348.

70. Knibbe RA Van gangbaar tot problematisch drankgebruik (thesis). Maastricht: University of Limburg. 1984.

71. Garretsen HFL. Probleomdrinken" prevalentiebepaling, beinvioedende factoren en preventiemogelijkheden: Theoretische overwegingen en onderzoek in Rotterdam. Lisse: Swets \& Zeitlinger; 1983.

72. Butrum RR, Clifford CK, Lanza E. NCl dietary guidelines: rationale. Am J Clin Nutr 1988;48:888-895.

73. Benito E. Overview of dietary recommendations on diet and cancer. In: Benito $E$, Giacosa $A, H i l l$ MJ, eds. Public education on diet and cancer: Dordrecht: Kluwer, 1992

74. Block G, Patterson B, Subar A. Fruit, vegetables, and cancer prevention: a review of the epidemiologic evidence Nutr Cancer 1992;18:1-29.

75. Kritchevski D. Diet, nutrition, and cancer: The role of fiber. Cancer 1986;58:1830-1836.

76. Patterson BH, Block G. Food choices and the cancer guidelines. Am J Publ Health 1988;78:282-286.

77. Baghurst KI, Record S., Baghurst PA, Syrette JA, Crawford D, Worsley A. Sociodemographic determinants in Australia of the intake of food and nutrients implicated in cancer aetiology. Med I Aust 1990: 153:444-452:

78. Gerhardsson M, Floderus B, Norell SE. Physical activity and colon cancer risk. Int J Epidemiol 1988;17: $743-746$.

79. Brownson RC, Zahm SH, Chang JC, Blair A. Occupational risk of colon cancer. Analysis by anatomic subsite. Am J Epidemiol 1989:130:675-687.

80. Graham S, Hellman R, Marshall J, et al. Nutritional epidemiology of postmenopausal breasit cancer in Western New York. Am J Epidemiol 1991;134:552-566.

81. Kelsey JL, Gammon MD. Epidemiology of breast cancer. Epidemiol Rev 1990;12:228-240.

82. Jacobsen $B K$, Lund $E$. Level of education, use of orall contraceptives and reproductive factors: The Trömsó Study. Int J Epidemiol 1990;19:967-970.

83. Van den Brandt PA, Goldbohm RA, Van 't Veer P, Volovics A, Hermus R.JJ" Sturmans F. A large-scale prospective cohort study on diet and cancer in the Netherlands. J Clin Epidemiol 1990;43:285-295.

84. Van den Brandt PA, Schouten LJ, Goldbohm RA, Dorant E, Hunen PMH. Development of a record linkage protocol for use in the Dutch cancer registry for epidemiological research. Int J Epidemiol 1990; 19:553-558. 
Chapter 3

LUNG CANCER: IS THERE AN ASSOCIATION WITH SOCIOECONOMIC STATUS IN THE NETHERLANDS?

A. Jeanne M. van Loon, R. Alexandra Goldbohm, Plet A. van den Brandt 


\section{ABSTRACT}

Study objective - To evaluate if there are differences in lung cancer incidence between socioeconomic groups in the Netherlands and if so, if smoking habits and other lifestyle characteristics could explain these differences.

Design - Prospective cohort study. Baseline measurement included information on socioeconomic status, smoking habits and other covariates by means of a self-administered questionnaire. Follow-up was established by computerized record linkage to cancer registries and a pathology register. Setting - Population originating from 204 municipalities in the Netherlands.

Participants - 58,279 men aged 55-69 years in September 1986. After 3.3 years of follow-up 490 microscopically confirmed incident lung cancer cases were detected.

Main results - An inverse association between lung cancer risk and highest levell of education was found "which persisted after adjustment for age, smoking, dietary intake of vitamin $\mathrm{C}$, beta-carotene and retinol (rate ratio (RR) highest/lowest level of education $=0.52 ; 95 \% \mathrm{Cl} 0.33-0.82$; trend $-\mathrm{p}<0.001$ ). Men with a lower white collar profession had a significantly lower relative rate of lung cancer compared with blue collar workers $(R R=0.66 ; 95 \% \mathrm{Cl} 0.47-0.96)$, but after adjustment for smoking habits this difference was reduced $(R R=0.73 ; 95 \%$ Cl 0.51-1.08).

Conclusions - There is an inverse association between highest level of education and lung cancer, which is still apparent after adjustment for age, smoking, dietary intake of vitamin $C$, beta-carotene and retinol. The significantly lower lung cancer risk of lower white collar workers compared with the risk of blue collar workers could be partially explained by smoking habits. 


\section{INTRODUCTION}

Lung cancer has very often been found to be inversely related to socioeconomic status (SES) ${ }^{1-6}$ Although SES is associated with lung cancer, it is not thought to be a direct risk factor. SES is commonly regarded as a proxy for lifestyle variables that have been identified as possible risk factors for lung cancer, for example smoking, dietary factors or occupational exposures to carcinogens. ${ }^{7}$ Differences in smoking prevalence are thought to be largely responsible for the difference in lung cancer risk between SES groups. 8.8 Smoking thas been found to be more prevalent among lower SES groups in most affluent societies. ${ }^{2,10-42}$ Intake of beta-carotene, vitamin $C$ and retinol is also related to lung cancer risk $^{13-15}$ and subjects of upper SES categories generally eat more fruit and vegetables. ${ }^{16,47}$ So, differences in smoking and dietary habits can be partially responsible for differences in lung cancer risk between SES groups. Strangely enough, we could only find one study in which smoking habits were included in the analysis of the relation between SES and lung cancer, ${ }^{2}$ surprisingly, this did not change the association between SES and lung cancer. Therefore we examined the assaciation between SES and lung cancer incidence and the influence of various lifestyle factors on it. In particular, we wanted to examine whether differences in smoking habits could explain possible differences in lung cancer incidence between socioeconomic groups in a prospective cohort study on diet, other lifestyle variables and cancer risk.

\section{MATERIALS AND METHODS}

\section{The cohort study}

In September 1986, a prospective cohort study on various lifestyle variables, sociodemographic indicators and cancer risk was started in the Netherlands. The cohort included 58,279 men aged $55-69$ years at the beginning of the study. Data were collected by means of a self-administered questionnaire. A detalled description of the cohort study design has been reported elsewhere. ${ }^{18}$ For data analysis the case-cohort approach was used in which cases are derived from the entire cohort, while the person-years at risk are estimated from a random sample of 1688 subjects (subcohort). After the baseline exposure measurement the subcohort was randomly sampled and it has been followed up biennially for vital status information.

Follow-up for incident cancer has been established by record linkage with all regional cancer registries in the Netherlands and with a national pathology register (PALGA). The method of record linkage has been described previously." The analysis is restricted to lung cancer incidence between September 1986 and December 1989. In this period, completeness of follow-up was estimated to be $95 \% .{ }^{20}$ After these 3.3 years of follow-up, 542 lung cancer cases had been detected. We excluded prevalent cancer cases other than skin cancer, cases with in situ carcinoma, and cases without microscopically confirmed diagnosis. Therefore, 490 incident cases were available for analysis. Prevalent cancer cases other than skin cancer were also excluded from the subcohort, with the result that 1630 remained in this group.

\section{Socioeconomic status}

SES was measured by means of highest attained level of education and occupational history, two of the recommended measures for SES. ${ }^{21}$ Educational level was classified as 
primary school, lower vocational school (for example technical school, domestic science school), junior high school, senior high school, higher vocational school, university and other education. Information about occupational history was coded according to a coding system of the Central Bureau of Statistics (CBS) frequently used in the Netherlands. ${ }^{22}$ For the present analysis, these CBS codes were aggregated according to occupational group and required training (EGP). The EGP coding scheme is a reconstruction of the scheme developed by Erikson, Goldthorpe and Portocarero, ${ }^{23,24}$ which is still comparable with the original list. ${ }^{25}$

\section{Lifestyle characteristics}

Other factors relevant to the association between SES and lung cancer risk that were measured are lifetime history of smoking habits and the intake of beta-carotene, vitamin $\mathrm{C}$ and retinol. Information on smoking habits comprised smoking status (never, ex-smoker or current), age at starting smoking, age at stopping smoking when applicable, total years of smoking and the amount of cigarettes, cigars and/or pipes smoked per day. For the multivariate analyses, pack-years for current and ex-smokers were computed. The usual consumption of food and beverages during the year preceding the start of the study was assessed at baseline with an 150 item, semiquantitative food frequency questionnaire. This questionnaire has been validated against a nine day diet record ${ }^{26}$ Mean individual nutrient intakes per day are computed using the Dutch food table of $1986 .{ }^{27}$

\section{Data analysis}

The distribution of SES indicators and potential confounders known to be associated with SES and lung cancer (particularly smoking habits) were compared between the case and subcohort group. Educational level was aggregated into five categories: primary school, lower vocational school, junior high school, senior high school, and higher vocational school or university. The SES indicator based on (EGP score) was derived from the last job that was heid, and was divided into four categories: upper white collar jobs' (professionals), lower white collar jobs (administrators and non-manual employees), blue collar jobs (lower grade technicians, semi- and unskilled manual workers) and other (farmers and self employed people). The associations between SES and covariates were also studied in the subcohort by comparing mean values of age; pack-years of cigarette smoking; and intake of beta-carotene, vitamin C and retinol in relevant SES categories.

To study the association between SES and lung cancer risk and the role of smoking habits with respect to that association, data were analyzed according to the case-cohort approach. ${ }^{20,28}$ Mantel-Haenszel rate ratios of lung cancer were determined for each of the SES indicators, stratified for age and smoking habits. In the multivariate case-cohort analyses, using the GLIM statistical package ${ }_{1}^{29}$ rate ratios and $95 \%$ confidence intervals of lung cancer were computed for the SES indicators, after adjustment for age, smoking (pack-years of current smokers and past smokers), and intake of beta-carotene, vitamin C and retinol. All these covariates were entered into the model as continuous variables.

\section{RESULTS}

The distribution of SES indicators and covariates in the case and the subcohort group is presented in table 1. On average, cases were older than members of the subcohort (mean age for cases is 62.9 years and for subcohort members 61.4 years) and current smoking 
was more prevalent in the case groups. Cases had a lower educational level and were more often employed in blue collar occupations than members of the subcohort.

Table 1: Distribution of socideconomic stalus indicators and other characteristics in ung cancer cases and the subcohort

\begin{tabular}{|c|c|c|c|c|}
\hline \multirow[t]{2}{*}{ Characteristic } & \multicolumn{2}{|c|}{ Subcohort } & \multicolumn{2}{|c|}{ Cases } \\
\hline & $n$ & $\%$ & $n$ & $\%$ \\
\hline Total & 1630 & & 490 & \\
\hline \multicolumn{5}{|l|}{ Age (yrs): } \\
\hline $55-59$ & 620 & 38.0 & 120 & 24.5 \\
\hline $60-64$ & 568 & 34.8 & 174 & 35.5 \\
\hline $65-69$ & 442 & 27.1 & 196 & 40.0 \\
\hline \multicolumn{5}{|l|}{ Smoking habits: } \\
\hline Never & 159 & 9.8 & 7 & 1.4 \\
\hline Ex-smakers & 771 & 47.4 & 146 & 30.2 \\
\hline Cument smokers & 697 & 42.8 & 332 & 68.4 \\
\hline \multicolumn{5}{|l|}{ Highest level of education: } \\
\hline Primary school & 458 & 28.4 & 166 & 34.6 \\
\hline Lower wocational & 338 & 20.9 & 125 & 26.0 \\
\hline Junior high school & 420 & 26.0 & 111 & 23.1 \\
\hline Senior high school & 123 & 7.6 & 31 & 6.5 \\
\hline Higher vocational / university & 275 & 17.0 & 47 & 9.8 \\
\hline \multicolumn{5}{|l|}{ EGP score: last profession: } \\
\hline Blue collar & 563 & 38.8 & 186 & 44.2 \\
\hline Lower while collar & 206 & 14.2 & 47 & 11.2 \\
\hline Upper white collair & 436 & 30.0 & 118 & 28.0 \\
\hline Other & 247 & 17.0 & 70 & 16.6 \\
\hline
\end{tabular}

The comparison of the distribution of never, ex-smokers and current smokers in the three SES indicators and the mean values of age, pack-years of cigarette smoking, and intake of beta-carotene, vitamin $C$ and retinol between SES categories is presented in table 2. The prevalence of smoking was higher among men with primary school only and although the percentage current smokers did not differ between the EGP categories, the prevalence of ex-smoking was higher among white collar workers. The mean number of pack-years of cigarette smoking in ex-smokers or current smokers was slightly lower for men with a lower educational level. There was no substantial association between the SES indicators and the intake of beta-carotene. The intake of vitamin $C$ and retinol was positively associated with the highest level of education. Associations between vitamin $\mathrm{C}$ or retinol and the EGP score were less consistent. 
Table 2. Association between possible confounders and sociceconomic status indicators in the subcohort

\begin{tabular}{|c|c|c|c|c|c|c|}
\hline \multirow[t]{2}{*}{ Charactenstistic } & \multicolumn{3}{|c|}{ Highest llevel of education } & \multicolumn{3}{|c|}{ EGP score } \\
\hline & Low & Medium & High & $\begin{array}{l}\text { Blue } \\
\text { collar }\end{array}$ & $\begin{array}{l}\text { White } \\
\text { collar }\end{array}$ & Other \\
\hline Age (mean yrs) & 64.9 & 61.3 & 61.1 & 61.3 & 61.1 & 64.8 \\
\hline Current smokers (\%) & 50.7 & 38.9 & 40.7 & 46.2 & 39.4 & 40.1 \\
\hline Ex.smokers (\%) & 40.2 & 51.2 & 49.0 & .46 .5 & 50.3 & 47.8 \\
\hline Pack-years ${ }^{2}$ (mean) & 23.6 & 25.1 & 24.1 & 23.0 & 22.2 & 209 \\
\hline Beta-carotene (mean, mg eq vit A) & 0.40 & 0.40 & 0.41 & 0.41 & 0.41 & 0.42 \\
\hline Vittamin C (nitean, mg) & 92.4 & 100.0 & 101.0 & 97.1 & 102.0 & 96.4 \\
\hline Retinol (mean, mg eq vit A) & 0.59 & 0.61 & 0.64 & 0.60 & 0.61 & 0.66 \\
\hline
\end{tabular}

\footnotetext{
"Highest level of education: : low = primary school" med tum = lower vocational or junior high school: high = senior high schood, higher vocational school or university

${ }^{2}$ Only for current and ex-smokers
}

The results of the stratified case-cohort analyses are presented in table 3 . After adjustment for age in three, five year categories, there was a significant inverse association between level of education and lung cancer risk (RR highest/lowest education $=0.50$; $95 \% \mathrm{Cl}$ 0.35-0.73; trend-p $<0.001$ ). There was still an inverse association between lung cancer risk and educational level after adjustment for age and smoking habits (RR highest/lowest education $=0.57 ; 95 \% \mathrm{Cl} 0.39-0.82$; trend-p $<0.001$ ), although the differences between the SES categories were somewhat diminished.

After adjustment for age, men with a lower white collar profession had a significantly lower lung cancer rate than blue collar workers ( $R R=0.66$; $95 \% \mathrm{Cl} 0.47-0.96$ ), while upper white collar workers had a non-significantly lower rate $(R R=0.84 ; 95 \% \mathrm{Cl} 0.64-1.10)$. Additional adjustment for smoking led to a non-significantly lower lung cancer rate for both upper and lower white collar workers, compared with blue collar workers.

Table 4 shows the results of the multivariate analyses where adjustment is made for age, pack-years of ex-smoking and current smoking and intake of beta-carotene, vitamin $\mathrm{C}$, and retinol. These results are comparable with the results of the stratified analyses. There was still a significant inverse association between levell of education and lung cancer risk (trend$p<0.001$ ). The rate ratio for men with a higher vocational training or university versus primary school education was $0.52(95 \% \mathrm{Cl} 0.33-0.82)$, but those with a lower vocational training had a higher risk for lung cancer than men with primary schooling $(R R=1.36$; $95 \% \mathrm{Cl}$ 0.97-1.91). After adjustment for age, smoking and the intake of beta-carotene, vitamin $\mathrm{C}$, and retinol, upper white collar workers still had a non-significantly lower risk for lung cancer compared with blue collar workers ( $R R=0.90 ; 95 \% \mathrm{Cl} 0.66-1.23$ ). The lung cancer rate of lower white collar workers was lower than the rate for blue collar or upper white collar workers. We have also conducted multivariate analyses including age of starting smoking as an additional covariable. This did not change the association between lung cancer and the SES indicators.

We have studied the association between highest level of education and lung cancer risk more extensively by conducting the multivariate analysis in the different smoking categories (table 5). Unfortunately it was not possible to carry out the analyses for non-smokers, since 
there were only seven cases in the non-smoking group. The irverse association between educational level and lung cancer risk seems restricted to curnent smokers ( $R R$ highest/lowest education $=0.51 ; 95 \%$ Cl 0.28-0.95; trend-p $=0.006$ ). For ex-smokers the rate ratio of lung cancer was still below one for men with higher wocational training or: university, but the rate ratios in the different categories and the trend test were not significant (RR highest/lowest $=0.84 ; 95 \%$ Cl $0.46-1.54 ;$ trend-p $=0.49$ ).

Table 3. Mantel-Haenszel rate ratios for ling cancer according to two different socioeconomic status indicators

\begin{tabular}{|c|c|c|c|c|c|c|}
\hline \multirow[t]{2}{*}{ SES indicator } & \multirow[b]{2}{*}{$\begin{array}{l}\text { No. of } \\
\text { cases in } \\
\text { cohort }\end{array}$} & \multirow[b]{2}{*}{$\begin{array}{l}\text { Person-years } \\
\text { in subcohort }\end{array}$} & \multicolumn{2}{|c|}{ Adjusted for age } & \multicolumn{2}{|c|}{ Adjusted for age and smoking } \\
\hline & & & $\mathrm{RR}_{\text {标 }}(95 \% \mathrm{Cl})$ & $\begin{array}{l}\text { Test for trend } \\
x^{2} \text { (p-value) }\end{array}$ & $\mathrm{RR}_{\text {料 }}(95 \% \mathrm{Cl})$ & $\begin{array}{l}\text { Test for trend } \\
X^{2} \text { (p-walue) }\end{array}$ \\
\hline \multicolumn{7}{|c|}{ Highest level of education: } \\
\hline Primary schooll & 166 & 1475 & $1^{\circ}$ & & $1^{*}$ & \\
\hline Lower vocational & 125 & 1098 & $1.07(0.81-1.42)$ & $19.7(<0.001)$ & $1.18(0.89-1.58)$ & $11.9(<0.001)$ \\
\hline Junior high schaal & 111 & 1344 & $0.76(0.57-1.60)$ & & $0.86(0.65-1.15)$ & \\
\hline Senior high school & 31 & 397 & $0.69(0.44-1.06)$ & & $0.75(0.48-1.18)$ & \\
\hline $\begin{array}{l}\text { Higher wocational } \\
\text { university }\end{array}$ & 47 & 882 & $0.50(0.35-0.73)$ & & $0.57(0.39 \times 0.82)$ & \\
\hline \multicolumn{7}{|c|}{ EGP score: last profession: } \\
\hline Blue colltar & 186 & 1804 & $1^{*}$ & & $1^{*}$ & \\
\hline Lower whilte collar & 47 & 666 & $0.66(0.47-0.96)$ & $1.97(0.16)$ & $0.73(0.51-1.08)$ & $0.41(0.52)$ \\
\hline Upper white collar & 118 & 1402 & $0.84(0.64-1.10)$ & & $0.94(0.71-1.24)$ & \\
\hline Other ${ }^{\prime}$ & 70 & 798 & $0.82(0.60-1.13)$ & & $0.90(0.64-1.25)$ & \\
\hline
\end{tabular}

"Reference catergory

Excluded from test for trend

\section{DISCUSSION}

We have found a significant inverse association between educational level and lung cancer risk. This association persisted but became somewhat weaker after adjustment for smoking behaviour and dietary intake of vitamins. The associations between lung cancer risk and the occupation-based SES indicator is less strong. Men with a lower white collar occupation had a significantly lower relative risk for lung cancer than blue collar workers but after additional adjustment for smoking habits this difference was reduced.

The cohort study has been performed in a large sample of the general population aged 55-69 years at baseline, resulting in a relatively large number of incident cases. The follow-up of person-years was $100 \%$ complete and the completeness of cancer follow-up was also very high, indicating that selection bias due to loss to follow-up is unlikely. Although known risk factors for lung cancer were carefully measured and controlled for in the multivariate analyses, residual confounding by smoking habits can still exist. Adjustment for smoking was made by means of pack-years of past and current smokers. This kind of control takes both duration and amount into account. We have also additionally 
adjusted for the age of starting smoking, with the same results. To exclude the confounding effect of smoking on the association between SES and lung cancer as completely as possible, we have studied the association between SES and lung cancer in the different smoking categories. Due to the number of cases this was only possible for ex-smokers and current smokers. We expect that after a longer follow-up period the number of cases also allows analyses in the non-smoking group and in subgroups of current smokers.

Table 4: Rate ratio for lung cancer according to two different socioeconomic status indicators in multivariate analysis

\begin{tabular}{llll}
\hline SES indicator & $\mathrm{RR}^{2}$ & $95 \% \mathrm{Cl}$ & $\begin{array}{c}\text { Test for trend } \\
\mathrm{X}^{2} \text { (p-value) }\end{array}$ \\
\hline Highest level of education: & & & \\
Primary school & $1^{*}$ & & $14.90(<0.001)$ \\
Lower wacational & 1.36 & $0.97-1.91$ & \\
Junior high school & 0.95 & $0.68-1.33$ & \\
Senior high school & 0.88 & $0.53-1.49$ & \\
Higher vocational / universily & 0.52 & $0.33-0.82$ & \\
& & & \\
EGP score: last profession: & & & \\
Bilue collar & $1 *$ & & \\
Lower white collar & 0.69 & $0.49-1.20$ & $0.85(0.36)$ \\
Upper white collar & 0.90 & $0.66-1.23$ & \\
Other ${ }^{3}$ & 0.78 & $0.53-1.14$ & \\
\hline
\end{tabular}

Relerence calegory

'Only respondents with complete dietary data

${ }^{2}$ Adjusted for age, smoking behaviour (pack-years), beta-carotene, vitamin C, and retino:

"Excluded from test for trend

Another fact that could have had an influence on the results is misclassification. SES is operationalized as highest level of education and EGP score (functional level), based on the last occupation. Highest level of education is a characteristic that is easily obtainable and recordable. It applies to every adult individual and in individuals it is stable over time. This stability has also negative implications for the suitability of level of education as an SES indicator, while it can mask important changes in individual circumstances after education is finished; ${ }^{30}$ therefore highest level of education is probably a less relevant SES indicator for the older generation. ${ }^{34}$ On the other hand, at an older age the level of education still has an association with level of knowledge, ${ }_{1}^{32}$ which is related to lifestyle. The EGP score reflects the more recent situation, but this occupation-based SES indicator leads to the problem of how to classify persons without formal occupation. Because we used occupation as an indicator of SES, it seems reasonable to take the last occupation instead of the occupation performed the longest. Also for pensioners - a relatively large part of the study population - the last occupation is used. This may not be an accurate reflection of the person's occupational status, however, as elderly people may take less demanding jobs before retirement. ${ }^{21}$ In some studies an aggregated summary measure is used as a SES indicator. We have chosen to use two separate SES indicators, since an aggregated measure focusses on the commonality shared by the separate measures, ${ }^{21}$ while education and occupation are not redundant measures of SES. ${ }^{33}$ 
Table 5: Rate ratios for lung cancer according to highest level of education, by calegory of smoking ${ }^{1}$ in multwariate analysis ${ }^{2}$

\begin{tabular}{|c|c|c|c|c|c|c|}
\hline \multirow[t]{2}{*}{ Smoking } & \multicolumn{5}{|c|}{ Highest level of education } & \multirow[b]{2}{*}{$\begin{array}{l}\text { Test for trend } \\
x^{2} \text { (p-walue) }\end{array}$} \\
\hline & $\begin{array}{l}\text { primary } \\
\text { school }\end{array}$ & $\begin{array}{c}\text { lower } \\
\text { vocational }\end{array}$ & $\begin{array}{l}\text { junior high } \\
\text { school }\end{array}$ & $\begin{array}{l}\text { sentor high } \\
\text { school }\end{array}$ & $\begin{array}{l}\text { higher vocationali } \\
\text { university }\end{array}$ & \\
\hline \multirow{2}{*}{$\begin{array}{l}\text { Ex-smoking } \\
(95 \% \text { Cll })\end{array}$} & $1^{\circ}$ & 1.21 & 0.86 & 1.37 & 0.84 & \\
\hline & & $(0.71-2.07)$ & $(0.51-1.44)$ & $(0.67-2.81)$ & $(0.46-1.54)$ & $0.49(0.49)$ \\
\hline \multicolumn{2}{|c|}{ Current smoking $1^{\circ}$} & 1.59 & 1.07 & 0.79 & 0.51 & \\
\hline \multicolumn{2}{|l|}{$(95 \% \mathrm{Cl})$} & $(0.99-2.54)$ & $0.68-1.69)$ & $(0.37-1.67)$ & $(0.28-0.95)$ & $7.65(0.006)$ \\
\hline \multirow{2}{*}{$\begin{array}{l}\text { Total } \\
(95 \% \mathrm{Cl})\end{array}$} & $1^{\circ}$ & 1.36 & 0.95 & 0.89 & 0.52 & \\
\hline & & $(0.97-1.91)$ & $(0.68-1.33)$ & $(0.53-1.49)$ & $(0.33-0.82)$ & $14.9(<0.001)$ \\
\hline
\end{tabular}

\section{Reference category}

"Onlly respondents with complete dietary data

? Adjust ed for age, pack-years of smoking and intake of beta-carotene, retinol, vitamin $\mathrm{C}$

These resuits are partly comparable with other studies on SES and lung cancer incidence. All studies on SES and lung cancer found an inverse (age-adjusted) association ${ }^{1.6}$ independent of study design, both for educational levell and occupation, with relative risks of the highest versus the lowest categories varying from 0.4 to 0.9 . Adjustment for smoking was made in only two studies on SES and lung cancer risk. In a cross-sectional study on SES and lung cancer ${ }^{2}$ the OR for lung cancer of the highest versus lowest education changed from 0.62 to 0.68 after adjustment for smoking. This is comparable with our findings which showed only a modest effect of adjustment for smoking. In a cohort study in Denmark, ${ }^{34}$ a significant inverse association was recently reported between social class (based on level of education and job profile) and lung cancer (RR highest/lowest $=0.27$; $95 \%$ Cl $0.1-0.5$ ), which became somewhat weaker but was still apparent after adjustment for smoking ( $\mathrm{RR}=0.34 ; 95 \% \mathrm{Cl} 0.2-0.7)$. In our cohort study there is a strong association between smoking and lung cancer, but in the study population only $10 \%$ of the men have never smoked and this percentage was not substantially different betweeri SES caitegories. Therefore differences between SES categories were probably too small to find an important effect of smoking on the association between SES and lung cancer incidence.

Another risk factor for lung cancer associated with SES is occupational exposure to carcinogens. ${ }^{35}$.36 Occupational categories with a higher risk of lung cancer are metal production and processing workers, road construction workers, chemical workers, ${ }^{37}$ textile workers, cooks, ship and dockyard workers and wood workers. ${ }^{36}$ in our cohort representing the general population, the proportion of these occupations is rather small. Therefore the power to study these association is still small with 3.3 years of follow-up. In future analyses with longer follow-up and more cases we will investigate this subject specifically.

We have studied the association between level of education and lung cancer risk in different smoking categories. These analyses show that the significant inverse association between education and lung cancer is restricted to current smokers, while there was no association found between education and lung cancer in the ex-smoking group. A cohort study in Denmark, with 17 years of follow-up, showed a significant inverse association between SES and lung cancer risk among current smokers. ${ }^{34}$ The number of cases was too 
small to get insight in the association between SES and lung cancer risk among ex-smokers and non-smokers.

In conclusion, we found a significant inverse association between lung cancer risk and highest level of education. This association was still apparent after adjustment for age, smoking, dietary intake of vitamin $C$, beta-carotene, and retinol. Men with a lower white collar profession had a significantly lower rate ratio of lung cancer compared with blue collar workers, but after adjustment for smoking habits this difference was reduced. Future analyses after a longer follow-up will give more information on occupational exposure to carcinogens.

\section{ACKNOWLEDGMENTS}

We thaink the participants in this study, the regional cancer registries $(\mathbb{K A}$, IKL, IKMN, $\| K N$, IKO $\left.I K R_{1}, I K S T, I K W, I K Z\right)$, PALGA for providing incidence data; $E$. Dorant, $S$. van de Crommert, $H$. Brants, P. Florax, $J$. Nelissen and W. van Dijk for assistance in the cohort study and $S$. var den Heuvel from the TNO-NIPG institute for coding the questions about occupation.

This work was financially supported by the Dutch Ministry of Welfare, Public Health and Cultural Affairs and by the Dutch Cancer Society.

\section{REFERENCES}

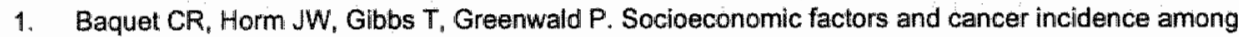
blacks and whites. J Nat/ Cancer Inst 1991;83:551-557.

2 Williams $\mathbb{R R}_{\text {, }}$ Horm. IW. Association of cancer sites with tobacco and alcohol consumption and socioeconomic status of patients: interview study from the third national cancer survey. J Natl Cancer Inst 1977:58:525-547.

3. Wynder EL, Stellman SD. Comparative epidemiology of tobacco-related cancers. Cancer Res 1977; 37:4608-4622.

4. Teppo L. Cancer incidence by living area, social class and occupation. Scand $J$ Work Enwron Health 1984:10:361-366.

5. Vágero D, Persson G. Occurrence of cancer in socloeconomic groups in Sweden. Scand J Soc Med $1986 ; 14: 154-160$.

6. Leon DA. Longitudinal study. Social distribution of cancer 1971-1975 (OPCS Series LS No. 3). London: HMSO, 1988 .

7. Slater $\mathrm{C}$, Carlton $\mathrm{B}$. Behavior, lifestyle, and socioeconomic wariables as determinants of health status: implications for health policy development. Am J Prov Med 1985;1:25-33.

8. Pearce NE, Howard JK. Occupation, social class and male cancer mortality in New Zealand, 1974-78. Int J Epidemiol 1986:15:456-462.

9. Levi $F$, Negri $E$, La Vecchia $C L$, Cong-Te V. Socio-economic groups and cancer: Risk at death in the Swiss canton of Vaud. Int $J$ Epidemiol 1988;17:711-717.

10. Sterling TD, Weinkam JJ. Smoking pattems by occupation, industry, sex, and race. Arch Environ Health $1978: 37: 313-317$.

11. Rósen $M$, Hanning $M_{1}$ Wall $S$. Changing smoking habits in Sweden: towards better health, but not for all Int $J$ Epidemiol 1990;19:316-322.

12. De Vries $H_{4}$, Hoekstra I, Dijkstra $M$, Kok GJ. Opvattingen van jongeren over roken: sociaal-economische statusverschillen. Tijdschir Soc Gezondheidsz 1992;70:303-309.

13. Kvale G, Bjelke E, Gart JJ. Dietary habits and lung cancer risk. Int J Cancer 1983;31:397-405.

14. Graham S. Epidemiology of retinoids and cancer. J Natl Cancer Inst 1984;73:1423-1428.

15. Byers TE, Graham S, Haughey BP, Marshall JR, Swanson M. Diet and lung cancer risk: findings from the western New York diet study. Am J Epidemiol 1987;125:351-363. 
46. Hulshof KFAM, Lowik MRH, Kok FJ, Wedel M, Kistemaker C, Brants HAM. Invloed van socilaaleconomische status op voeding en andere levensstiffactoren. Un: Mackenbach JP, ed. Sociakteconomische gezonctheidsverschilen onderzocht. Deell III. Den Haag: DOP, 1991.

17. Block $G$, Sorenson A. Vitamin $C$ intake and dietary sources by demographic characteristics. Nutr Cancer $1987 ; 10: 53-65$.

॥8. Van den Brandit. PA, Goidbohm RA, Van tt Veer P, Volovics A, Hermus RJj, Sturmans F. A large-scale prospective cohort study on diet and cancer in the Nethertands. I Clin Epidemiol 1990,43:285 295.

19. Van den Brandt PA, Schouten LJ, Goldbohm RA, Dorant E, Hunen PMH. Development of a record linkage protocolf for use in the Dutch cancer registry for epidemiological research. Int J Epidemiol 1990; 19.553-558.

20. Van den Brandi PA, Van t Veer P, Goldbohm RA, Dorant E, Volovics A, Hermus RJJ, Sturmans F. A prospective cohort study on dietary fat and the risk of postmenopausal breast cancer. Cancer Res 1993:53:75-82.

21. Liberatos P. Link BG, Kelsey JL. The measurement of social class in epidemiology. Epidomiol Rov 1988; 10:87-121.

22. Centraal Bureau woor de Statistiek. Beroepenclassificatie 1984. Lijst van bonamingen per beroepencode. Voorburg: CBS, 1985.

23. Erikson $\mathrm{R}$, Goldthorpe $\mathrm{JH}$, Portocarero L. Intergenerational class mobility in three western countries: England, France and Sweden. British Joumal of Sociology 1979;30:415 441.

24. Van Berkel-van Schaik AB, Tax B. Naar een standaardoperationalisatie van sociasl-economische status voor epidemiologisch en sociaal-medisch onderzoek. Sociaal-economische gezondheidsverschillen nr 6 . Den Haag: DOP, 1990.

25. Ganzeboom $H_{\text {, Luyk }} \mathrm{R}$, Dessens J, De Graaf $\mathbb{P}$, De Graaf ND, Jansen W, Ultee W. Intergenerationele klassenmobiliteit in Nederland tussen 1970 en 1985. Mens en Maatschappij 1987;62:17-43.

26. Goldbohm RA, Van den Brandt PA, Brants HAM, et al. Validation of a dietary questionnaire used in a large-scale prospective cohort study on diet and cancer. Eur J Chin Nutr 1994;48:253-265.

27. Stichting NEVO. NEVO-tabel; Nederlands voedingsstoffenbestand 1986-1987. The Hague: Voorlichtingsbureau voor de voeding. 1986.

28. Self SG, Prentice RL. Asymptotic distribution theory and efficiency results for case-cohort studies. Ann Stat 1988;16:64-81.

29. Baker RJ. Glim 3.77, Reference Manual. Oxford: Numerical Algorithms Group, 1985.

30. Zurayk $H_{*}$ Halabi $S_{\text {, }}$ Deeb $M$. Measures of social class based on education for use in health studies in developing countries. I Epidemiol Community Health 1987;41:173-179.

31. Thijssen LuM. Sociale stratificatie onder ouderen. Soc Cult Kwarther 1986;8(2):10-27.

32. Wetenschappelijke Raad voor het Regeringsbeleid. Over sociale ongelijkheid. Rapporten aan de regering no. 16. Den Haag: Staatsuitgeveri], 1977.

33. Winkleby MA Jatulis DE, Frank E, Fortmann SP. Socioeconomic status and health: how education, income and occupation contribute to risk factors for cardiovascular disease. Am J Publ Health 1992 ; $82.816-820$.

34. Hein HO, Suadicani P. Gyntelberg F. Lung cancer risk and social class. The Copenhagen Male study - 17-year follow-up. Dan Med Bull 1992;39:173-176.

35. Fox AJ, Adelstein AM. Occupational mortality: work or way of life? $J$ Epidemiol Community Health $1978: 32 ; 73-78$

36. Pastorino U, Berrino $F$, Gervasio A, Presenti V, Riboli E, Crosignani P. Proportion of lung cancers due to occupational exposure. Int $J$ Cancer 1984;33:231-237.

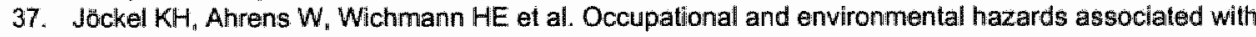
lung cancer. Int $J$ Epjidemiol 1992;21:202-213.

38. Notani PN, Shah $P$, Jayant $K$, Balakrishman $V$. Occupation and cancers of the lung and bladder: $A$ case-control study in Biombay. Int J Epidemiol $4993 ; 22: 185-191$. 
Chapter 4

SOCIOECONOMIC STATUS AND BREAST CANCER INCIDENCE:

a prospective cohort study

A. Jeanne M van Loon, R. Alexandra Goldbohm, Piet A. van den Brandt 


\section{ABSTRACT}

Background - To gain more insight into the relation between socioeconomic status (SES) and breast cancer risk, we have studied that association, before and after adjustment for traditional risk factors for breast cancer, in a prospective cohort study on lifestyle and cancer that started in 1986 in the Netherlands among 62,573 women aged $55-69$ years.

Methods - At baseline, data on SES, diet, reproductive factors and other covariates were collected by means of a self-administered questionnaire. For data-analysis a case-cohort approach was used. After 3.3 years of follow-up, 471 incident cases were available for analysis.

Results - We did not find a higher age-adjusted risk of breast cancer for those with a higher level of education (RR highest/lowest level of education $=0.94 ; 95 \% \mathrm{Cl} 0.63-1.39$; trend- $\mathrm{p}=0.15$ ). Although upper white collar workers had a slightly higher breast cancer risk than blue collar workers $(R R=1.16 ; 95 \% \mathrm{Cl} 0.83-1.62$; trend-p $=0.34)$, women with a profession of higher social standing did not have a higher risk (RR highest/lowest social standing $=0.73 ; 95 \% \mathrm{Cl} 0.24-2.23$; trend- $p=0.86$ ). Additional adjustment for traditional risk factors did not alter the association between SES and breast cancer risk.

Conclusions - We did not find an association between SES and breast cancer risk. This is not in agreement with studies conducted in other European countries and North America. 


\section{INTRODUCTION}

Recent epidiemiological investigations have indicated a positive relation between breast cancer and socioeconomic status (SES): ${ }^{*+12}$ all studies but one $e^{7}$ show positive associations, with relative risks of the highest versus the lowest categories varying from 1.0 to 2.5 . Important risk factors like nulliparity, late age at first birth and late age at menopause ${ }^{18-15}$ may be (partially) responsible for this positive association because these characteristics are more prevalent among women of higher SES. ${ }^{16}$ In some of the studies on SES and breast cancer adjustment is made for these reproductive variables, $4,6,7,10$ This led to different results: one study still found significant positive associations between occupational status and breast cancer after adjustment for the covariates mentioned above, but not for education and breast cancer ${ }^{4}$ In two studies the positive age-adjusted association between SES and breast cancer did not remain significant after adjustment for age, place of residence, parity ${ }^{*}$ and other relevant reproductive variables, body mass index and alcohol Use. ${ }^{10}$ The fourth study did not report positive assoclations between SES and breast cancer with or without adjustment for known risk factors. ${ }^{7}$ To gain more insight into the relation between SES and breast cancer risk we have studied the association in the Netherlands ${ }_{\text {, }}$ in a prospective cohort study on diet, other lifestyle variables and cancer, without and with adjustment for traditional risk factors for breast cancer.

\section{MATERIALS AND METHODS}

\section{The cohort study}

In September 1986, a prospective cohort study was started in the Netherlands on various lifestyle variables, sociodemographic indicators and cancer risk. The cohort include 58,279 men and 62,573 women aged 55-69 years at the beginning of the study. Data were collected by means of a self-administered questionnaire. A detailed description of the cohort study design has been reported elsewhere. ${ }^{17}$ For data analysis the case-cohort approach was used in which cases are derived from the entire cohort, while the person-years at risk are estimated from a random sample of 3500 subjects (subcohort). After the baseline exposure measurement the subcohort was randomly sampled (1688 men and 1812 women) and it has been followed up biennially for vital status information. Follow-up for incident cancer has been established by record linkage with all regional cancer registries in the Netherlands and with a national pathology register (PALGA). The method of record linkage has been described previously. The analysis is restricted to breast cancer incidence from September 1986 to December 1989. In this period, completeness of follow-up was estimated to be $95 \%{ }^{19}$

After these 3.3 years of follow-up 553 breast cancer cases were detected. We excluded prevalent cancer cases other than skin cancer $(n=67)$ and cases with in situ carcinoma $(n=15)$. Therefore 471 incident cases were available for analysis. Prevalent cancer cases other than skin cancer were also excluded from the subcohort, in which 1716 women remained. 


\section{Socioeconomic status}

Socioeconomic status was measured by means of highest level of education attained and occupational history, two of the recommended measures for SES. ${ }^{20}$ Educational level was classified as primary school, lower vocational school (e.g, technical, domestic science school), Junior high school, senior high school, higher vocational school university and other education. Information was available on the highest level of education for the individual and for her partner. Information about occupational history was coded according 10 a coding system of the Central Bureau of Statistics (CBS) frequently used in the Netherlands. For the present analysis, these CBS codes were aggregated according to occupational sector and training required (EGP) and according to social standing (U\&S). The ESP coding scheme is a reconstruction of the scheme developed by Erikson et al ${ }^{22}$ This coding scheme is based on four facets of occupation: occupational group, required training, seff-supportindependence and leadership Each occupation ils classified into 10 categories according to these aspects. ${ }^{23}$ This list has been adapted for the Netherlands and is still comparable with the original list. ${ }^{24}$ The U\&S score ls also comparable with international classffications. ${ }^{23}$ The construction of this list was based on the ranking of 16 occupational titles by 500 respondents according to social standing. ${ }^{23}$ Other factors relevant to the association between SES and breast cancer risk that were measured included benign breast disease, familial breast cancer, parity, age at first birth, age at menarche, age at menopause, oral contraceptive use, current cigarette smoking, Quetelet index $\left(\mathrm{kg} / \mathrm{m}^{2}\right)$ and alcohol intake. In the cohort study the association between dietary fat and breast cancer risk has been studied previously ${ }^{19}$ and since no association was found, we did not include fat intake into our analyses.

\section{Data analysis}

The distribution of SES indicators was compared in the case and subcohort groups. Educational level was aggregated into five categories: primary school, lower vocational school, junior high school, senior high school and higher vocational school or university. The EGP score of the last occupation was divided into four categories: upper white collar jobs (professionals and managers), lower white collar jobs (non-manual workers), blue collar jobs (manual workers) and others (farmers, self-employed people and housewives). The UIS score (also based on last occupation) was divided into five categories ranging from low (e.g. cleaner) to high social standing (e.g. teacher). An extra category was addled for housewives and included women who had never had paid employment. The associations between SES and covarlates were also studied in the subcohort by comparing mean values of age, parity, age at first birth, age at menarche, age at menopause, alcohol consumption and Quetelet index and comparing the prevalence of benign breast disease, familial breast cancer, smoking and oral contraceptive use in relevant SES categories. To study the association between SES and breast cancer risk and the role of the potential risk factors mentioned above, data were analyzed according to the case-cohort approach, ${ }^{19,25}$ Mantel-Haenszel rate ratios of breast cancer were determined for each of the SES indicators, stratified for age. In the multivariate case-cohort analyses, using the GLIM statistical package, ${ }^{26}$ rate ratios and $95 \%$ confidence intervals (C) of breast cancer were computed for the four SES indicators, after adjustment for the covariates mentioned above. 


\section{RESULTS}

The distribution of SES indicators in the cases and in the subcohort is presented in table 1. Cases had a somewhat lower level of education than subcohort members, but this difference was very small. The same pattern is seen when the highest level of education in the household is compared between cases and the subcohort. Cases more often had a white collar occupation but there was no appreciable difference in the distribution among the social standing categories. The results of the age-stratified analysis of traditional risk factors for breast cancer in the cohort study have been reported previously. ${ }^{19}$ Briefly, women with benign breast disease had a higher risk for breast cancer compared with women without benign breast disease. Maternal breast cancer and breast cancer in sisters were also associated with a higher relative risk. Age at first birth and age of menopause were positively associated with breast cancer risk, whereas parity and age at menarche were negatively associated. No associations were found between breast cancer risk and artificial menopause, use of oral contraceptives, current cigarette smoking and Quetelet index.

Table 1: Distribution of socioeconomic status indicators in breast cancer cases and subcohort

\begin{tabular}{|c|c|c|c|c|c|}
\hline \multirow[t]{2}{*}{ Characteristic } & & \multicolumn{2}{|c|}{ Subcohort } & \multicolumn{2}{|c|}{ Cases } \\
\hline & & $n$ & $\%$ & $n$ & $\%$ \\
\hline Total & & $\$ 716$ & & 471 & \\
\hline \multicolumn{6}{|l|}{ Highest levell of education: } \\
\hline Primary school & & 603 & 35.8 & 172 & 37.1 \\
\hline Lower wacational & & 384 & 22.8 & 109 & 23.5 \\
\hline Junior high school & & 476 & 28.2 & 120 & 25.9 \\
\hline Senior high school & & 86 & 5.1 & 26 & 5.6 \\
\hline Higher vocational / university & & 137 & 8.1 & 37 & 8.0 \\
\hline \multicolumn{6}{|c|}{ Highest level of education (houshold): } \\
\hline Primary school & & 371 & 220 & 108 & 233 \\
\hline Lower vocational & & 350 & 20.7 & 107 & 23.1 \\
\hline Junior high school & & 517 & 30.6 & 127 & 27.4 \\
\hline Senior high school & & 132 & 7.8 & 43 & 9.3 \\
\hline Higher vocational / uniwersity & & 320 & 48.9 & 79 & 17.0 \\
\hline \multicolumn{6}{|l|}{ EGP score: "last proflession: } \\
\hline Blue collar & & 457 & 32.8 & 128 & 31.9 \\
\hline Lower white collar & & 350 & 25.1 & 111 & 27.7 \\
\hline Upper white collar & & 212 & 15.2 & 70 & 17.5 \\
\hline Other & & 376 & 27.0 & 92 & 22.9 \\
\hline \multicolumn{6}{|l|}{ U\&S score: "last profession: } \\
\hline 1 (llowest) & & 449 & 32.2 & 130 & 32.4 \\
\hline 2 & & 215 & 15.4 & 61 & 152 \\
\hline 3 & & 444 & 31.8 & 144 & 35.9 \\
\hline 4 & & 79 & 5.7 & 22 & 5.5 \\
\hline 5 (highest) & & 19 & 1.4 & 4 & 1.0 \\
\hline 6 Houswifte & & 189 & $\$ 3.5$ & 40 & 10.0 \\
\hline
\end{tabular}

See text for explanation 
Table 2 shows the associations between relevant covariates and three SES indicators in the subcohort. The relation between covariates and highest level of education in the household (not presented) is comparable to the relation between covariates and highest level of education of the individual. Women with a higher SES had on average fewer children, a later age at first birth, an earlier age at menarche, a later age at menopause and a higher mean alcohol intake. The mean Quetelet index was higher for women in the lower SES groups. Benign breast disease was more prevalent for women in the highest SES groups, as was the use of oral contraceptives and the percentage ever smoking. The prevalence of breast cancer in sisters was higher in the lowest SES groups, whereas the prevalence of maternal breast cancer was highest in the group with the highest level of education and almost equal in the occupational groups.

Table 2: Association between possible confounders and socioeconomic stalus indicators in the subcohort

\begin{tabular}{|c|c|c|c|c|c|c|c|c|c|}
\hline \multirow[t]{2}{*}{ Charactierisic } & \multicolumn{3}{|c|}{ Highest level of education ${ }^{\prime}$} & \multicolumn{3}{|c|}{$E G P^{2}$} & \multicolumn{3}{|c|}{ U\&S $^{2}$} \\
\hline & Low & Medium & High & $\begin{array}{l}\text { Blue } \\
\text { collar }\end{array}$ & $\begin{array}{l}\text { White } \\
\text { collar }\end{array}$ & Other & Low $^{3}$ & High ${ }^{3}$ & Housewife \\
\hline \multicolumn{10}{|l|}{ Mean } \\
\hline Age (mean yrs) & 62.3 & 61.0 & 61.1 & 64.3 & 61.2 & 61.1 & 61.1 & 61.3 & 61.2 \\
\hline Parity ${ }^{4}$ & 2.7 & 2.5 & 1.8 & 2.8 & 1.7 & 2.9 & 2.7 & 1.7 & 3.2 \\
\hline Age at first birth ${ }^{4}$ (mean yrs) & 26.3 & 27.0 & 27.8 & 26.5 & 27.8 & 26.7 & 26.6 & 27.8 & 26.6 \\
\hline Age at menarche (mean yrs) & 13.9 & 13.7 & 13.3 & 13.9 & 13.6 & 13.5 & 13.8 & 43.5 & 13.7 \\
\hline Age at menopause (mean yrs) & 48.5 & 48.7 & 49.5 & 48.4 & 49.0 & 48.7 & 48.6 & 48.9 & 48.7 \\
\hline Alcohol intake (mean g/ day) & 3.8 & 6.0 & 9.4 & 4.5 & 7.6 & 5.0 & 5.1 & 7.2 & 4.7 \\
\hline Quelelet index (mean $\left.\mathrm{kg} / \mathrm{m}^{2}\right)$ & 25.8 & 25.1 & 23.8 & 25.8 & 24.4 & 25.3 & 25.5 & 24.5 & 25.7 \\
\hline \multicolumn{10}{|l|}{ Percentage yes } \\
\hline Benign breast disease & 5.1 & 8.3 & 10.3 & 6.8 & 8.0 & 6.6 & 7.4 & 8.1 & 4.2 \\
\hline Maternal breast cancer & 2.3 & 3.5 & 4.0 & 3.3 & 3.2 & 3.2 & 3.2 & 3.3 & 3.2 \\
\hline Breast cancer sister(s) & 7.6 & 4.1 & 3.6 & 6.3 & 4.4 & 4.3 & 5.9 & 4.1 & 4.8 \\
\hline Smoking (\% ever) & 34.8 & 41.7 & 51.1 & 40.0 & 47.2 & 36.4 & 42.2 & 45.6 & 30.7 \\
\hline Oral contraceptives ( $\%$ ever) & 18.9 & 26.3 & 320 & 24.2 & 26.4 & 27.8 & 24.5 & 29.0 & 22.8 \\
\hline
\end{tabular}

Highest lewel of educalion: low = primary school; medium = lower wocational or junior thigh school, high = senior high school, higher vocational or university

See text for explanation

3. Low social standing U\&S categories $\#$ and 2 ; high social standing U\&S categories 3,4 and 5

4 for parous woman only

The results of the stratified analyses are presented in table 3 . After stratification for age in three 5-year categories there was no association between the highest level of education and breast cancer risk (RR highest/lowest $=0.94 ; 95 \% \mathrm{Cl} 0.63-1.39$; trend-p $=0.70$ ). Upper white collar workers had a higher breast cancer rate compared to blue collar workers $(R R=1.16 ; 95 \% \mathrm{Cl} 0.83-1.62)$ with intermediate values for lower white collar workers (trend-p $=0.34$ ). Women with a higher social standing job had a non-significantly lower rate of breast cancer than women with a lower U\&S score ( $R R=0.73 ; 95 \% \mathrm{Cl} 0.24-2.23$ ).

After further adjustment for the covariates (table 4), there are only slight changes in the relation between highest level of education and breast cancer risk (trend-p $=0.45$ ). The 
breast cancer rate of lower white collar workers became comparable to the rate of blue collar workers (RR $=1.01 ; 95 \% \mathrm{Cl} 0.69-1.49$ ), whereas upper white collar workers still had a somewhat higher breast cancer rate $(\mathrm{RR}=1.19 ; 95 \% \mathrm{Cl} 0.80-1.76)$. The association between social standing and breast cancer changed a little: the breast cancer rate ratio in the middle U\&S groups was estimated somewhat higher, but rate ratios for breast cancer in the highest U\&S groups were still below one.

We have also conducted analyses with the two highest categories of U\&S score combined and this did not alter the results. The same applies to level of education.

Table 3: Mantel-Haenszel rete ratios for breast cancer according to four different socioeconomic status indicators, adjusted for age

\begin{tabular}{|c|c|c|c|c|}
\hline SES indicator & $\begin{array}{l}\text { No. of cases } \\
\text { in cohort }\end{array}$ & $\begin{array}{l}\text { Person-years } \\
\text { in subcohort }\end{array}$ & $\mathrm{RR}_{\text {WN }}(95 \% \mathrm{Cl})$ & $\begin{array}{l}\text { Test for trend } \\
x^{2} \text { (p-walue) }\end{array}$ \\
\hline \multicolumn{5}{|l|}{ Highest level of ed ucation: } \\
\hline Primary schooll & 172 & 1951 & 1 & \\
\hline Lower vocational & 109 & 1240 & $1.05(0.79-1.39)$ & $0.15(0.70)$ \\
\hline Junior high school & 120 & 1548 & $0.90(0.69-1.17)$ & \\
\hline Senior high school & 26 & 276 & $1.08(0.67-1.73)$ & \\
\hline Higher wocational / university & 37 & 450 & $0.94(0.63-1.39)$ & \\
\hline \multicolumn{5}{|c|}{ Higher levell of education (household): } \\
\hline Primary schooll & 108 & 1194 & $1^{\circ}$ & \\
\hline Lower vocational & 107 & 1135 & $1.08(0.79-1.48)$ & $0.98(0.32)$ \\
\hline Junior high school & 127 & 168.8 & $0.85(0.63-1.14)$ & \\
\hline Senior high school & 43 & 420 & $1.12(0.74-1.69)$ & \\
\hline Higher wocational / university & 79 & 1041 & $0.83(0.60-1.16)$ & \\
\hline \multicolumn{5}{|l|}{ EGP score: 'last profession: } \\
\hline Bilue collar & 128 & 1477 & $1^{\circ}$ & \\
\hline Lower white collar & 111 & 1136 & $1.12(0.84-1.50)$ & $0.91(0.34)$ \\
\hline Upper white collar & 70 & 698 & $1.16(0.83-1.62)$ & \\
\hline Other ${ }^{2}$ & 92 & $12 \Downarrow 3$ & $0.87(0.64 \cdot 1.18)$ & \\
\hline \multicolumn{5}{|l|}{ U\&S score: 'last profession } \\
\hline 1 (lowest) & 130 & 1454 & $1^{*}$ & \\
\hline 2 & 61 & 699 & $0.96(0.68-1.36)$ & \\
\hline 3 & 144 & 1444 & $1.10(0.84-1.44)$ & $0.03(0.86)$ \\
\hline 4 & 22 & 260 & $0.95(0.57-1.58)$ & \\
\hline 5 (highest) & 4 & 62 & $0.73(0.24-2.23)$ & \\
\hline Houswite $^{2}$ & 40 & 603 & $0.73(0.49-1.08)$ & \\
\hline
\end{tabular}

Reference catergory

'See text for explanation

${ }^{3}$ Excluded from test for trend

\section{DISCUSSION}

We did not find a higher risk of breast cancer for those with higher SES. The EGP score of the last profession showed a weak association, with the highest risk for upper white collar workers, who had a $19 \%$ higher risk for breast cancer compared with blue collar workers. 
This is not considered to be a large increase. Besides, the trend test did not show significance nor were the relative rates in the different categories statistically significantly different from one. Neither highest level of education nor U\&S score had a positive association with breast cancer. Adjustment for known risk factors for breast cancer that were associated with SES did not alter the association between SES and breast cancer risk.

Table 4: Rate ratio for breast cancer acconding to four different socioeconomic status indicators in multivariate analysis

\begin{tabular}{|c|c|c|c|}
\hline SES indicator & $\mathrm{RR}^{\prime}$ & $95 \% \mathrm{Cl}$ & $\begin{array}{l}\text { test for trend } \\
x^{2} \text { (p-value) }\end{array}$ \\
\hline \multicolumn{4}{|l|}{ Highest level of education: } \\
\hline Primary school & $1^{*}$ & & \\
\hline Lower vocational & 1.07 & $0.77-1.49$ & $0.60(0.45)$ \\
\hline Junior high school & 0.88 & $0.63-1.21$ & \\
\hline Senior high school & 1.14 & $0.66-1.97$ & \\
\hline Higher vocational / universily & 0.86 & $0.50-146$ & \\
\hline \multicolumn{4}{|c|}{ Higher levell of education (household): } \\
\hline Primary school & 1 “ & & \\
\hline Lower wocational & 1.06 & $0.72-1.56$ & $0.96(0.33)$ \\
\hline Junior high schooll & 0.87 & $0.61-1.26$ & \\
\hline Senior high school & 1.31 & $0.81-2.13$ & \\
\hline Higher wocational / university & 0.81 & $0.52-1.26$ & \\
\hline \multicolumn{4}{|l|}{ EGP score: "last profession" } \\
\hline Blue collar & $1^{*}$ & & \\
\hline Lower white collar & 1.01 & $0.69-1.49$ & $1.93(0.16)$ \\
\hline Upper white collar & 1.19 & $0.80-1.76$ & \\
\hline Other $^{2}$ & 0.95 & $0.66-1.36$ & \\
\hline \multicolumn{4}{|l|}{ U\&S score: "last profession } \\
\hline 1 (lowest) & $4^{\circ}$ & & \\
\hline 2 & 1.06 & $0.71-1.59$ & \\
\hline 3 & 1.23 & $0.89-1.70$ & $0.41(0.52)$ \\
\hline 4 & 0.95 & $0.53-1.70$ & \\
\hline 5 (highest) & 0.76 & $0.24-2.40$ & \\
\hline Houswife & 0.76 & $0.45-1.31$ & \\
\hline
\end{tabular}

\footnotetext{
"Reference catergory

"Relative rate after adjustment for age, benign breast disease, matemal breast cancer, breast cancer in sister(s), age alt firsl; birth, parily, age al menarche, age au menopause, oral contraceplive use, Quetelet index, alcohol use, current cigarethe smoking.

Seve text for explanation.

${ }^{3}$ Excluded from test for trend:
}

This cohort study was conducted in a large sample of the general population of women aged 55-69 years at baseline. After the follow-up period of 3.3 years, 471 breast cancer cases were detected. This is considered to be a sufficient number to find significant associations when risk factors have a near normal distribution. ${ }^{27}$ Most of the women had attended primary school, lower vocational school or junior high school, and a substantial number had attained higher educational levels resulting in a distribution of subjects over the 
SES categories which is not optimal but still made it possible to study the association with breast cancer risk. During the follow-up period of 3.3 years, there was $100 \%$ follow-up of person-years and the completeness of cancer follow-up was also very high, indicating that selection bias due to loss to follow-up is unlikely. Also, there were no reasons to assume that residual confounding was still present, because all known risk factors for breast cancer were measured and controlled for in the multivariate analyses.

Another fact that could have influenced the results is misclassification of exposure. Socioeconomic status is operationalized as highest level of education, EGP score (functional level) and U\&S score (social standing), both based on the last occupation. Highest level of education is a characteristic that is easily obtainable and recordable, moreover it applies to every adult individual. With the occupation-based SES indicators there is a problem how to classify the large majority of women with no formal employment. All women were classified according to their last occupation although almost $50 \%$ of the women finished their formal employment 30 years before, which was typical for the Netherlands. ${ }^{28}$ The SES of the last occupation will therefore have a limited value.

It is also possible to classify women according to their husband's occupation. This may lead to misclassification since other studies have indicated that $40 \%$ of the working women in the USA had an occupational status higher than that of their husband. ${ }^{20}$ This difference most often occurs when the husband has a manual blue collar job and the wife has a sales or clerical white collar job. ${ }^{30}$ Although this is merely an artefact of the occupational scales, because women in routine non-manual jobs seem comparable to men doing manual work with respect to SES, ${ }^{34}$ it seems better to use the highest occupational level in the household. Unfortunatelly, we had only the occupational history of the woman and not that of her partner. However, we did have information about the highest level of education of the individual and her partner and used them both in the analyses on SES and breast cancer risk: this did not lead to different results.

Detection bias may be another concern in breast cancer studies. In the Netherlands there are no large differences in access to medical care between SES categories and at the sttart of our cohort study breast cancer screening was not widespread. So, it is unlikely that these factors have an influence on the results. Moreover, we have examined the association between tumour site at time of diagnosis and the three SES indicators within the cohort and we did not find a clear association among the different SES categories (data not shown).

We did not include dietary fat intake into our models, since earlier analyses in the cohort study did not show an association between dietary fat intake and breast cancer. ${ }^{10}$ Besides, subjects of upper SES categories in general eat more fruit, vegetables and dietary fiber and less fat and energy, ${ }^{32-34}$ indicating that differences in dietary habits between SES categories should rather lead to an inverse association between SES and breast cancer, instead of a positive association.

In eleven studies on SES and breast cancer highest levell of education or years of completed schooling were used as SES indicator. ${ }^{1.11}$ Although almost all report a positive association between SES and breast cancer, there were differences in significiance and magnitude: relative risks of the highest versus the lowest category varied from 1.0 to 2.5 . 
These differences in results are probably due to differences in the use of control variables; because in almost all studies that included age as the only confounding variable, significant positive associations were found, with relative rates varying from to 1.2 to 2.5 . This is not comparable with our results, since we did not find a positive association between level of education and breast cancer risk in the age-adjusted analyses.

In two case-control studies ${ }^{48}$ the association between breast cancer risk and occupationbased SES indicators were investigated. We could not directly compare our results with these studies, because other reference categories were used, e.g. farmers, ${ }^{4}$ housewives or the self-employed. ${ }^{b}$ Both studies reported a higher breast cancer risk among white collar workers compared with blue collar workers, after adjustment for education and marital status $s^{4}$ or age, parity and place of residence. ${ }^{6}$ Only one cohort study used a subject's occupation as SES indicator and no regular pattern between occupation and breast cancer risk was reported. "In another cohort study the occupation of the head of household was used as indicator of $\mathrm{SES}^{\ominus}$ and a third cohort study was restricted to economically active women at baseline; $;^{12}$ in these two studies significant positive associations were reported between SES and breast cancer risk. Therefore, various SES indicators (years of education, educational levell, own occupation or highest occupation in the household) showed positive associations with breast cancer risk, indicating that differences in SES indicators between our study and the reviewed studies are not responsible for discrepancies in results. All the risk factors for breast cancer we have studied except breast cancer in sister(s) and a higher Quetelet index, were more prevalent in the highest SES groups, suggesting that women in the highest SES groups might have a higher unadjusted breast cancer risk. However, some of the differences were modest and the relative risks associated with these factors are mostly modest as well. ${ }^{19}$ It is therefore possible that differences in the distribution of these risk factors are not big enough to cause differences in breast cancer risk between SES groups. While it is possible that confounding by traditional breast cancer risk factors can explain part of the association in other published studies, the fact that we did not find a positive association with SES is comparable with the finding that differences in self-reported health between SES categories are smaller for women in the Netherlands compared to differences in most other European countries and North America. ${ }^{35}$ This may be a result of relatively small inequalities in level of education and income in the Netherlands and the social security and welfare system.

In conclusion, we found no association between breast cancer risk and various indicators of SES. This is not in agreement with studies conducted in other European countries and North America, which often report weak associations between SES and breast cancer. While confounding by traditional risk factors for breast cancer may explain part of the positive associations reported in other studies; the fact that we did not find a positive association between SES and breast cancer is comparable with the finding that health differences between SES categories are smaller in the Netherlands than in most other European countries and North America.

\section{ACKNOWLEDGMENTS}

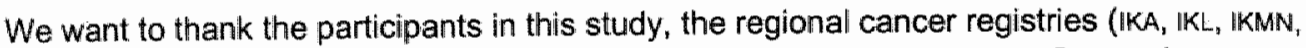
$\mathbb{K N}, \mathbb{K K O},\|K R, I K S T\| K W,, I K Z$ ), PALGA for providing incidence data; $E$. Dorant, $S$. van de 
Crommert, H. Brants, P. Florax, J. Nelissen and W. van Dik for assistance in the cohort study, and S. van den Heuvel from the TNO-NIPG institute for coding the questions about occupation. This work was financially supported by the Dutch Ministry of Welfare, Public Health and Cultural Affairs and by the Dutch Cancer Society.

\section{REFERENCES}

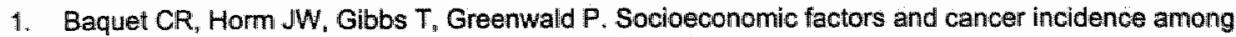
blacks and whites. J Natl Cancer inst 1991;83:551-557.

2. Williams RR, Horm JW. Association of cancer sites with tobacco and alcohol consumption and socioeconomic status of patients: interview study from the third national cancer survey. I Natl Cancer /nst $1977 ; 58: 525-547$.

3. Harris RE, Wynder EL. Breast cancer and alcohol consumption. A study in weak associations: JAMA 1988;259:2867-2871.

4. Talamini $R_{n}$ La Vecchia $C$, Decarli $A$, et al. Social factors, diet and breast cancer in a northem ltalian population. Br J Cancer 1984;49:723-729.

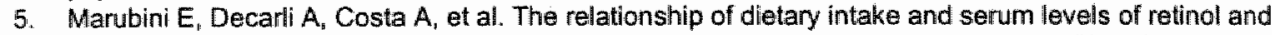
beta-carotene with breast cancer. Results of a case-control study. Cancer 198:8;61:173-180.

6. Ewertz M. Risk of breast cancer in relation to social factors in Denmark. Acta Oncol 1988;27:787-792.

7. Harris RE, Zang EA, Wynder EL. Oral contraceptives and breast cancer risk: a case-control study. Int $J$ Epidemial 1990;19:240-246.

8. Van "t Veer P. Dekker JM, Lamers JWL, et al. Consumption of fermented milk products and breast. cancer: a case-control study in the Netherlands. Cancer Res 1989:49:4020-4023.

9. Rimpela $A H_{1}$ Pukkala $E$. Cancers of affluence: positive social class gradient and rising incidence trend in some cancer forms. Sac Sci Med 1987;24:601-606.

10. Carter CL, Jones DY, Schatzkin A, Brinton LA. A prospective study of reproductive, familial and socioeconomic breast cancer using the NHANES I data. Public Health Rep 1989;104:45-50.

11. Leon DA. Longitudinal study:" Social distribution of cencer, 1971-1975. (OPCS Series LS No. 3). London: $\mathrm{HMSO}, 1988$.

12. Văgerö D. Persson G. Occurrence of cancer in socioeconomic groups in Sweden. Scand J Soc Med $1986 ; 14: 151-160$.

13. Ewert $M$, Duffy $S W, A d a m i ~ H-O$, et al. Age at first birth, parity and risk of breast cancer: A meta-analysis of 8 studies from the Nordic countries. Int $J$ Cancer 1990;46:597-603.

14. Graham $S$, Hellman R, Marshall $J_{n}$ et al. Nutritional epidemiology of postmenopausal breast cancer in Western New York. Am J Epidemiol 1991; 134:552-566.

15. Kelsey $\mathrm{JL}$, Gammon MD. Epidemiology of breast cancer. Epidemiol Rov 1990;12:228-240.

16. Jacabsen $\mathrm{BK}$, Lund $\mathrm{E}$. Level of educatiom, use of oral contraceptives and reproduclive factors: The Trömsö Study. Int J Epidemiol 1990;19:967-970.

17. Van den Brandt PA, Goldbohm RA, Van "t Veer P, Volovics A, Hermus RJJ, Sturmans F. A large-scale prospective cohort study on diet and cancer in the Netheriands. J Clin Epidemiol 1990;43:285-295.

18. Yan den Brandt PA, Sichouten LJ, Goldbohm RA, Dorant E, Hunen PMH. Development of a record linkage protocol for use in the Dutch cancer registry for epidemiological research. Int $J$ Epidemiol $1990 ; 19: 553-558$.

19. Van den Brandt $P A$, Van 't Veer $P$, Goldbohm RA, et all. A prospective cohort study on dietary fat and the risk of postmenopausal breast cancer. Cancer Res 1993:53:75-82.

20. Liberatos P, Link BG, Kelsey IL. The measurementt of social class in epidemiology. Epidemiol Rev 1988: 10:87-121.

21. Centraal Bureau voor de Statistiek. Beroepenclassificatie 1984. Lijst ven benamingen per beraepencode. Voorburg: CBS, 1985.

22. Erikson $\mathrm{R}$, Goldthorpe $\mathrm{JH}$, Portocarero $\mathrm{L}$. Intergenerational class mobility in three western countries: England, France and Sweden. Br I Sociol 1979;30:415-441.

23. Van Berkel-van Schailk AB. Tax B. Naar een standaardoperationalisatie van sociaal-economische status voor epidemiologisch en sociaal-medisch onderzoek. Sociaal-economische gezondheidsverschillen nr.6. Den Haag: DOP, 1990.

24. Ganzeboom $H$, Luykx $R_{n}$ Dessens J, et al. Intergenerationele klassenmobiliteit in Nederland tussen 1970 en 1985. Mens en Maatschappij 1987;62:17-43.

25. Self SG, Prentice RL. Asymptotic distribution theory and efficiency results for case-cohort studies. Ann Stat 1988;16:64-81.

26. Baker RJ. GLIM 3. 77. Reference Manual. Oxford: Numerical algorithms group, 1985. 
27. Philps AN, Pocock S. Sample size requirements for prospective studies, with examples for coronany hewat disease. 1 Clin Epidemiol 1989;42:639-648.

23. Hooghimmstra BT3, Niphuis-Nill M. Sociale atlas van de wrous. Deel 2 Anbeid, inkomen en facilfteiten om waten en de zomg voor kinderen te combineron. Den Haag: VUGA, 1993.

20. Haug MR. Social dess measurement and women's occupational roles. Social Forces 1973; $52: 86-98$.

30. Stanwort M. Women and class analysis: A reply to John Goldthorpe. Sociology 1984:18:159-170.

31. Goldthoppe $3 H$. Women and class analysis: In defence of the conventional view. Sociology 1983;17: $305-488$

32. Hulshol KFAM, Lowrik MRH, Kok FJ, Wedel M, Kistemaker C, Brants HAM. Inwloed van sociaaleconomische status op voeding en andere levenisstij|factoren. In: Mackenbach JP (ed). Sockateconomische gezondheidsverschillen onderzocht. Deel III. Den Haag: DOP, 1991.

33. Patterson BH, Block G. Food choices and the cancer guidelines. Am J Public Health 1988;78: 282-286.

34. Baghurst KI, Record S., Baghurst PA, Syrette JA, Crawford D, Worsley A. Sociodemographic determinants in Australia of the intake of food and nutrients implicated in cancer aetiology. Med $J$ Aust 1990: 153: $444-452$.

35. Kunst $A E_{,}$Geurts $J M_{4}$ Van den Berg J. International variation in socio-economic inequalities in selfreported health. In: Mackenbach J P (ed). Saciaal-economische gezondheidswerschillen onderzacht, V. Den Haag: DOP, 1993. 
Chapter 5

SOCIOECONOMIC STATUS AND COLON CANCER INCIDENCE:

a prospective cohort study

A. Jeanne M. van Loon, Piet A. van den Brandt, R. Alexandra Goldbohm 


\begin{abstract}
The assaciation between socioeconomic status and colon cancer was investigated in a prospective cohort study, that started in 1986 in the Netherlands among 120,852 men and women aged 55-69 years. At baseline, data on socioeconomic status, alcohol consumption and other dietary and non-dietary covariates were collected by means of a self-administered questionnaire. For data analysis a case-cohort approach was used, in which the person-years at risk were estimated using a randomly selected subcohort ( 1688 men and 1812 women). After 3.3 years of follow-up, 312 incident colon cancer cases were detected: 157 men and 155 women. After adjustment for age, we found positive associations between colon cancer risk and highest level of education (trend-p $=0.13$ ) and social standing (trend- $p=0.008$ ) for men. Also, male upper white workers had a higher colon cancer risk than blue collar workers $(R R=1.42$; $95 \% \mathrm{Cl} 0.95-2.11)$. Only the significant association between social standing and colon cancer risk persisted after additional adjustment for other risk factors for colon cancer (trend-p $=0.005$ ), but the higher risk was only found in the highest social standing category (RR highest/lowest social standing $=2.60 ; 95 \% \mathrm{Cl} 1.31-5.14)$. In women, there were no clear associations between the socioeconomic status indicators and colon cancer.
\end{abstract}




\section{INTRODUCTION}

Different associations between socioeconomic status (SES) and colon cancer risk have been observed depending on study design. Correlation ${ }^{1}$ and cross-sectional ${ }^{2.3}$ studies did not show consistent associations but case-contro| $\left.\right|^{4-5}$ and cohort studies ${ }^{7-8}$ showed predominantly positive associations between SES and colon cancer risk. In these studies hardly any adjustment was made for potential confounders. Most of the time, age was included in the analyses, and two studies included some lifestyle characteristics such as smoking ${ }^{3}$ and coffee and alcohol consumption. ${ }^{6}$ Although associations have been reported between SES and colon cancer, SES is not thought to be a direct risk factor. Lifestyle variables that have been identified as possible risk factors for colon cancer, e.g. dietary factors such as fat, fiber or energy intake, ${ }^{10,11}$ alcohol consumption, ${ }^{12}$ physical activity ${ }^{13,14}$ or reproductive factors, ${ }^{15}$ are all characteristics associated with SES. ${ }^{16-19}$ Therefore we examined the association between SES and colon cancer incidence and the influence of various lifestyle factors such as Quetelet index, alcohol consumption, large bowel cancer in the family, physical activity and reproductive factors (the last for women only) in a prospective cohort study on diet, other lifestyle variables and cancer risk. Earlier research in the cohort study did not show associations between (fresh) meat consumption or fat intake and risk of collon cancer. ${ }^{20}$ Therefore, these dietary factors were omitted from our analyses.

\section{MATERIALS AND METHODS}

\section{The cohort study}

In September 1986, the Netherlands Cohort Study (NLCS), investigating various lifestyle variables, sociodemographic indicators and cancer risk, was started. A detailed description of the cohort study design has been reported elsewhere. ${ }^{21}$ Briefly, the cohort included 58,279 men and 62,573 women aged $55-69$ years at the beginning of the study. The study population originated from 204 municipal population registries throughout the country. Data were callected by means of a self-administered questionnaire. For data analysis the case-cohort approach was used in which cases are derived from the entire cohort, while the person-years at risk are estimated from a random sample of 3500 subjects (subcohort). After the baseline exposure measurement the subcohort was randomly sampled (1688 men and 1812 women) and it has been followed up biennially for vital status information. Follow-up for incident cancer has been established by record linkage with all regional cancer registries in the Netheriands and with a national pathology register (PALGA). The method of record linkage has been described previously. ${ }^{22}$ The analysis is restricted to colon cancer incidence in the period from September 1986 to December 1989. In this period, completeness of follow-up was estimated to be $95 \%{ }^{23}$ After these 3.3 years of follow-up 351 colon cancer cases were detected. We excluded self-reported prevalent cancer cases other than skin cancer $(n=28)$, cases with in situ carcinoma $(n=8)$, cases without microscopically confirmed diagnosis $(n=2)$ and sarcoma $(n=1)$. Therefore 312 incident cases ( 157 males and 155 females) were available for analysis. Self-reported prevalent cancer cases other than skin cancer were also excluded from the subcohort, with the result that 3346 subjects ( 1630 men and 1716 women) remained in this group. 


\section{Socioeconomic status}

SES was measured by means of highest level of education attained and by means of occupational history, two of the recommended measures for SES. ${ }^{24}$ Educational level of the individual and his or her partner was classified as primary school, lower vocational school (e.g. technical school, domestic science school), junior high school, senior high school, higher vocational school, university and other education. Information about occupational history was coded according to a job coding system of the Central Bureau of Statistics (CBS) frequently used in the Netherlands. ${ }^{25}$ For the present analysis, these CBS codes were aggregated according to occupational sector and required training (EGP) and according to social standing (U\&S). The EGP coding scheme is a reconstruction of the scheme developed by Erikson et al. ${ }^{26}$ which is still comparable with the original list. ${ }^{27}$ The U\&S score is based on an ordering of occupational titles according to sociall standing and is also comparable with international classifications..$^{28}$ Other factors relevant to the association between SES and colon cancer risk that were measured are Quetelet index $\left(\mathrm{kg} / \mathrm{m}^{2}\right)$, alcohol intake, large bowel cancer in the family, physical activity during work and the prevalence of cholecystectomy. For women parity and age at first birth were also measured.

\section{Data analysis}

The distribution of SES indicators and potential confounders known to be associated with SES and colon cancer were compared between the case and subcohort group, for men and women separately. Educational level was aggregated into five categories: primary school, lower vocational school, junior high school, senior high school and higher vocational school or university. The EGP score of the last occupation was divided into four categories: blue collar jobs (lower-grade technicians, semi- and unskilled manual workers), lower white collar jobs (administrators and non-manual employees), upper white collar jobs (professionals) and other (farmers, self-employed people and housewives). The U\&S score (also based on the last occupation) was divided into five categories increasing from low (e.g. garbage collector) to high social standing (e.g. lawyers); for women an extra category for housewives was added. The associations between SES and covariates were also studied in the subcohort, by comparing mean values of age, Quetelet index, alcohol intake, parity and mean age at first birth and comparing the prevalence of chollecystectomy, large bowel cancer in the family and high physical activity at work in relevant SES categories. To study the association between SES and colon cancer risk and the role of possible confounders, data were analyzed according to the case-cohort approach ${ }_{i}^{23,29}$ using the GLIM statistical package. ${ }^{\text {so }}$ Mantel-Haenszel rate ratios of colon cancer were determined for each of the SES indicators, stratified for age. In the multivariate analyses, rate ratios and $95 \%$ confidence intervals of colon cancer were computed for the different SES indicators, after adjustment for the covariates mentioned above. The analyses were conducted for men and women separately.

\section{RESULTS}

The distribution of SES indicators and covariates in the group of cases and the subcohort is presented in table 1. Cases were on average older than members of the subcohort (mean age for cases is 62.7 and for subcohort members 61.4), the mean alcohol intake was 
higher among cases and a history of large bowel cancer in the family and cholecystectomy was also more prevalent in the case groups. High physical activity at work was somewhat more prevalent among cases. Female colon cancer cases had a lower mean number of children and a higher mean age at first birth.

The association between the different SES indicators and colon cancer incidence is consistent in men; in the case group there were more men with a higher level of education, a white collar job and a high U\&S score (social standing) compared with the subcohort. For women there was hardly any difference in distribution of the SES indicators between cases and subcohort.

Table t: Distribution of sccigeconomic status indicators and potential confounders in colon cancer and subcohourt, for men and wornen separately

\begin{tabular}{|c|c|c|c|c|c|c|c|c|}
\hline \multirow[t]{3}{*}{ Characteristic } & \multicolumn{4}{|c|}{ Men } & \multicolumn{4}{|c|}{ Women } \\
\hline & \multirow{2}{*}{\multicolumn{2}{|c|}{$\begin{array}{l}\text { Subcohort } \\
(n=1630)\end{array}$}} & \multirow{2}{*}{\multicolumn{2}{|c|}{$\frac{\text { Cases }}{(n=157)}$}} & \multirow{2}{*}{\multicolumn{2}{|c|}{$\frac{\text { Subcohoit }}{(n=1716)}$}} & \multirow{2}{*}{\multicolumn{2}{|c|}{$\begin{array}{l}\text { Cases } \\
(n=155)\end{array}$}} \\
\hline & & & & & & & & \\
\hline & mean & \pm s.d. & mean & \pm s.d. & mean & $\pm s d$ & mean & $\pm s .0$ \\
\hline Age & 61,4 & \pm 42 & 62.9 & \pm 4.2 & 61.5 & \pm 4.3 & 62.6 & \pm 4.0 \\
\hline Quetelel index & 25.0 & \pm 2.7 & 25.3 & \pm 2.9 & 25.2 & \pm 3.5 & 24.5 & \pm 3.6 \\
\hline Ajcohol intake & 14.5 & \pm 16.5 & 16.0 & \pm 17.7 & 5.8 & \pm 9.6 & 6.4 & \pm 10.6 \\
\hline Parity" & & & & & 2.5 & \pm 2.7 & 2.1 & \pm 2.7 \\
\hline \multirow[t]{2}{*}{ Agle at first birth 4,2} & & & & & 26.8 & \pm 4.2 & 27.3 & \pm 4.2 \\
\hline & n & $\%$ & $n$ & $\%$ & $n$ & $\%$ & $n$ & $\%$ \\
\hline Cholecystectomy (yes) & 74 & 4.6 & 12 & 7.6 & 229 & 13.6 & 31 & 20.0 \\
\hline Large bowel cancer in family (yes) & 84 & 5.2 & 10 & 6.4 & 91 & 5.3 & 14 & 9.0 \\
\hline Physical activity at work ${ }^{3}$ (high) & 267 & 20.7 & 32 & 23.5 & 252 & 22.7 & 25 & 25.3 \\
\hline \multicolumn{9}{|l|}{ Highest level of education: } \\
\hline Primary school & 458 & 28.4 & 38 & 24.5 & 603 & 35.8 & 54 & 35.3 \\
\hline Lower wocational & 338 & 20.9 & 33 & 24.3 & 384 & 228 & 33 & 21.6 \\
\hline Junior higlh school & 420 & 26.0 & 35 & 22.6 & 476 & 28.2 & 42 & 27.5 \\
\hline Senior thigh school & 123 & 7.6 & 19 & 12.3 & 86 & 5.1 & 8 & 5.2 \\
\hline Higher wocational / university & 275 & 17.0 & 30 & 19.4 & 137 & 8.1 & 16 & 10.5 \\
\hline \multicolumn{9}{|l|}{ EGP score: last profession: } \\
\hline Blue collar & 563 & 38.8 & 53 & 35.8 & 457 & 32.8 & 37 & 30.6 \\
\hline Lower white collar & 206 & 14.2 & 14 & 9.5 & 350 & 25.1 & 41 & 33.9 \\
\hline Upper white collar & 436 & 30.0 & 58 & 39.2 & 212 & 15.2 & 17 & 14.0 \\
\hline Other & 247 & 17.0 & 23 & 15.5 & 376 & 270 & 26 & 21.5 \\
\hline \multicolumn{9}{|l|}{ USS score: last profession: } \\
\hline I (llowest) & 301 & 20.7 & 25 & 6.9 & 449 & 32.2 & 39 & 32.2 \\
\hline 2 & 369 & 25.4 & 32 & 21.6 & 215 & 15.4 & 19 & 15.7 \\
\hline 3 & 400 & 27.5 & 38 & 25.7 & 444 & 31.8 & 39 & 32.2 \\
\hline 4 & 207 & 14.3 & 19 & $12 B$ & 79 & 5.7 & 7 & 5.8 \\
\hline 5 (highest) & 175 & 12.1 & 34 & 23.0 & 19 & 1.4 & 2 & 1.7 \\
\hline 6 Housewife & & & & & 189 & 13.5 & 15 & 12.4 \\
\hline
\end{tabular}

Only for women

2 Far parous only

3. The index is based on the physical activity at work from the age of 20 untill 1986 and is therefore age dependent 
The association between SES indicators and covariates was studied in the suocohort by means of comparing mean values of age, Quetelet index, alcohol intake and the prevalence of cholecystectomy, large bowel cancer in the family and high physical activity at work between SES categories (table 2). Mean values of parity and age at first birth were only studied for women. In general, higher mean age, higher mean Quetelet index, lower mean alcohol intake and a higher percentage high physical activity at work were associated with a lower SES. For women higher prevalence of cholecystectomy was also associated with a lower SES, while for men the prevalence of cholecystectomy was slightly higher among white collar workers and high social standing professions. Mean parity was higher in the lowest SES groups and age at first birth was somewhat higher among women with a higher SES. The prevalence of large bowel cancer in the family was slightly higher among people with a higher educational level or a white collar occupation.

Table 2: Associalion between possible confounders and socioeconomic stalus indicators in the subcohort

\begin{tabular}{|c|c|c|c|c|c|c|c|c|c|}
\hline \multirow[t]{2}{*}{ Characteristic } & \multicolumn{3}{|c|}{ Highest llevel of education } & \multicolumn{3}{|c|}{ EGP } & \multicolumn{3}{|c|}{ U\&S } \\
\hline & Low & Medium & High & $\begin{array}{l}\text { Blue } \\
\text { collar }\end{array}$ & $\begin{array}{l}\text { White } \\
\text { coillar }\end{array}$ & Other & Low $^{2}$ & High & Housemife \\
\hline \multicolumn{10}{|l|}{ Men } \\
\hline Age (mean yrs) & 61.9 & 61.3 & 61.4 & 61.3 & 61.1 & 61.8 & 61.4 & 61.2 & \\
\hline QI (mean $\mathrm{kg} / \mathrm{m}^{21}$ & 25.4 & 24.9 & 24.6 & 25.2 & 24.7 & 24.8 & 25.3 & 24.6 & \\
\hline Alcohol intake (mean g/ day) & 12.3 & 13.7 & 18.3 & 12.5 & 17.7 & 10.8 & $\$ 2.5$ & 16.2 & \\
\hline Cholecystectomy (\% yrs) & 4.4 & 4.5 & 5.0 & 4.1 & 5.0 & 4.0 & 3.9 & 5.3 & \\
\hline Large bowel cancer in family (\% yes) & 4.6 & 5.2 & 5.5 & 4.6 & 4.8 & 7.3 & 5.2 & 5.1 & \\
\hline Physical activity at work (\% high) & 34.6 & 23.4 & 2.6 & 40.0 & 4.7 & 21.7 & 38.9 & 5.8 & \\
\hline \multicolumn{10}{|l|}{ Women } \\
\hline Age (mean yrs) & 62.3 & 61.0 & 61.1 & 61.3 & 61.2 & 61.1 & 61.1 & 61.3 & 61.2 \\
\hline Qll (mean $\left.\mathrm{kg} / \mathrm{m}^{2}\right)$ & 25.8 & 25.1 & 23.8 & 25.8 & 24.4 & 25.3 & 25.5 & 24.5 & 25.7 \\
\hline Alcohol intake (mean g/ day) & 3.8 & 6.0 & 9.4 & 4.5 & 7.6 & 5.0 & 5.1 & 7.2 & 4.7 \\
\hline Parity (mean) & 2.7 & 2.5 & 1.8 & 2.8 & 1.7 & 2.9 & 2.7 & 1.7 & 3.2 \\
\hline Age at frrst birth ${ }^{3}$ (maan yrs) & 26.3 & 27.0 & 27.0 & 26.5 & 27.8 & 26.7 & 26.6 & 27.8 & 26.6 \\
\hline Cholecystectomy (\% yes:) & 15.4 & 13.0 & 10.8 & $13: 9$ & 10.9 & 15.2 & 13.3 & 11.3 & 16.4 \\
\hline Large bowel cancer in family (\% yes) & 4.5 & 5.5 & 7.6 & 4.6 & 5.3 & 4.5 & 5.1 & 4.8 & 4.8 \\
\hline Physical activity at work (\% high) & 34.8 & 19.3 & 12.3 & 31.8 & $\$ 7.1$ & 16.7 & 28.6 & 15.4. & - \\
\hline
\end{tabular}

"Highest lovel of education: bow = primary school: medium = lower vocational or junior high school; high = senior high school higher vociational or university

* Low social standing: U\&S-categories 4 and 2 ; high social standing: U\&S-categories 3,4 and 5

For parous only

The results of the stratified analyses are presented in table 3 . After adjustment for age in three five-year categories, for men there was a non-significant positive association between level of education and colon cancer risk (RR highest/lowest level of education $=1.41$; trend- $p=0.13$ ). Male upper white collar workers had a higher rate ratio than blue collar workers ( $R R=1.42 ; 95 \% \mathrm{Cl} 0.95-2.11$ ), but lower white collar workers had a lower colon cancer rate. Finally, a significant positive association between U\&S score and colon cancer risk was observed for men (RR high/low social standing $=2.42 ; 95 \% \mathrm{Cl} 1.39-4.20$; trend- $p=0.008$ ). These positive associations between SES and colon cancer were not found in women. 
Table 3: Mantel-Haenszel rate ratios for colon cancer adjusted for age according to three different socioeconomic status indicalors

\begin{tabular}{|c|c|c|c|c|c|c|}
\hline \multirow[t]{2}{*}{ SES indicator } & \multicolumn{3}{|c|}{ Men } & \multicolumn{3}{|c|}{ Women } \\
\hline & $\begin{array}{l}\text { No of cases } \\
\text { in cohort }\end{array}$ & $\begin{array}{l}\text { Person-years } \\
\text { in subcohort }\end{array}$ & $\mathrm{RR}_{\mathrm{wNH}}(95 \% \mathrm{Cl})$ & $\begin{array}{l}\text { No. of cases } \\
\text { in cohort }\end{array}$ & $\begin{array}{l}\text { Person-years. } \\
\text { in subcohort }\end{array}$ & $\mathrm{RR}_{\text {就 }}(95 \% \mathrm{Cl})$ \\
\hline Ifighest level of education: & 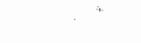 & & & & & \\
\hline Primary school & 38 & 1455 & 1 & 54 & 1959 & $1 "$ \\
\hline Lower wocational & 33 & 1098 & $1.24(0.76-2.04)$ & 33 & 1240 & $1.04(0.64-1.69)$ \\
\hline Junior high school & 35 & 1345 & $1.05(0.65-1.74)$ & 42 & 1551 & $1.00(0.65-1.54)$ \\
\hline Senior high school & 19 & 397 & $1.82(1.01-3.29)$ & 8 & 280 & $1.04(0.48 .2 .27)$ \\
\hline Higher vocational / university & 30 & 883 & $1.41(0.84-2.35)$ & 16 & 450 & $1.31(0.71 \cdot 2.39)$ \\
\hline $\begin{array}{l}\text { Test for trend } \\
x^{2} \text { (p-value) }\end{array}$ & & & $2.33(0.13)$ & & & $0.61(0.43)$ \\
\hline \multicolumn{7}{|l|}{ EPG score: last profession: } \\
\hline Blue collar & 53 & 1803 & $1^{*}$ & 37 & 1475 & $1^{*}$ \\
\hline Lower white collar & 14 & 667 & $0.69(0.37-1.28)$ & 41 & 1139 & $1.46(0.91-2.33)$ \\
\hline Upper white collar & 58 & 1404 & $1.42(0.95-2.11)$ & 17 & 696 & $0.95(0.52-1.73)$ \\
\hline Other ${ }^{1}$ & 23 & 798 & $0.95(0.57-1.58)$ & 26 & 1222 & $0.85(0.51-1.43)$ \\
\hline $\begin{array}{l}\text { Test for trend } \\
x^{2} \text { (p-value) }\end{array}$ & & & $2.70(0.40)$ & & & $0.05(0.82)$ \\
\hline \multicolumn{7}{|l|}{ U\&S score: last profession } \\
\hline 1 (lowest) & 25 & 969 & $1^{\circ}$ & 39 & 1456 & 1 \\
\hline 2 & 32 & 1188 & $1.05(0.61-1.81)$ & 19 & 697 & $0.96(0.54-7.70)$ \\
\hline 3 & 38 & 1282 & $1.14(0.68-1.95)$ & 39 & 1449 & $0.99(0.62-1.57)$ \\
\hline 4 & 19 & 667 & $1.12(0,60-2,10)$ & 7 & 259 & $0.95(0.41-2.22)$ \\
\hline 5 (highest) & 34 & 564 & $2.42(1.39-4.20)$ & 2 & 62 & $1.08(0.23-5.18)$ \\
\hline Housewife & & & & 15 & 610 & $0.93(0.50-173)$ \\
\hline $\begin{array}{l}\text { Test for trend } \\
x^{2} \text { (p-value) }\end{array}$ & & & $7.05(0.008)$ & & & $0.00(0.98)$ \\
\hline
\end{tabular}

\footnotetext{
Reference category

"Excluded for test for trend
}

Table 4 shows the results of the multivariate analyses in which adjustment was made for age, Quetelet index, cholecystectomy, alcohol intake, large bowel cancer in the family and physical activity during work. For women additional adjustment was made for parity and age at first birth. After adjustment there was no clear association between level of education and colon cancer risk for men or for women; subjects with lower vocational school or senior high school thad the highest adjusted colon cancer rate, but the collon cancer rate of people with higher vocational training or university was close to one. The association between EGP score and colon cancer risk is also inconsistent. A significant positive association between U\&S score and colon cancer rate remained after additional adjustment for men (trend-p $=0.005$ ), but the higher risk was only found in the group with the thighest U\&S score (RR highest/lowest $=2.60 ; 95 \% \mathrm{Cl} 1.31-5.15$ ). This association was not seen among women. We have also conducted multivariate analyses including energy intake and the intake of dietary fiber as additional covariables. This did not change the association between colon cancer and the SES indicators (not presented). 
Table 4: Rate ratio for colon cancer according to three different socioeconomic status indicators in mutivariate analyses;

\begin{tabular}{|c|c|c|c|c|}
\hline SES indicator & $\begin{array}{l}\text { Men } \\
\text { RR }(95 \% \mathrm{Cl})\end{array}$ & $\begin{array}{l}\text { Test for trend } \\
x^{2} \text { (p-walue) }\end{array}$ & $\begin{array}{l}\text { Women }{ }^{2} \\
\text { RR ( } 95 \% \text { CI) }\end{array}$ & $\begin{array}{l}\text { Test for trend } \\
x^{2} \text { (p-value) }\end{array}$ \\
\hline \multicolumn{5}{|l|}{ Highest level of education: } \\
\hline Primary school & $1^{\circ}$ & & $1^{\circ}$ & \\
\hline Lower vocational & $1.18(0.68-2.03)$ & $0.03(0.86)$ & $1.49(0.80-2.78)$ & $0.15(0.69)$ \\
\hline Junior high school & $0.68(0.38-1.21)$ & & $0.96(0.54-1.72)$ & \\
\hline Senior hilgh school & $1.58(0.82-3.06)$ & & $1.22(0.47-3.16)$ & \\
\hline Hightiri vocational / university & $1.00(0.54 \cdot 1.84)$ & & $0.88(0.39-1.99)$ & \\
\hline \multicolumn{5}{|l|}{ EGP score: last profession: } \\
\hline Buse collar & $1^{*}$ & & $1^{*}$ & \\
\hline Lower white coller & $0.56(0.27-1.13)$ & $0.91(0.34)$ & $1.30(0.76-2.22)$ & $0.61(0.43)$ \\
\hline Upper white collar & $1.09(0.65-1.83)$ & & $0.63(0.30-1.29)$ & \\
\hline Other ${ }^{3}$ & $0.71(0.39-1.30)$ & & $0.72(0.34-1.50)$ & \\
\hline \multicolumn{5}{|l|}{ U\&S score: last profession: " } \\
\hline 1 (lowest) & $1^{\circ}$ & & $1^{*}$ & \\
\hline 2 & $1.10(0.60-2.03)$ & $7.83(0.005)$ & $0.93(0.50-1.75)$ & $1.19(0.28)$ \\
\hline 3 & $1.26(0.66-2.41)$ & & $0.79(0.46-1.35)$ & \\
\hline 4 & $1.12(0.52-2.39)$ & & $0.63(0.24-1.66)$ & \\
\hline 5 (highest) & $2.60(1.31-5.15)$ & & $0.82(0.17-3.84)$ & \\
\hline
\end{tabular}

\footnotetext{
Mulfivariate analyses with adjustment for age, Quetelet index, cholecystectomy, alcohol intake, large bowel cancer in family and physical activity at work.

${ }^{2}$ Additional adjustment for parity and age at first birth

Excluded for test for trend

4 Without the category housewives for reasons of multicollinearity with physical activity during work
}

\section{DISCUSSION}

We have found a significant positive association between social standing (U\&S score) and colon cancer risk for men. This association persisted after adjustment for age, Quetelet index, cholecystectomy, aicohol intake, large bowel cancer in the family and physical activity during work, but was restricted to the highest category of social standing. The positive association between highest level of education and colon cancer risk in men became inconsistent after adjustment for the covariates mentioned above and the colon cancer rate of subjects with the highest level of education was similar with the colon cancer rate of subjects with the lowest level of education. According to the EGP score, male upper white collar workers had, after adjustment, almost the same colon cancer rate as blue collar workers. For women the association between EGP score and colon cancer was opposite to that for men, with the highest risk among the lower white collar workers. But none of these associations was significant. There were no associations found between the other two SES indicators and colon cancer risk in women.

The non-significant positive association between level of education and colon cancer risk for men observed in our study is similar to results from cross-sectional| $\left.\right|^{2.3}$ and case-control ${ }^{4,6}$ studies on education and colon cancer. In a cohort study in Finland ${ }^{7}$ significant positive associations between level of education and colon cancer incidence were reported, with the 
highest risk for men with high school education, whereas in a cohort study in England a non-significant inverse association between level of education and colon cancer risk was reported for men. This is probably due to the categorization of education in two categories with only $12.6 \%$ of the men being in the highest category. The association between education and colon cancer risk is not clear for women. A correlation study, ${ }^{\prime}$ a cross sectional study ${ }^{2}$ and a case-control study ${ }^{5}$ reported no association between education and colon cancer risk for women, while an inverse association was found in a cross-sectional study, $^{3}$ and significant positive associations were reported in two cohort studies in Scandinavia. ${ }^{7,9}$ We did not find an association between education and colon cancer, which is consistent with the finding that health differences between SES categories for women are smaller in the Netherlands than in most other European countries and North America, ${ }^{34}$ probably because of relatively small differences in education within the female population.

Almost all studies that used occupation as SES indicator reported significant positive (age adjusted) associations for men, ${ }^{5,7-9}$ comparablle with our results. One study found only a positive association with left colon cancer and not with right colon cancer. ${ }^{2}$

Owing to a limited number of cases our study could not differentiate between left and right colon cancer. Those studies that also reported a significant positive association for women used the occupation of the head of household as SES indicator, ${ }^{5,7}$ or was restricted to economically active persons. ${ }^{9}$ We did not find an association between the occupation-based SES indicators for women. All women were classiffed according to their last occupation, although almost $50 \%$ of the women finished their formal employment 30 years ago, which is typical for the Netherlands. ${ }^{32}$ This resulted in a substantial proportion of housewives among women in the cohort. The SES measures based on the last occupation therefore have only limited value for women in the NLCS.

In only one study was adjustment made for potential risk factors for colon cancer, other than age and place of residence: a non-significant association between colon cancer and education or occupation was found after adjustment for age, sex, marital status, smoking, coffee and alcohol consumption. ${ }^{6}$ In our study the positive association between highest level of education and colon cancer disappeared after adjustment for age, cholecystectomy, Quetelet index, alcohol consumption, large bowel cancer in the family and physical activity at work. Also, after adjustment, the higher risk of upper white collar workers became similar to the rate for blue collar workers. The significant positive associlation between social standing (U\&S) and colon cancer risk persisted after adjustment was made, but the significantly higher risk was only found in the highest U\&S category. We found a slightly higher prevalence of cholecystectomy and a higher imean alcohol intake in this group, compared with the second highest U\&S group (not presented), but since we adjusted for these potential confounders, this cannot explain the difference in relative rates. Unfortunately none of the studies on SES and colon cancer used a prestige-based SES indicator, as a result of which we cannot compare our finding with other studies.

The cohort study has been performed in a large sample of the general population aged $55-69$ years at baseline. The follow-up period of 3.3 years resulted in 157 male and 155 female colon cancer cases, indicating that the study had reasonable but not very large power, because in general about 400 cases are needed to detect relevant associations. Another disadvantage of the still limited length of follow-up could be a high proportion of cases diagnosed in the first year of follow-up, with the possibility of change in exposure 
owing to symptoms of predlagnostic cancer. Fortunately, education and occupation are relativelly fixed and would have preceded even occurrence of these cases. The follow-up of person-years was $100 \%$ complete, and the completeness of cancer follow-up was also very high, indicating that selection bias due to loss to follow-up is unlikely. Although known risk factors for colon cancer were measured and controlled for in the multivariate analyses, residual confounding by physical activity could still have existed, since a relatively crude physical activity score was used to classify occupations, possibly resulting in misclassification. The intake of ethanol ( $g /$ day) divided into five categories was used to control for alcohol intake. Residuall confounding due to alcohol consumption is unlikely because alcohol consumption has shown to be hardly related to collon cancer in this data set. Only one study on SES and colon cancer adjusted for alcohol intake, and none of the studies paid attention to physical activity or other confounders.

Another fact that could have influenced the results is misclassification of exposure. SES is operationalized as highest level of education, EGP score (functional level) and U\&S score (social standing), the last two both based on the last occupation. Highest level of education is a characteristic that is easily obtainable and recordable. It applies to every adult individual, and in individuals it is stable over time; thus avoiding the risk of reverse causation. This stability has also negative implications for the suitability of level of education as SES indicator, since it can mask important changes in individual circumstances after education is completed. ${ }^{34}$ Therefore highest level of education is probably a less relevant SES indicator for the older generation. ${ }^{35}$ The occupation-based SES indicators reflect the more recent situation, but occupational status as SES indicator leads to the problem of how to classify persons without formal occupation, such as the large majority of women with no formal employment. In our study, women are classified according to their last occupation and there is a separate category of housewives for women who have never had a formal occupation. Another possibility is to use the occupation of the husband or head of household when the person of interest has no formal employment. Unfortunately, we did not have that information. Detection bias may be another concern in colon cancer studies. In the Netherlands, however, there is no mass screening of subjects without symptoms of colorectal cancer: A first colonoscopy is only performed in patients with gastrointestinal complaints or in family members of pathents with hereditary colorectal cancer. Because there are no large differences in access to medical care between SES categories in the Netherlands, this is not likely to lead to a higher detection of colon cancer within the higher SES groups.

In conclusion, we found a positive age-adjusted association between colon cancer risk and three SES indicators for men. After additional adjustment for Quetelet index, cholecystectomy, alcohol intake, large bowel cancer in the family and physical activity during work, the association between colon cancer risk and social standing remained significant, although the higher risk was only found in the highest social standing category. We found no clear associations between the SES indicators and colon cancer incidence for women. More research on differences in colon cancer risk between men and women is warranted, to find out whether these differences are mainly due to differences in the meaning of SES for men and women or if these differences are related to differences in the distribution of risk factors. 
23. Van den Brandt PA, Van ' $t$ Veer $P$, Goldbohm RA, et al. A prospective cohort study on dietary fat and the risk of postmenopausal breast cancer. Cancer Res 1993; 53:75-82.

24. Liberatos P, Link BG, Kelsey JL. The measurement of social class in epidemiology. Epidemiol Rev 1980; $10: 87-121$.

25. Centraal Bureau voor de Statistiek. Beroepenclassificatie 1984. Lijst van benamingen per beroepencode. Voorburg: CBS, 1985.

26. Erikson R, Goldthorpe JH, Portocarero L. Intergenerational class mability in three European societies: England, France and Sweden. Br I Sociol 1979;30:415-441

27. Ganzeboom H, Luijkx $F_{i}$ Dessens $j$, et ali: Intergenerationele klassenmobiliteit in Nederland tussen 1970 en 1985. Mens en Maatschappil 1987;62:17-43.

28. Van Berkel-Van Schaik AB, Tax B. Naar een standaardoperationalisatie van sociaal-economische status woor epidemiologisch en sociaal-medisch onderzoek. Sociaal-economische gezondheidsverschillen nr.6. Dien Haag: DOP, 1990.

29. Self SG, Prentice RL. Asympiatic distribution theory and efficiency results for case-cohort studies. Ann Stat 1988;16:64-81.

30. Baker R.J. GLM 3.77. Reference Manual. Oxford: Numerical algorithms group, 1985.

31. Kunst $A E$, Geurts JJM, Van den Berg J. International variation in socio-economic inequalities in self-reported health. In: Mackenbach JP (ed). Scciaal-economische gezondheidsverschillen onderzocht, V. Den Haag, DOP. 1993.

32. Hooghiemstra BTJ, Niphuis-Nell M. Sociale atias van de vrouw. Deel 2 Arbeid, inkomen en faciliteiten om werken en de zorg woor kinderan te combineren. Den Haag: VUGA, 1993.

33. Goldbohm RA, Van den Brandt PA, van 't Veer P, Dorant E, Sturmans F, Hermus RJJ. Prospective study on alcohol consumption and the risk of cancer of the colon and rectum in the Netherlands. Cancer Causes Control 1994:5:95-104.

34. Zurayk $H_{i}$ Halabi $S$, Deeb M. Measures of social class based on education for use in health studies in developing countries. J Epiderniol Community Health 1987:41:173-179.

35. Thijssen LJM: Sociale stratificatie onder ouderen. Soc Cult Kwarther 1986;8:10-27. 


\section{ACKNOWLEDGMENTS}

We want to than the participants in this study, the regional cancer registries (1KA, $1 \mathrm{KL}, \mathbb{K M M N}$, $\left\|K N_{2}, 1 K O,\right\| K R_{\text {, }} \| K S T$, IKW, IKZ), PALGA for providing incidence data; $E$. Dorant, S. van de Crommert, H. Brants, P. Florax, J. Nelissen and W. van Dijk for assistance in the cohort study; and S. van den Heuvel from the TNO-PG institute for coding the questions about occupation. This work was financially supported by the Dutch Ministry of Welfare, Public Health and Cultural Affairs and by the Dutch Cancer Soclety.

\section{REFERENCES}

1. Baquet CR, Horm JW, Gibbs T, Greenwald P. Socioeconomic factors and cancer imcidence among blacks and whites. INatl Cancer lnst 1991:83:55 $1-557$.

2. Faivre J, Bedenne L, Boutron MC, Milan C, Collonges R, Arveux P. Epidemlological evidence for" distinguishing subsites of colorectal cancer. J Epidemiol Community Hea/th 1989;43:356-361.

3. Williams RR, Horm JW. Association of cancer sites with tobacco and alcohol consumption and socioeconomic status of patients: interview study from the third national cancer survey. INat/ Cancer Inst $1977.58: 525-547$

4. Papadimitriou C, Day N, Tzonou A, Gerovassilis F, Manousos O, Trichopoulos D. Biosocial correlates of colorectal cancer in Greece. Int I Epidemiol 1984,13:155-159.

5. Bidoli $E_{8}$ Franceschi $S$, Talamini $R$, Barra $S$, La Vecchia $C$. Food consumption and cancer of the colon and rectum in Northeastern Italy. Int $J$ Cancer 1992;50:223-229.

6. Ferraroni M, Negri E, La Vecchia C, D' Avanzo B, Franceschi S. Socioeconomic indicators, tobacco and alcohol in the aetiology of digestive tract neoplasms. Int J Epidemiol 1989;18:556-562.

7. Pukkala E, Teppo L. Socioeconomic status and education as risk determinants of gastrointestinal cancer. Prev Med 1986;15:127-138.

8. Leon DA. Longitudinal study. Socjal distribution of cancar, 1971-1975 (OPCS Series LS no.3). London: HMSO, 1988.

9. Vágerö D. Persson G. Occurrence of cancer in socioeconomic groups in Sweden. Scand $J /$ Soc Med $1986 ; 14: 151-160$.

10. Freudenheim JL, Graham S. Toward a dietary prevention of cancer. Epidemio/ Rev 1989;11:229-235.

11. Willett W. The search for the causes of breast and colon cancer. Nature 1989;338:389-394.

12. Kune GA, Vitetta $L$. Alcohol consumption and the etiology of colorectal cancer. A review of the scientific evidence firom 1957 to 1991. Nutr Cancer 1992;18:97-111.

13. Gemardsson $M_{4}$ Floderus B, Norell SE. Physical activity and colon cancer risk. Int $J$ Epidemiol 1988; 17:743-746.

14. Slattery ML, Schumacher MC, Smith KR, West DW, Abd-Elghany N. Physical actiwity, diet and risk of colon cancer in Utah. Am J Epidemiol 1988; 128:989-999.

15. Kravdal $O$, Glattre $E$, Kwale $G$, Tretti $S$. A sub-site-specific analysis of the relationship between colorectal cancer and parity in complete male and female Nowegian birth cohorts. Int $J$ Canger 1993,53:56-61.

16. Hulshof KFAM, Löwik MRH, Kok FJ, Wedel M, Kistemaker C, Brants HAM. Invloed van sociaal-economische status op voeding en andere levensstijlfactoren. In: Mackenbach . AP(ed.). Sociaal-economische gezondheidsverschillen onderzocht. Deel lill. Den Haag: DOP. 1991.

17. Baghurst KI, Record SJ, Baghurst PA, Syrette JA. Crawtord D. Worsley A. Sociodemographic determinants in Australia of the intake of food and mutrients implicated in cancer aetiology. Med $J$, Awsit $1990 ; 153,444-452$.

18. Noppa H. Bengtsson $\mathrm{C}$. Obesity in relation to socloeconomic status. A population study of women in Golteborg, Sweden. I Epidemiol Community Health 1980;34:139-142.

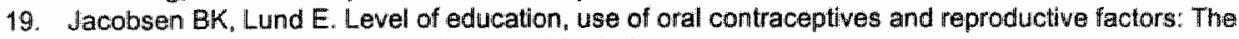
Tromsio Study. Int I Epidemiol 1990,19:967-970.

20. Goldbohm RA, Van den Brandt PA, Van "t Veer $P$, et al. A prospective cohort study on the relation between meat consumption and the risk of colon cancer. Cancer Res 1994:54:718-723.

21. Van den Brandt PA, Goldbohm RA, Van tt Veer $P$, Volovics $A_{1}$ Hermus RJJ, Sturmans $F$. A large-scale prospective cohort study on diet and cancer in the Netherlands. J Chin Epidemiof 1980;43:285-295.

22. Van den Brandt PA, Schouten La, Goldbohm RA, Dorant E, Hunen PMH. Development of a record linkage protocol for use in the Dutch cancer registry for epidemiological research. Int J Epidemiol 1990 ; $19.553-558$ 
Chapter 6

SOCIOECONOMIC STATUS AND STOMACH CANCER INCIDENCE IN MEN:

results from the Netherlands Cohort Study

A. Jeanne M. van Loon, R. Alexandra Goldbohm, Plet A. van den Brandt 


\section{ABSTRACT}

The association between socioeconomic status (SES) and stomach cancer incidence (cardia and non-cardia) was investigated in the Netherlands Cohort Study that started in 1986 among 58,279 men aged $55-69$ years. Data were collected by means of a self administered questionnaire. After 4.3 years of follow-up, 162 incident stomach cancer cases were detected (49 cardia and 113 non-cardia cases). After adjustment for age, we found a lower overall stomach cancer risk for men with the highest attained level of education (RR highest/lowest level $=0.54 ; 95 \% \mathrm{Cl} 0.33-0.89$; trend-p $=0.02$ ). This association became less strong after additional adjustment for smoking, intake of vitamin C, beta-carotene, alcohol and coffee, family history of stomach cancer and history of stomach disorders ( $R R=0.61 ; 95 \% \mathrm{Cl} 0.34-1.07$; trend- $p=0.11$ ). No clear association was found between occupation-based SES indicators and stomach cancer risk. Analyses per subsite of stomach cancer revealed that for people with the highest level of education the age-adjusted rate ratio for cardia cancer changed from $0.37(95 \% \mathrm{Cl} 0.13-1.00)$ to $0.60(95 \% \mathrm{Cl} 0.19-1.87)$ after additional adjustment for lifestyle variables, whereas the rate ratio for non-cardia cancer ( $R R=0.59 ; 95 \% \mathrm{Cl} 0.33-1.05)$ did not change after additional adjustment. 


\section{INTRODUCTION}

Stomach cancer has very often been found to be inversely related to socioeconomic status (SES); $;^{1 \cdot 12}$ all studies but one ${ }^{1}$ showed inverse associations between level of education or occupation and stomach cancer risk. However, in these studies hardly any adjustment was made for potential confounders. In most studies only age was included in the analyses, whereas four studies included some lifestyle characteristics such as smoking ${ }^{2-4}$ coffee and alcohol consumption, ${ }^{3}$ or vegetable consumption. ${ }^{12}$ Although associations have been reported between SES and stomach cancer, SES is not thought to be a direct risk factor. Some lifestyle variables which have been identified as possible risk factors for stomach cancer, e.g. vitamin $C$ intake, ${ }^{13,14}$ intake of beta-carotene, ${ }^{13}$ alcohol consumption ${ }^{15,16}$ and smoking habits, ${ }^{* 6.17}$ are all characteristics associated with SES. ${ }^{19-20}$ Therefore, we examined the association between SES and stomach cancer incidence and the role of these lifestyle factors in explaining a possible association in the Netherlands Cohort Study (NLCS) on diet, other lifestyle variables and cancer risk. Earlier research in the NLCS showed an association between coffee consumption and stomach cancer risk. ${ }^{21}$ Thus, coffee consumption is also included in the analyses. Moreover, adjustment is made for age, family history of stomach cancer and prevalence of stomach disorders, because these factors may confound the association between SES and stomach cancer. ${ }^{22.23}$

There are strong indications that risk factors for stomach cancer differ between subsites. ${ }^{24,25}$ Accordingly, we have studied the association between SES and stomach cancer more extensively by distinguishing cardia cancer from the more distal stomach cancers (non-cardia).

\section{MATERIALS AND METHODS}

\section{The cohort study}

In September 1986, the Netherlands Cohort Study (NLCS) investigating various lifestyle variables, sociodemographic indicators and cancer risk was started. The cohort included 58,279 men aged 55-69 years at the beginning of the study, originating from 204 municipalities in the Netherlands. Data were collected by means of a self-administered questionnaire. A detailed description of the cohort study design has been reported elsewhere. ${ }^{20}$ For data analysis the case-cohort approach was used in which cases are derived from the entire cohort, while the person-years at risk were estimated from a random sample of 1688 subjects (subcohort). After the baseline exposure measurement the subcohort has been followed up biennially for vital status information. In this period, no subcohort members were lost to follow-up.

Follow-up for incident cancer has been established by record linkage with all regional cancer registries in the Netherlandls and with a national pathology register (PALGA). The method of record linkage has been described previously. ${ }^{27}$ The analyses are restricted to microscopically confirmed stomach cancer incidence (excluding lymphoma) in the period from September 1986 to December 1990. In this period completeness of follow-up of the cohort through linkage with the cancer registries and PALGA was estimated to be at least $96 \%{ }^{26}$ After excluding subjects with self-reported prevalent cancer other than skin cancer 162 stomach cancer cases were detected; 49 cardia and 113 non-cardia cases. Prevalent cancer cases other than skin cancer were also excluded from the subcohort, leaving 1630 subjects available for analysis. 


\section{Socioeconomic status}

SES was measured by means of highest level of education attained and by means of occupational history, two of the recommended measures for SES. ${ }^{20}$ Educational level was classified as primary school, lower vocational school, junior high school, senior high school, higher vocational schoof, university and other education. Information about occupational history was coded according to the job coding system of the Central Bureau of Statistics (CBS) frequently used in the Netherlands ${ }^{30}$ For the present analyses, these CBS codes were aggregated accordling to occupational sector and required training (EGP) and according to social standing (U\&S). The EGP coding scheme is a reconstruction of the scheme developed by Erikson, Goldthorpe and Portocarero, ${ }^{31}$ which is still comparable with the original list. ${ }^{32}$ The U\&S score is based on an ordering of occupational titles according to social standing and is also comparable with international classifications. ${ }^{33}$ Other factors possibly relevant to the association between SES and stomach cancer risk that were measured in the baseline questionnaire are age, smoking habits, alcohol intake, coffee consumption, intake of vitamin $\mathrm{C}$ and beta-carotene, the prevalence of stomach disorders (any stomach disease in the past that required medical attention) and family history of stomach cancer.

\section{Data analysis}

The distribution of SES indicators and potential confounders known to be associated with SES and stomach cancer was compared between the case and subcohort group. Educational level was aggregated into four categories: primary school, lower vocational school, junior high school and senior high school, higher vocational school or university. The EGP score of the most recent occupation was divided into four categories: blue collar jobs (lower-grade technicians, semi and unskilled manual workers), lower white collar jobs (administrators and non-manual employees), upper white collar jobs (professionals) and other (farmers and self-employed people). The U\&S score (also based on the last occupation) was divided into five categories increasing from low (e.g. garbage collector) to high social standing (e.g. lawyers).

To study the association between SES and stomach cancer risk and the role of possible confounders, data were analyzed according to the case-cohort approach, ${ }^{34,35}$ using the GLIM stätistical package. ${ }^{36}$ Mantel-Haenszel rate ratios of stomach cancer were determined for each of the SES indicators, stratified for age: In the multivariate analyses, rate ratios and $95 \%$ confidence intervals of stomach cancer were computed for the different SES indicators, after adjustment for the covariates mentioned above. Recent research has pointed out that there seem to be etiological differences between cardia cancer and the more distal stomach cancers. ${ }^{24,25}$ Therefore, we have also determined Mantel-Haenszel rate ratios of cardia cancer (ICD-O topography 151.0 ) and non-cardia cancer (ICD-O 151.1-151.9) for one SES indicator. Subsequently multivariate analyses were conducted for these subsites.

\section{RESLLTS}

The distribution of SES indicators and covariates in the group of cases and the subcohort is presented in table 1. Cases were on average older than members of the subcohort (mean age for cases is 63.0 years and for subcohort members 61.4 years). There was no 
substantial difference in the intake of beta-carotene between cases and the subcohort members, but the dietary intake of vitamin $C$ was for cases somewhat lower compared with subcohort members. There were more non-smokers among subcohort members compared with cases and proportionally more cases consumed large amounts of coffee $>4$ cups per day) than subcohort members. There was no difference in alcohol intake between cases and subcohort members. Stomach disorders were more prevalent among cases compared with members of the subcohort. The same was found with regard to family history of stomach cancer. The associations between the various SES indicators and stomach cancer incidence are consistent: in the case group there were proportionally more men with a lower levell of education, a blue collar job and a low U\&S score (social standing) compared with the subcohort.

Table 1: Distribution of socioeconomic status indicators and polential contounders in male stomach cancer cases and subcohot.

\begin{tabular}{|c|c|c|c|c|}
\hline \multirow[t]{2}{*}{ Characteristic } & \multicolumn{2}{|c|}{$\begin{array}{l}\text { Subcohort } \\
(n=1630)\end{array}$} & \multicolumn{2}{|c|}{$\begin{array}{l}\text { Cases } \\
(n=162)\end{array}$} \\
\hline & mean & \pm s.d & mean & $\pm s .0$ \\
\hline Age (mean yrs \pm s.d.) & 61.4 & \pm 4.2 & 63.0 & \pm 4 . \\
\hline Bela-carotene "(mean mg eq vit A /day $\pm \mathrm{s} d \mathrm{~d}$ ) & 0.40 & \pm 0.24 & 0.30 & \pm 0.2 \\
\hline \multirow[t]{2}{*}{ Vitamin $C^{:}$(mean mg /day \pm s.d.) } & 98.2 & \pm 41.8 & 929 & \pm 43 \\
\hline & $n$ & $\%$ & $n$ & $\%$ \\
\hline Smoking (\% never) & 159 & 9.8 & 5 & 3: \\
\hline Coffee intake ${ }^{1}(\%>4$ cups per day) & 216 & 14.2 & 29 & 19. \\
\hline Alcohol intake (\% $\geq 30 \mathrm{~g}$ per day) & 221 & 13.9 & 21 & 13 \\
\hline Stomach disorders ( $\%$ ever) & 213 & 13.1 & 36 & 22. \\
\hline Family history of stomach cancer (\% yes) & 114 & 7.0 & 16 & 9 \\
\hline \multicolumn{5}{|l|}{ Highest level of education: } \\
\hline Pitmary school & 458 & 28.4 & 54 & 34.2 \\
\hline Lower vocational & 338 & 20.9 & 36 & 22.8 \\
\hline Junior high school & 420 & 26.0 & 44 & 27. \\
\hline Senior high school / higher vocational / university & 398 & 24.7 & 24 & $15:$ \\
\hline \multicolumn{5}{|l|}{ EGP score: last profession: } \\
\hline Blue collar & 568 & 38.7 & 62 & 43. \\
\hline Lower white collar & 206 & 14.1 & 17 & 12. \\
\hline Upper white collar & 439 & 29.9 & 31 & 21. \\
\hline Other & 253 & 17.3 & 32 & 22. \\
\hline \multicolumn{5}{|l|}{ U\&S score: last profession: } \\
\hline 1 (lowest) & 302 & 20.7 & 30 & 21 \\
\hline 2 & 372 & 25.5 & 43 & 30 \\
\hline 3 & 401 & 27.5 & 39 & 27 \\
\hline 4 & 208 & 14.3 & 13 & 9 \\
\hline 5 (highest) & 176 & 12.1 & 16 & 11 \\
\hline
\end{tabular}

${ }^{1}$ Only subjects with complete dietary data (1525 subcohort members and 146 tases) 
The association between SES indicators and covariates was studied in the subcohort (table 2). SES was inversely related to age. The mean intake of beta-carotene did not differ among the SES categories, whereas the mean intake of vitamin $C$ was higher in the highest SES categories. The proportion of men who never smoked was somewhat higher among men with a high level of education or a white collar profession. Proportionally more men with a low SES consumed large amounts of coffee ( 4 cups per day), whereas proportionally more men with a high SES consumed large amounts of alcohol ( $\geq 30 \mathrm{~g}$ per day): The prevalence of stomach disorders was higher among the lower SES categories and there was no substantial difference in family history of stomach cancer among SES categories.

Table 2: Association between possible confounders and socioeconomic status indicators in the subcohort

\begin{tabular}{|c|c|c|c|c|c|c|c|c|}
\hline \multirow[t]{2}{*}{ Characteristic } & \multicolumn{3}{|c|}{ Highest level of education " } & \multicolumn{3}{|c|}{ EGP } & \multicolumn{2}{|c|}{ U\&S } \\
\hline & Low & Medium & High & $\begin{array}{l}\text { Blue } \\
\text { collar }\end{array}$ & $\begin{array}{l}\text { White } \\
\text { collar }{ }^{2}\end{array}$ & Other & Low $^{3}$ & High \\
\hline Age (mean yrs) & 61.9 & 6113 & 61.1 & 61.3 & 61.1 & 61.8 & 61.4 & 61.2 \\
\hline Beta-caratene "(mean mg eq wit A / dag) & 0.40 & 0.40 & 0.41 & 0.41 & 0.41 & 0.41 & 0.42 & 0.40 \\
\hline Vitamin $C^{4}$ (mean mg / day) & 92.4 & 100.0 & 101.0 & $97: 1$ & $102: 0$ & $95: 6$ & 97.0 & 100.9 \\
\hline Smoking (\% never) & 9.2 & 9.9 & 10.3 & 7.4 & 10.4 & 12.6 & 10.5 & 8.5 \\
\hline Coffee intake ${ }^{4}(\%>4$ cups per day) & 19.6 & 14.9 & 6.9 & 20.3 & 9.4 & 11.3 & 17.9 & 10.7 \\
\hline Alcohol intake (\% ₹ $30 \mathrm{~g}$ per day) & 9.1 & 12.5 & 22.2 & 10.6 & 20.6 & 11.8 & 10.8 & 16.7 \\
\hline Stomach disorders (\% ever) & 15.3 & 13.5 & 9.8 & 15.4 & 9.6 & 15.0 & 16.8 & 9.2 \\
\hline Family history of stomach cancer ( $\%$ yes) & 7.0 & 7.1 & 7.0 & 8.1 & 6.8 & 5.9 & 7.1 & 7.3 \\
\hline
\end{tabular}

"Highest level of education: low = primary school" medium $\approx$ lower vocational or junior high school; high = senior high school, higher vocational school or university

2 White collar = lower white collar or upper white collar

Low social standing: U\&S-categories 1 and 2; high saciall standing: U\&S-categories 3,4 and 5

Only subjects with complete dietary data

The results of the stratified analyses are presented in table 3. After adjustment for age in three five-year categories, there was a statistically significant inverse association between level of education and stomach cancer risk (RR highest/lowest level of education $=0.54$; $95 \%$ C $0.33-0.89$; trend-p $=0.02$ ) and a statistically non-significant inverse association between EGP score and stomach cancer risk (RR upper white collar/blue collar $=0.67$; $95 \% \mathrm{Cl} 0.42-1.04$; trend-p $=0.07$ ). There was no clear association between U\&S score and stomach cancer risk ( $R R$ high/low social standing $=0.99 ; 95 \% \mathrm{Cl} 0.52-1.85$; trend-p $=0.34$ ). To find out whether an association between the SES indicators and stomach cancer risk was due to lifestyle characteristics, additional adjustment was made for smoking, alcohol intake "coffee intake, vilamin C, beta-carotene, stomach disorders and family history of stomach cancer (table 3). After that adjustment there was still an inverse association between level of education and stomach cancer risk (RR highest/lowest level of education $=0.61 ; 95 \% \mathrm{Cl} 0.34-1.07$ ), but the test for trend was not statisticaliy significant any more (trend- $p=0.11$ ). The association between EGP score and stomach cancer risk also became less prominent (RR upper white collar/blue collar $=0.76 ; 95 \% \mathrm{Cl} 0.45-1.28$; trend-p $=0.21$ ), and there was still no association between U\&S score and stomach cancer risk. 
We have studied the association between level of education and stomach cancer more extensively by distinguishing cardia cancer from non-cardia cancer. The results of the stratified analyses and multivariate analyses are presented in table 4 . Men with a higher level of education had a lower age-adjusted risk for cardia cancer compared with men with a lower level of education (RR highest/lowest level of education $=0.37 ; 95 \% \mathrm{C} \| .0 .13-1.00$ ). On the other hand, men with lower vocational school or junior high school had an age-adjusted rate ratio greater than one, compared with men with primary school. After additional adjustment for lifestyle variables mentioned above the rate ratios for cardia cancer changed markedly. However, people with a higher level of education still had a non-significant lower risk for cardia cancer than people with a lower level of education (RR highest/lowest levell of education $=0.60 ; 95 \% \mathrm{Cl} 0.19-1.87$ ).

Table 3: Age-adjusted Mantel-Haenszel rate ratios and multivariate "rate ratios for stomach cancer according to three different socioeconomic status indicators

\begin{tabular}{|c|c|c|c|c|}
\hline SES indicator & $\begin{array}{l}\text { No. of cases } \\
\text { in cohort }\end{array}$ & $\begin{array}{l}\text { Person-years } \\
\text { in subcohort }\end{array}$ & $\mathrm{RR}_{\text {料 }}(95 \% \mathrm{Cl})$ & $\begin{array}{l}\mathrm{RR}(95 \% \mathrm{Cl}) \\
\text { multivariate }\end{array}$ \\
\hline \multicolumn{5}{|l|}{ Highest level of education: } \\
\hline Primary school & 54 & 1888 & 1 & $1^{*}$ \\
\hline Lower wocationall & 36 & 1426 & $0.94(0.60-1.47)$ & $0.81(0.48-1.38)$ \\
\hline Junior high school & 44 & 1754 & $0.93(0.60-1.43)$ & $0.90(0.56-1.45)$ \\
\hline $\begin{array}{l}\text { Senior high school / higher vocational/ } \\
\text { university }\end{array}$ & 24 & 1655 & $054 .(0.33 \cdot 0.89)$ & $0.61(0.34-1.07)$ \\
\hline $\begin{array}{l}\text { Test for trend } \\
x^{2} \text { (p-value) }\end{array}$ & & & $5.19(0.02)$ & $2.50(0.11)$ \\
\hline \multicolumn{5}{|l|}{ EPG score: last profession: } \\
\hline Bleu collar & 62 & 2361 & $1^{*}$ & $1^{\circ}$ \\
\hline Lower white collar & 17 & 863 & $0.74(0.42-1.30)$ & $0.80(0.43-1,49)$ \\
\hline Upper white collar & 31 & 4831 & $0.67(0.42-1.04)$ & $0.76(0.45-1.28)$ \\
\hline Other ${ }^{2}$ & 32 & 1062 & $1.11(0.70-1.74)$ & $1.16(0.69-1.95)$ \\
\hline $\begin{array}{l}\text { Test for trend } \\
x^{2}(p-\text {-value })\end{array}$ & & & $3.35(0.07)$ & $1.57\{0.21\}$ \\
\hline \multicolumn{5}{|l|}{ URS score: last profession } \\
\hline I (lowest) & 30 & 1264 & $1^{\prime \prime}$ & $1^{*}$ \\
\hline 2 & 43 & 1554 & $1.17(0.71 \cdot 1.92)$ & $1.46(0.82-259)$ \\
\hline 3 & 39 & 1668 & $1.00(0.60-1.64)$ & $1.18(0.65-2.44)$ \\
\hline 4 & 13 & 869 & $0.64(0.33+1.27)$ & $0.95(0.44-2.07)$ \\
\hline 5 (highest) & 16 & 736 & $0.99(0.52-1.85)$ & $1.36(0.61-3.04)$ \\
\hline $\begin{array}{l}\text { Test for trend } \\
x^{2} \text { (p-value) }\end{array}$ & & & $0.92(0.34)$ & $0.03(0.86)$ \\
\hline
\end{tabular}

\footnotetext{
Reference catergory

'Multivariate analyses with adjustment for age, smoking, alcohol intake, coffee intake, intake of vitamin C, beta-carotene, farnily history of stomach cancer and stomach disorders

${ }^{2}$ Excluded for test for trend
}

After adjustment for age, there was a non-significant inverse association between level of education and the risk of non-cardia cancer (RR highest/lowest level of education $=0.59$; $95 \% \mathrm{Cl} 0.33-1.05)$. This inverse association changed very little after additional adjustment for lifestyle variables (RR highest/lowest level of education $=0.58 ; 95 \% \mathrm{Cl} 0.31-1.11$ ). This is in contrast with the results from the association between SES and cardia cancer risk. 
Table 4 Age adjugted hantel Hacnszel rate ratios and multwariate rate ratios for cardia cancer and other subsites of stomach cancer according to highest fevel of eduction

\begin{tabular}{|c|c|c|c|c|}
\hline Highest level of education & $\begin{array}{l}\text { No of cases } \\
\text { in cohort }\end{array}$ & $\begin{array}{l}\text { Person-years } \\
\text { in subeohort }\end{array}$ & $\mathrm{RR}_{\mathrm{W}}(95 \% \mathrm{Cl})$ & $\begin{array}{l}\mathrm{RR}(95 \% \mathrm{Cl}) \\
\text { multivariate }\end{array}$ \\
\hline \multicolumn{5}{|l|}{ Cardia cancer } \\
\hline Prinary schiool & 15 & 1888 & $1^{*}$ & $1^{*}$ \\
\hline Lower wocational & 12 & 1426 & $1.03(0.48 .221)$ & $1.30(0.53-319)$ \\
\hline Junior high schicol & 16 & 1754 & $1.17(0.57-2.38)$ & $1.33(0.56-3.14)$ \\
\hline $\begin{array}{l}\text { Senior high schoo I higher vocational / } \\
\text { university }\end{array}$ & 5 & 1655 & $0.37(0.13-1.00)$ & $0.60(0.19-1.87)$ \\
\hline $\begin{array}{l}\text { Test for trend } \\
x^{2} \text { (p-value) }\end{array}$ & & & $256(0.10)$ & $0.35(0.55)$ \\
\hline \multicolumn{5}{|l|}{ Other subusitites of stomach cancer } \\
\hline Primary school & 39 & 1888 & $1 *$ & $1^{*}$ \\
\hline Lower vactional & 24 & 1426 & $0.88(0.51-1.49)$ & $0.63(0.34-1.19)$ \\
\hline Junior high school & 28 & 1754 & $0.86(0.52-1.43)$ & $0.77(0.45-1.34)$ \\
\hline $\begin{array}{l}\text { Senior high schoo / / higher vocalional / } \\
\text { universily }\end{array}$ & 19 & 1655 & $0.59(0.33-1.05)$ & $0.58(0.31-1.11)$ \\
\hline $\begin{array}{l}\text { Test for trend } \\
x^{2} \text { (p-value) }\end{array}$ & & & $3.08(0.08)$ & $2.54(0.11)$ \\
\hline
\end{tabular}

Reference calergory

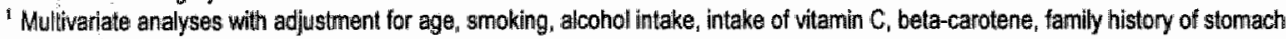
cancer and stomach disorders

\section{DISCUSSION}

We have found an inverse association between level of education and stomach cancer risk. This association became less apparent when adjustment was made for various lifestyle variables, indicating that part of the higher risk for stomach cancer for people with a low level of education may be due to lifestyle characteristics. The association between the occupation-based SES indicators and stomach cancer risk was less clear. Both for cardia cancer as well as for non-cardia cancer a non-significantly inverse association with level of education was observed. Adjustment for potential risk factors for stomach cancer showed different results: the lower cardia cancer risk for people with the highest level of education changed markedly after adjustment, while the inverse association between level of education and non-cardia cancer changed very little after additional adjustment.

The significant inverse association between level of education and stomach cancer risk for men observed in our study is comparable with results from cross-sectional, ${ }^{2}$ case-control $\left.\right|^{3,8,10,12}$ and cohort studies. ${ }^{7.8}$ From the six studies ${ }^{3,4,6-8,12}$ in which occupation was used as SES indicator, four found a significant inverse association. ${ }^{3.6,8.12}$ in one case-control study ${ }^{4}$ a non-significant inverse association was reported, while a cohort study showed no clear association. ${ }^{7}$ In the latter the incidence of stomach cancer among managerial and clerical workers was significantly lower compared with the stomach cancer risk in the whole population, but unskilled workers did not have a significantly higher risk. In four studies lifestyle characteristics such as smoking, ${ }^{2-4}$ alcohol consumption ${ }^{3}$ or vegetable 
consumption ${ }^{12}$ were includied. Overall, adjustment for these factors did not dramatically change the association between SES and stomach cancer risk. Although in one case control study, ${ }^{12}$ where adjustment was made for age, gender, vegetable consumption, body mass index at age 20 , age at first access to refrigerator and number of siblings, the risk estimates in relation to occupation and duration of education had a tendency to approach unify. Nevertheless, there was still a significant inverse association between education and stomach cancer risk.

We found three studies which described the association between SES and stomach cancer, that made a distinction between cardia cancer and the more distal stomach cancers ${ }_{m}^{24,37,38}$ One study examined incidence trends in oesophageal and gastric cancer in the UK, during 1962 to 1981 . The authors reported that in the higher SES groups there were more cardia cases and less pyloric cases recorded than expected and in the lower SES groups there were less cardia cases and more pyloric antrum cases. ${ }^{24}$ Another study evaluated risk factors for cancers of the cardia and more distal sites, in white males under the age of 55 years. ${ }^{37}$ They found no association between level of education and cardia cancer, whereas level of education was strongly associated with the more distal stomach cancers. However, in this case-control study age- and sex-matched neighborhood controls were used. Since there is an association between SES and neighborhood, ${ }^{39}$ the control group seems not entirely appropriate for studying SES and cancer. The third study ${ }^{38}$ reported both for cardia cancer and for other subsites a decreased risk with increasing social class (based on a combination of occupation and education).

In our study both cardia cancer and non-cardia cancer showed a non-significant inverse association with level of education, although the lower cardia cancer risk was only found among people with senior high school, higher vocational school or university. Adjustment for potential risk factors, including lifestyle variables showed different results for cardia and non-cardia canicer. Cardia cancer is found to be aetiologically more related to carcinoma of the distall oesophagus than to distal gastric cancers. ${ }^{24}$ This indicates that risk factors for cardia cancer may differ from risk factors for non-cardia cancer. Several studies thave investigated this hypothesis ${ }^{37,38,40,41}$ with varying results. One study reported no difference in cigarette and alcohol use between patients with "esophagocardia" cancer and patients with stomach cancer not involving the cardia. ${ }^{40}$ Nevertheless, it seems that if there is a positive association between smoking and stomach cancer, it is thought for both cardia cancer as well as for non-cardia cancer..$^{37,4}$ On the other hand, if there is a positive association found between alcohol use and stomach cancer, this only seems to apply to cardia cancer. ${ }^{37,30,41}$ Furthermore, there are indications that a joint effect of alcohol drinking and smoking may play an important role in the development of gastric cancer, especially of cardia cancer ${ }^{41}$

The cohort study has been performed in a large sample of the general population agled $55-69$ years at baselline. The follow-up period of 4.3 years resulted in 162 male stomach cancer cases, indicating that the study had reasonable but not very large power. Moreover", when distinction was made between cardia cancer and non-cardia cancer respectively 49 and 113 cases were available for anallysis. The follow-up of person-years was $100 \%$ complete and the completeness of cancer follow-up was also very high, indicating that selection bias due to loss to follow-up is unlikely. Although known risk factors for stomach cancer were measured and controlled for in the multivariate analyses, residual confounding could still have existed. Besides, we had no information about the prevalence of heficobacter pylori infection, which may be an important risk factor for stomach cancer, ${ }^{42}$ 
especially for non-cardia cancer ${ }^{43}$ and is known to be associated with SES.44 Another fact that could have influenced the results is misclassification of exposure. SES is operationalized as highest level of education EGP score (functional level) and U\&S score (social standing), both based on the last occupation. Highest level of education is a characteristic that is easily obtainable and recordable. It applies to every adult individual and in individuals it is stable over time. This stability has also negative implications for the suitability of level of education as SES indicator, since it can mask important changes in individual circumstances after education is completed.$^{45}$ Therefore highest level of education is probably a less relevant SES indicator for the older generation. ${ }^{46}$ The occupation-based SES indicators reflect the more recent situation, but occupational status as SES indicator leads to the problem how to classify persons without formal occupation. Because we used occupation as an indicator of SES, it seems reasonable to take the most recent occupation instead of the occupation performed the longest. Also for pensioners, a relatively large part of the study population, the most recent occupation is used.

In conclusion, we found an inverse age-adjusted association between stomach cancer risk and highest level of education for men. This association became less apparent after additional adjustment for smoking, alcohol intake, coffee intake, intake of vitamin $\mathrm{C}$, beta-carotene, family history of stomach cancer and stomach disorders. The association between the occupation-based SES indicators and stomach cancer risk was less clear. Nevertheless, the number of cases in our study is quite small. Therefore, a longer follow-up time is required. When distinction was made between cardia and non-cardia cancer, it became evident that, although both cardia and non-cardia cancer showed an inverse association with level of education, adjustment for other risk factors reduced the association with cardia cancer but did not effect the association with non-cardia cancer.

\section{ACKNOWLEDGMENTS}

We want to thank the participants in this study, the regional cancer registries $\left(I K \mathrm{~A}_{\mathrm{z}}, \mathrm{KL}, I \mathrm{KMN}\right.$, IKN, IKO, IKR, IKST, IKW, IKZ), PALGA for providing incidence data" $E$. Dorant, $S$. van de Crommert, $H$. Brants, P. Florax, J. Nelissen and W. van Dijk for assistance in the cohort study, E. Dorant for useful comments on this manuscript and $S$. van den Heuvel from the TNO-PG institute for coding the questions about occupation.

\section{REFERENCES}

1. Baquet CR, Horm JW, Gibbs T, Greenwald P. Socioeconomic factors and cancer incidence among blacks and whites. J Natl Cancer inst 1991;83:551-557.

2. Williams RR, Horm JW. Association of cancer sites with tobacco and alcohol consumption and socioeconomic status of patients: interview study from the third national cancer survey. $J$ Natl Cancer Inst 1977; 58:525-547.

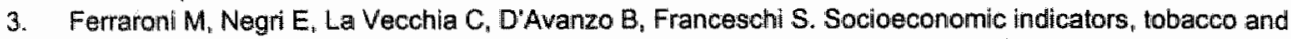
alcohol in the aetiology of digestive tract neoplasms. Int J Epidemiol 1989;18:556-562.

4. Dockerty JD, Marshall S, Fraser J "Pearce N. Stomach cancer in New Zealand: time trends, ethnic group differences and a cancer registry-based case-control study. Int J Epidemiol 1991;20;45-53.

5. Cuello $C$, Correa $P$, Haenszel W. Socio-economic class differences in cancer incidence in Cali, Colombia. Int J Cancer 1982;29:637-643. 
6. Vagerö D. Persson G. Occumence of cancer in socioeconomic groups in Sweden. Scand 1 Soc Mod 1986:14:151-160.

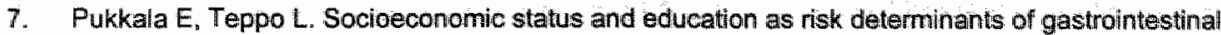
cancer. Pre Med 1986;15:127-138.

8. Leon DA. Longitudinal study. Social distribution of cancer, 1971-1975 (OPCS Series LS No. 3). London: $H \mathrm{HO}_{1}, 1988$.

9. Choi SY, Kahyo H. Effect of cigarette smoking and alcoholl consumption in the etiology of cancers of the digestive tract Int $A$ Gancer 1991;49:381-386.

10. Jedrychowski W, Wahrendorf J, Popiela T, Rachtan J. A case-control study of dietary factors and stomach cancer risk in Poland. Int $J$ Cancer 1986;37:837-842.

11. Williams $\mathrm{J}$, Clifford $\mathrm{C}$, Hopper J, Giles $\mathrm{G}$. Socioeconomic status and cancer mortally and incidence in Melboume. Eur J Cancer 1991;27:917-921.

12. Hansson L-E. Baron J., Nyrén $O$, et all. Early-life indicators of gastric cancer. A population-based case-control study in Sweden. Int $J$ Cancer 1994;57:32-37.

13. Cipriani $F$. Buiatti E, Pall D. Gastric cancer in Italy, hal J Gastroenterol 1991;23:429-435.

14. Trichopoulos D, Ouranos G, Day NE, et al. Diet and cancer of the stomach: A case-control study in Greece. Int J Cancer 1985:36:291-297.

15. Hoey J, Montvernay C, Lambert R. Wine and tobacco: risk factors for gastric cancer in France. Am $J$ Epidemiol 1981; 113:668-674.

16. De Stefani $R$, Correa $P$, Fierro L, Carzoglio J, Deneo-Pellegrini H. Zavala D. Alcohol drinking and tobacco smoking in gastric cancer. A case-control study. Rev Epidem Santé Pub/ 1990;38:297-307.

17. Hansson L-E, Baron J, Nyren $O$, Bergström R, Wolk A, Adami H-O. Tobacco, alcohol and the risk of gastric cancer. A population-based case-control study in Sweden. Int J Cancer 1994;57:26-34.

18. Block $G$. Sorenson A. Vitamin $C$ intake and dietary sources by demographic characteristics. Nutr Cancer 1987;10.53-65.

19. Hulshof KFAM, Lowik MRH, Kok FJ Wedel M, Kistemaker C, Brants HAM. Invloed van sociaaleconomische status op voeding en andere levensstillfactoren. In: Mackenbach JP (ed). Sociaal-economische gezondheidsverschillen onderzocht, III. Den Haag: DOP, 1991.

20. Sterling TD, Weinkam JJ. Smoking patterns by occupation, industry, sex, and race. Arch Environ Health 1978;37:313-317:

21. Goldbohm RA, Hertog MGL, Brants HAM, Van Poppel G, Van den Brandt PA. Consumption of black tea and cancer risk: a prospective cohort study. I Natl Cancer Inst 1996;88:93-100.

22. Palli $\mathrm{D}$, Galli $\mathrm{M}_{1}$, Caporaso $\mathrm{NE}_{\text {n }}$ et al. Family history and risk of stomach cancer in Itally. Cancer Epidemiol Biomarkers Prew 1994;3:15-18.

23. La Vecchia C, Negri E. Franceschi S, Gentile A. Family history and the risk for stomach and colorectal cancer. Cancer 1992; 70:50-55.

24. Powell J, McConkey CC. Increasing incidence of adenocarcinoma of the gasitric cardia and adjjacent sites. Br J Cancer 1990;62;440-443.

25. Yang $P C$, Dawis S. Epidemiological characteristics of adenocarcinoma of the gastric cardia and distall stomach in the United States, 1973-1982. Int J Epidamiol 1991;17/293-297.

26. Van den Brand PA, Goldbohm RA, Van 't Veer P. Volowics A, Hermus RJJ. Sturmans F. A large-scale prospective cohort study on diet and cancer in the Netherlands. J Clin Epldemiol 1990;43:285-295.

27. Van den Brandt PA, Schouten LJ, Goldbohm RA, Dorant E, Hunen PMH. Dievelopment of a record linkage protocol for use in the Dutch cancer registry for epidemiological research. Int $J$ Epidemiol 1990 ; $19.553-558$.

28. Goldbohm RA, Van den Brandt PA, Dorant E. Estimation of the coverage of Dutch municipalities by cancer registries and PALGA based on hospltal discharge data. Tijdschr Soc Gezondheidsz 1994;72: $80-84$.

29. Liberatos P, Link BG, Kelsey JL. The measurement of social class in epidemiology. Epidamiol Row $1988 ; 10: 87-121$

30. Centraal Bureau voor de Statistiek. Beroepenclessificatio 1984. Lijst van benamingen per beroepencode. Voorburg: CBS, 1985.

31. Erikson R, Goldthorpe JH, Portocarero L. Intergenerational class mobility in three European socletes: England "France and Sweden. Br J Sociol 1979;30:415-441.

32. Ganzeboom H, Luilkx R, Dessens J, et al. Intergenerationele klassenmobillteil in Nedertand tuissen 1970 en 1985. Mens an Maatschappij 1987;62;17-43.

33. Wan Berkel-Van Schaik AB, Tax B. Naar ean standaardoperationalisatio van sociaal-economische status voor epidemiologisch en sociaal-medisch onderzoak. Saciaal-economilsche gezondheidsverschillen nr.6. Den Haag: DOP, 1990.

34. Self SG, Prentice RL. Asymptotic distribution theory and efficiency results for casemcohort studies. Ann Stat $1988 ; 16: 64-81$. 
35. Van den Brandt PA, Van 't Veer P, Goldbohm RA, al. A prospective cohort study on dietary fat and the risik of postmenopausal breast cancer. Cancer Res $1993 ; 53: 75-82$.

36. Baker RJ. Glim 3. 77. Reference Manual. Oxford: Numerical Algorithms Group. 1985.

37. WU-Williams AH, YU MC, Mack TM Life-style, workplace, and stomach cancer by subsite in young men of Los Angeles county Cancer Res 1990,50:2569-2576.

38. Pall $\mathrm{D}$, Bianchi $\mathrm{S}$, Decarli $\mathrm{A}$, et all A case-control study of cancers of the gastric cardia in Italy. $\mathrm{Br} J$ Cancor 1992;65:263-266.

39. Slolwjk AM, Raat $\mathrm{H}$. Sociaa-economische status. Het begrip, de meting en de classificatie in epidemiologisch onderzoek. GGD Ftotterdiam, 1990.

40. Gray JR, Coldman AJ, MacDonald WC. Cigarette and alcohol use in patients with adenocarcinoma of the gastric cardia or lower esophagus, Cancer 1992,69:2227-2231.

41. Inoue $M$, Tajima $K$, Hirose $K$, Kuroishi $T$, Gao $C-M$, Kitoh $T$. Life-style and subsite of gastric cancer joint effect of smoking and drinking habits. Int $J$ Cancer 1994;56:494-499.

42. Forman D, Newell DG, Fullerton F, Yamell JWG, Stacey AR, Wald N, Sitas F. Association between infection with Helicobacter pylon and risk of gastric cancer: evidence from a prospective investigation. $\mathrm{Br}$ Med J 1991;302:1302-1305.

43. Parsonnet J. Helicobacter pylori and gastric cancer. Gastroenterol Clin North Am 1993;22:89-105.

44. Taylor DN, Blaser MJ. The epidemiology of helicobacter pylori infection. Epidemiol Rev 1991:13:42-59.

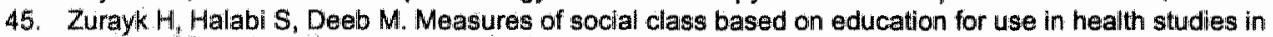
developing countries. I Epidemiol Community Health 1987;41:173-179.

46. Thijssen LJM. Sociale stratificatie onder ouderen. Soc Cult Kwartber 1986:8:10-27. 


\section{OCCUPATIONAL EXPOSURE TO CARCINOGENS AND LUNG}

CANCER RISK: results from the Netherlands Cohort Study

A. Jeanne M. van Loon, IJmert Kant, Gerard M. H. Swaen, R. Alexandra Goldbohm, Anja M. Kremer, Piet A. van den Brandt. 


\section{ABSTRACT}

Objectives - The aim of the study was to investigate lung cancer risks associated with fairly common, established carcinogenic occupational exposures (asbestos, paint dust, polycyclic aromatic hydrocarbons and welding fumes) in a prospective cohort study among the general population, and to estimate the proportion of lung cancer cases attributable to these occupational exposures.

Methods - A prospective cohort study on diet, other lifestyle factors, job history and cancer risk that started in 1986 in the Netherlands among 58,279 men, aged $55-69$ years. Based on information about job history obtained from a self-administered questionnaire, case by case expert assessment was carried out to assign to each study subject a cumulative probability of occupational exposure for each carcinogenic exposure. For analysis, a case-cohort approach was used, in which the person-years at risk were estimated from a randomly selected subcohort $(n=1688)$. After 4.3 years of follow-up, 524 lung cancer cases with complete job history were available.

Results - After adjustment for age, each of the other occupational exposures and for smoking habits and intake of vitamin $\mathrm{C}$, beta-carotene and retinol, significant associations were found between lung cancer risk and cumulative probability of exposure to asbestos (RR highest/no exposure $=3.49$; $95 \% \mathrm{Cl} 1.69-7.18$; trend-p $<0.01$ ) or paint dust (RR highest/ no exposure $=2.48 ; 95 \% \mathrm{Cl} 0.88-6.97$; trend-p $<0.01$ ). The population attributable risk (PAR) for the four exposures based on the multivariately adjusted rate ratios for ever exposed versus never exposed was $13.3 \%$, mainly due to exposure to asbestos (PAR $=11.6 \%$ ).

Conclusions - This prospective cohort study among the general population showed that occupational exposure to asbestos or paint dust is associated with higher rate ratios for lung cancer, after adjustment for smoking habits and dietary habits. 


\section{INTRODUCTION}

Lung cancer is the major cause of cancer mortality and incidence among men in the Netherlands. In the period of 1979 to $1990,37.6 \%$ of all fatal cancer in men was diagnosed as lung cancer ${ }^{1}$ and in the preceding decade this percentage was $35.9 \% .^{2}$ In $1991,35.5 \%$ of all incident cases of cancer diagnosed in the male Dutch population were lung cancer cases. ${ }^{3} \mathrm{~A}$ high proportion of lung cancer cases is attributable to past smoking habits. Doll and Peto have estimated that approximately $85 \%$ of the lung cancer deaths is attributable to cigarette smoking. Also a number of chemicals to which workers can be exposed have been identified as agents that increase the risk of lung cancer. Therefore, we wanted to study the association between occupational exposure to carcinogens and lung cancer risk: after adjustment for smoking habits. The selection of agents and occupations presenting an increased risk for lung cancer to be included in this study was based on the evaluations made by the International Agency for Research on Cancer (IARC). From the update presented by IARC in 1987, agents were identified that were judged to have sufficient evidence for carcinogenity for the human lung and to which exposure was estimated to occur frequently in a cross-section of the general population. Two agents, asbestos and polycyclic aromatic hydrocarbons (PAHs) fulfilled these requirements. ${ }^{5}$ Next, later IARC monographs were reviewed to see if any other relevant occupations or agents had subsequently been identified. Two occupations met these criteria, namely painters and welders. ${ }^{7}$ For welders welding fumes was regarded to be the relevant exposure. For painters, the rellevant exposure was less clear. However, the IARC Working Group concluded that there was sufficient evidence for the carcinogenity of occupational exposure as a painter, but there was inadequate evidence for the carcinogenity of occupational exposure in paint manufacture. ${ }^{*}$ Therefore, we defined the relevant exposure for painters in relation to lung cancer as exposure to paint dust (which is always combined with exposure to solvents) instead of exposure to solvents (which is not always combined with exposure: to paint dust). So, asbestos . PAHs, welding fumes and paint dust were selected as the occupational lung canicer risks to be evaluated.

Doll and Peto have estimated the proportion of lung cancer cases attributable to occupational exposures in men to be $15 \%$. Other estimates vary from $9.2 \%$ to $13 \%$. population attributable risk (PAR) or etiologic fraction has been defined as the proportion of all cases in the target population attributable to a specific exposure. "The PAR cannot be estimated solely on the basis of cohort studies of exposed workers, because it is necessary to have information on the prevalence of exposure in the general population. The Netherlands Cohort Study on diet, lifestyle, job history and cancer does provide this information for the general population. Information from this study was used to investigate lung cancer risks from the four occupational exposures mentioned above. Since the intake of beta-carotene, vitamin $C$ and retinol is also related to lung cancer risk, ${ }^{12,13}$ information about smoking habits and intake of vitamin $\mathrm{C}_{\text {, }}$, beta-carotene and retinol was used to disentangle possible effects from occupational exposure and possible effects from lifestyle factors. Finally, the corrected rate ratios for ever exposed men versus never exposed men were used to estimate the PAR of lung cancer due to occupational exposures. 


\section{MATERIALS AND METHODS}

\section{The cohort study}

The Netherlands Cohort Study (NLCS) is a prospective cohort study on diet, other lifestyle factors, sociodemographic characteristics, job history and cancer risk, which started in 1986 among the general population in the Netherlands. ${ }^{14}$ The cohort included 58,279 men aged 55-69 years in 1986. Data on diet, various lifestyle variables, job history and other risk factors for cancer were collected by means of a self-administered questionnaire. Follow-up for cancer incidence has been established by periodic record linkage with a national pathology register (PALGA) and with all regional cancer registries in the Netherlands. ${ }^{15}$ For data analysis the case-cohort approach was used in which cases are derived from the entire cohort, while the person-years at risk are estimated from a random sample of 1688 subjects (subcohort). After the baseline exposure measurement the subcohort has been followed up biennially for vital status information. The lung cancer cases were diagnosed in the periad from September 1986 through December 1990. In this period, no subcohort members were lost to follow-up. After excluding subjects with self-reported cancer other than skin cancer, 677 incident lung cancer cases were detected within these 4.3 years of follow-up. Self-reported prevalent cancer cases other than skin cancer were also excluded from the subcohort, in which 1630 men remained.

\section{Exposure assessment}

For the exposure assessment by experts information from the baseline questionnaire of the NLCS was used. This information can be best described as a self-reported job history. containing data on job-title, name of the company, type of company, time period and information about what was being produced at the department. The whole data-processing and ascertainment of exposure probability was done without knowledge of the disease status (case/subcohort) of the subjects. First a list of all jobs in the Netherlands was independently reviewed by an occupational hygienist (IJ.K.) and an occupational epidemiologist (G.M.H.S.). In this first examination all jobs with no potential exposure to lung cancer carcinogens were excluded. Secondly, for a more refined exposure assessment the name of the company, type of company, time period and information about what was being produced at the department was used, since the probability of exposure to some carcinogens may differ between companies and between time periods. Therefore, each job title, specified by period and company, was scored separately according to the probability of exposure to the four carcinogens: asbestos, paint dust, polycyclic aromatic hydrocarbons (PAHs) and welding fumes (particularly stainless steel welding). Four exposure categories were defined: no exposure to the specific carcinogen, possible exposure (probability of exposure estimated to be smaller than $30 \%$ ), probable exposure (probability of exposure between 30 and $90 \%$ ) and nearly certain exposure (probability of exposure over $90 \%$ ). In a final review round all the jobs for which at. least one of the two reviewers suspected relevant exposure were re-evaluated and a definite probability of exposure was assigned to each of the job titles within the NLCS.

\section{Quantification of occupational exposures}

For a quantification of exposure a cumulative probability of exposure (CPE) was calculated, which combines information about the probability of exposure and the duration of possible exposure. Therefore a weight was assigned to each exposure category: no exposure - 
weight 0 ; possible exposure - weight 0.15 ; probable exposure - weight 0.6 and nearly certain exposure - weight 0.95 . Each weight corresponds to the midpoint of probability in each exposure category. The CPE was calculated by multiplication of the weight given to each exposure category by the number of years exposed. Subsequently, for each person all weighted exposures were summed up for each of the four carcinogens separately.

\section{Data analysils}

In the subcohort 1316 of the 1630 men ( $81 \%$ ) had completed the self-reported job history inventory, while 524 of the 677 cases $(77 \%$ ) had done so. For these persons the distribution of the CPE was compared between the cases and subcohort. The CPE to asbestos, PAHs or welding fumes was divided into four categories (no exposure and tertiles of exposure) and the CPE to paint dust was divided into three categories (no exposure and below and above the median exposure value). This categorization was based on the distribution of CPE's in the subcohort. The associations between CPE to occupational carcinogens and covariates were also studied in the subcohort by comparing the prevalence of smoking and by comparing mean values of age, pack-years of smoking and dietary intake of vitamin $\mathrm{C}$, beta-carotene and retinol between CPE categories. To study the association between CPE to carcinogens and lung cancer risk, data were analyzed according to the case-cohort approach ${ }^{16.17}$ using the GLIM statistical package. ${ }^{10}$ In the multivariate analyses, rate ratios and $95 \%$ confidence intervals of lung cancer risk were computed for each of the different occupational exposures, after adjustment for age and after further adjustment for the other three occupational exposures. All these covariates were entered in the model as continuous variables. Additional adjustment was made for smoking habits (never/ex/current and pack-years of cigarette smoking) and for dietary intake of vitamin $\mathrm{C}$, beta-carotene and retinol (as continuous variables). Finally, the population attributable risk was calculated, based on the corrected rate ratios for ever exposed versus never exposed persons.

\section{RESULTS}

The distribution of the cumulative probability of exposure to each of the four carcinogens in the case and the subcohort group is presented in Table 1. Cases were more often exposed to asbestos and paint dust compared with subcohort members. No marked difference in CPE to PAHs or welding fumes was observed between cases and subcohort members.

Table 2 shows the association between the CPE and covariates in the subcohort.

Differences in mean age between ever exposed and never exposed persons were small. The prevalence of smoking was lower among persons who were ever exposed to asbestos, PAHs or welding fumes, compared with never exposed persons; whereas the prevalence of smoking was higher among persons who were ever exposed to paint dust. The mean number of pack-years (for current and ex-smokers) was higher among persons who were ever exposed to one of the investigated carcinogens compared to those who were never exposed. The mean dietary intake of vitamin $\mathrm{C}$ was somewhat higher among persons who were ever exposed to asbestos and lower among persons who were ever exposed to paint dust or PAHs, compared with never exposed men in the subcohort. The mean intake of beta-carotene was also lower among persons who were ever exposed to paint dust or PAHs and the mean intake of retinol was only lower among persons who were ever 
exposed to paint dust. Finally, there was a correlation between exposure to asbestos, PAHs and welding fumes; while there was no correlation between exposure to paint dust and exposure to asbestos; PAHts or welding fumes.

Table 1: Distribution of exposure categores in male lung cancer cases and subcohort cimulative probabilty of exposure "

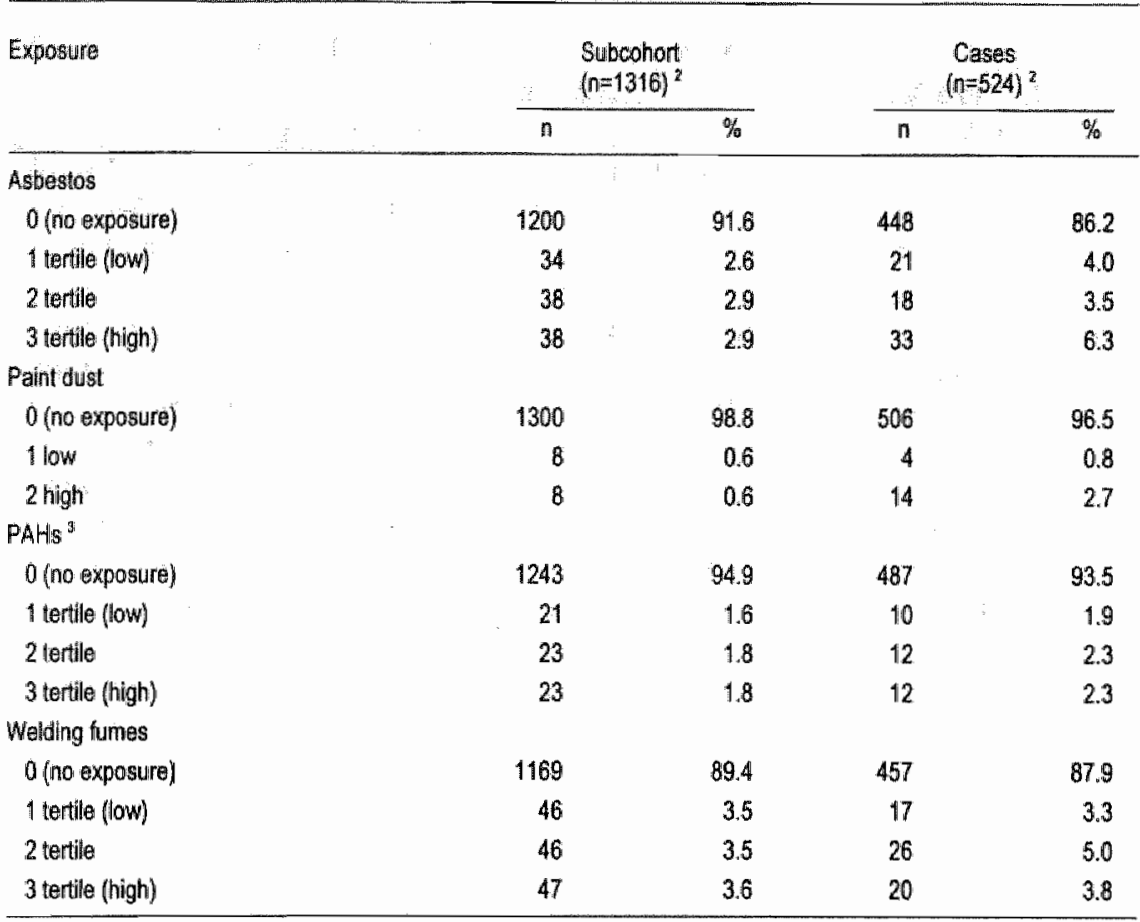

"Producl of probability (weights $0.15,0.6$ and 0.95) and duration (years) of exposure, approximately divided into lertiles or into two equal categories (paint dust)

${ }^{2}$ Numbers may not add up to 1316 or 524 due to missing values for duration of exposure

${ }^{3}$ PAHS: polycyclic aromatic hydrocarbons

The results of the case-cohort analyses are presented in table 3. After adjustment for age, there was a positive association between $\mathrm{CPE}$ to asbestos and lung cancer risk (trend-p < 0.01). Men in the highest exposure category had a statistically significant higher lung cancer risk compared to men with no occupational exposure to asbestos $(R R=2.66$; $95 \% \mathrm{Cl} 1.66-4.26$ ). There was also a significant positive association between CPE to paint dust and lung cancer risk (RR highest exposure/no exposure $=3.60 ; 95 \% \mathrm{Cl} 1.48-8.74$; trend-p < 0.01). No significant association between CPE to PAHs and lung cancer risk was observed (trend- $p=0.07$ ), but the rate ratios for the three exposure categories (compared to non-exposed) were all above one. The risk estimate for the CPE to welding fumes was only significantly different from 1 in the middle tertile ( $R R=1.73 ; 95 \% \mathrm{Cl} 1.05-2.85$ ).

Nevertheless, the trend test was also significant (trend- $p=0.03$ ).

After adjustment for age and for each of the other occupational exposures, the relative rates of PAHs and welding fumes were greatly diminished. The relative rates of exposure to asbestos and paint dust changed only marginally after adjustment and remained statistically significant (see table 3). 
After additional adjustment for smoking habits and intake of vitamin $C_{n}$ beta-carotene and retinol, there was still a statistically significant positive association between the cumulative probability of exposure to asbestos and lung cancer risk (RR highest exposure/no exposure $=3.49 ; 95 \% \mathrm{Cl} 1.69-7.18$; trend-p $<0.01$ ). There was also a positive association between CPE to paint dust and lung cancer risk after this latter adjustment (RR highest exposure/no exposure $=2.48 ; 95 \% \mathrm{Cl} 0.88-6.97$; trend-p < 0.01), but part of the higher age-adjusted risk among men in the highest paint dust exposure category seems to be explained by smoking and intake of vitamin $\mathrm{C}$, beta-carotene and retinol: The cumulative probability of exposure to PAHs became inversely associated with lung cancer risk after additional adjustment for smoking and intake of vitamin $C$, beta-carotene and retinol (RR highest exposure/no exposure $=0.28 ; 95 \% \mathrm{CI} 0.09-0.89 ;$ trend-p $<0.01$ ). The association between the CPE to welding fumes and lung cancer risk did not substantially change after additional adjustment.

Table 2: Assoctation between possible confounders and probability of exposure in the subcohort

\begin{tabular}{|c|c|c|c|c|c|c|c|c|}
\hline \multirow[t]{2}{*}{ Porbability of exposure } & \multicolumn{2}{|c|}{ Asbestos } & \multicolumn{2}{|c|}{ Paint dust } & \multicolumn{2}{|c|}{ PAHs ${ }^{1}$} & \multicolumn{2}{|c|}{ Welding fumes } \\
\hline & Never & Ever & Newer & Ever & Never & Ever & Never & Ever \\
\hline Age (mean yrs) & 613 & 60.7 & 61.3 & 61.8 & 61.3 & 60.6 & 61.4 & 60.3 \\
\hline Current smokers (\%) & 42.4 & 35.3 & 44.5 & 62.5 & 42.2 & 35.6 & 42.6 & 35.4 \\
\hline Ex-smokers (\%) & 47.8 & 54.3 & 48.5 & 37.5 & $48: 0$ & 54.8 & 47.5 & $5 i 5.8$ \\
\hline Pack-years 2 (mean) & 21.9 & 23.4 & 22.0 & 24.3 & 21.8 & 27.4 & 22.0 & 228 \\
\hline \multicolumn{9}{|l|}{ Dietary intake of } \\
\hline Vitamin C (mean, mg) & 99.0 & 101.6 & 99.3 & 96.3 & 99.6 & 93.0 & 99.2 & 99.8 \\
\hline Beta-carotene (mean, mg eq vitamin A) & 0.41 & 0.41 & 0.41 & 0.34 & 0.41 & 0.38 & 0.41 & 0.40 \\
\hline retinol (mean, $\mathrm{mg}$ eq witamin $\mathrm{A}$ ) & 0.62 & 0.63 & 0.62 & 0.55 & 0.62 & 0.63 & 0.62 & 0.63 \\
\hline \multicolumn{9}{|l|}{ Expossure to } \\
\hline Asibestos (\% ever) & - & - & 8.9 & 0 & 5.5 & 65.8 & $\$ .9$ & 63.9 \\
\hline Paint dust (\% ever) & 1.3 & 0 & - & - & 1.2 & 1.4 & 1.4 & 0 \\
\hline PAHS (\% ever) & 2.1 & 41.4 & 5.5 & 6.3 & - & - & 2.6 & 20,3 \\
\hline Welding fumes (\% ever) & 4.4 & 84.0 & 11.3 & 0 & 8.4 & 58.9 & - & - \\
\hline
\end{tabular}

PAHs: Polycyclic aromatic hydrocarbons

F Only for current and ex-smokers

Calculation of the population attributable risk is based on the rate ratios for ever exposed versus never exposed persons, adjusted for age, other exposures (never/ever), smoking and intake of vitamin $\mathrm{C}_{\text {, }}$ beta-carotene and retinol (table 4). Because we did not expect a protective effect of exposure to carcinogens, only RRs above 1 were used to calculate the PAR. Therefore, exposure to asbestos (RR ever exposed/never exposed $=2.49_{i}$ $95 \% \mathrm{Cl} 1.31-4.75$ ) and exposure to paint dust (RR ever exposed/never exposed $=2.46$; $95 \% \mathrm{Cl} 1.08-5.60)$ were the relevant exposures and the PAR of these exposures was $13.3 \%$. The PAR depends not only on the strength of the causal relation, but also on the prevalence of the risk factor. In the subcohort 116 men were ever exposed to asbestos $(8.8 \%)$ and 16 men were ever exposed to paint dust $(1.2 \%)$. Hence, $87 \%$ of the population attributable risk was dule to exposure to asbestos. 
Tabie 3: Rate rabios for lung cancer accoinding lo occupational exposures in age-adjusted and multwariate analysis

\begin{tabular}{|c|c|c|c|c|c|}
\hline $\begin{array}{l}\text { Lifetime expoisure } \\
\text { index }\end{array}$ & $\begin{array}{l}\text { No. of cassess } \\
\text { in cohort }\end{array}$ & $\begin{array}{l}\text { Person-yeans } \\
\text { in subcohort. }\end{array}$ & $\operatorname{RR}(95 \% \mathrm{Cll})^{2}$ & $\operatorname{RR}(95 \% \mathrm{CI})^{2}$ & $\operatorname{RR}(95 \% \mathrm{Cl})^{*}$ \\
\hline . & & & & $\therefore$ & . \\
\hline Astestos & & & & & \\
\hline 0 (no exposure) & 448 & 5005 & $1^{*}$ & 自" & 1 \\
\hline 1 tertle (low) & 21 & 141 & $1.76(1.02-3.03)$ & $1.82(1.04-3.17)$ & $1.59(0.75-3.34)$ \\
\hline 2 tertife: & 18 & 163 & $1.26(0.71-2.23)$ & $1.29(0.73-2.30)$ & $0.96(0.42-2.19)$ \\
\hline 3 lentle (high) & 33 & 157 & $2.66(1.66-4.26)$ & $272(1.5(5-4.75)$ & $3.49(1.69-7.18)$ \\
\hline $\begin{array}{l}\text { Test for trend } \\
x^{2}(p-v a l u e)\end{array}$ & & 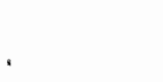 & $23.16(<0.01)$ & $19.07(<0.01)$ & $12.72(<0.01)$ \\
\hline \multicolumn{6}{|l|}{ Paint dust } \\
\hline 0 (no exposute) & 506 & 5425 & $1^{\circ}$ & $1^{\circ}$ & $1 *$ \\
\hline $110 \mathrm{w}$ & 4 & 33 & $1.46(0.43-4.97)$ & $1.53(0.45-5.21)$ & $2.29(0.61-8.63)$ \\
\hline 2 hingh & 14 & 34 & $3.60(1.48-8.74)$ & $3.74(1.53-9.11)$ & $2.48(0.88-6.97)$ \\
\hline $\begin{array}{l}\text { Test for trend } \\
\mathrm{X}^{2}(\mathrm{p} \text {-value })\end{array}$ & & & $15.58(<0.011)$ & $16.48(<0.01)$ & $7.67(<0.01)$ \\
\hline \multicolumn{6}{|l|}{ PAHs } \\
\hline 0 (no exposure) & 487 & 5196 & $1^{*}$ & $1^{*}$ & $1^{*}$ \\
\hline 1 tertíle (low) & 10 & 86 & $1.44(0.67-3.09)$ & $1.32(0.60-2.69)$ & $0.53(0.13-2.14)$ \\
\hline 2. Lertile & 12 & 96 & $1.61(0.78-3.34)$ & $1.09(0.49-2.40)$ & $0.83(0.32-2.20)$ \\
\hline 3 tertile (high) & 12 & 92 & $1.35(0.66-2.76)$ & $0.63(0.25-1.58)$ & $0.28(0.09-0.89)$ \\
\hline $\begin{array}{l}\text { Test for trend } \\
X^{2} \text { (p-value) }\end{array}$ & & & $3.20(0.07)$ & $0.56(0.45)$ & $9.05(<0.01)$ \\
\hline \multicolumn{6}{|l|}{ Welling fumes } \\
\hline 0 (no exposure) & 457 & 4884 & $1^{\prime \prime}$ & $1^{\circ}$ & $1:$ \\
\hline 1 tertille (low) & 17 & 194 & $1.06(0.60-1.89)$ & $0.98(0.55-1.76)$ & $0.71(0.31-1.60)$ \\
\hline 2 tertile & 26 & 192 & $1.73(1.05-2.85)$ & $1.16(0.63-2.11)$ & $1.49(0.72-3.07)$ \\
\hline 3 tertille phigh) & 20 & 191 & $1.26(0.732 .18)$ & $1.02(0.56-1.85)$ & $1.01(0.49-2.06)$ \\
\hline $\begin{array}{l}\text { Tosi for trend } \\
x^{2}(p \text { waloes }\end{array}$ & & & $4.49(0.03)$ & $0.09(0.77)$ & $0.10(0.75)$ \\
\hline
\end{tabular}

Peference caltegory

'Product of probabily (weights $0.15,0.6$ and 0.95 ) and duration (vears) of exposure, approximalely divided into tertiles or into two categories (paint dust)

Adjusted for age

Adjusted for age and other occupational exposures

"Adjusted for age, olher oceupational exposures, smoking (never f ex / cument and pack-years) and intake of vitamin C, beta-carotene and relinol

"PAHS: Polycyclic aromatic hydrocartoons

\section{DISCUSSION}

We have found a statistically significant age-adjusted positive association between the cumulative probability of exposure to asbestos, paint dust and welding fumes and lung cancer risk among men in the general population of the Netherlands. There was no age-adjusted association between the cumulative probability of exposure to PAHs and lung cancer risk. The positive association between exposure to welding fumes and lung cancer 
risk disappeared after additional adjustment for exposure to asbestos, paint dust and PAHs, while the positive associations between asbestos or paint dust and lung cancer risk remained after additional adjustment for the other exposures. Differences in smoking habits and intake of vitamin $C_{n}$ beta-carotene and retinol could not explain the positive association between exposure to asbestos or paint dust and lung cancer risk, although the rate ratios for exposure to paint dust became somewhat smaller after adjustment for these lifestyle factors. The PAR from these four carcinogens was $13.3 \%$, after adjustment for relevant lifestyle variables. The main part of this PAR was due to occupational exposure to asbestos.

Table 4: Rate ratios and population attributable risks for accupational exposures (mon-exposed versus over-exposied)

\begin{tabular}{lccr}
\hline $\begin{array}{l}\text { Occupational } \\
\text { exposures }\end{array}$ & $\begin{array}{l}\text { Proportion of ever exposed } \\
\text { subcohort members }\end{array}$ & RR $(95 \% \mathrm{Cl})^{2}$ & PAR $^{2}$ \\
\hline Asbestos & 0.088 & $2.49(1.31-4.75)$ & 11.6 \\
Paint dust & 0.012 & $2.46(1.08-5.60)$ & 1.7 \\
PAHs $^{3}$ & 0.055 & $0.53(0.26-1.07)$ & \\
Welding fumes & 0.112 & $0.86(0.46-1.58)$ &
\end{tabular}

Total

\footnotetext{
The proportion of ever exposed subcohort members is based on information about the probability of exposure, information about duration of exposure is not included

${ }^{2}$ After adjustment for age, other occupational exposures (neveriever), smoking (never/ex/cuntrent and pack-years of cigarelte smoking) and intake of vitamin C, beta-carotene and retinol

PAHs: Polycyclic aromatic hydrocarbons
}

The statistically significant positive association between exposure to asbestos and lung cancer risk is comparable with results from other studies. In most studies on exposure to asbestos and lung cancer risk, exposure to asbestos is measured by means of job title, job history or job exposure matrix and this information is either categorized as exposed versus non-exposed, ${ }^{18}$ as no exposure, possible exposure and definite exposure, ${ }^{20,21}$ or by means of a lifetime exposure index. ${ }^{22,23}$ In all these studies a statistically significant positive association was found after adjustment for smoking habits, with relative risk estimates varying from $2.0^{211}$ to $4.1 .^{22}$ In one case-control study ${ }^{24}$ information about asbestos fiber concentration was available and the authors reported a statistically significant positive association between fiber count and lung cancer risk. Only one study reported a non-significant positive association between asbestos exposure and lung cancer risk, ${ }^{25}$ in which information about occupational history and information about exposure to asbestos was used to assess cumulative asbestos exposure.

In most studies on lung cancer risk of painters, no statistically significant elevated risk was reported, ${ }^{25-28}$ although in all studies the odds ratios were above one. In our study attention was mainly focussed on exposure to paint dust instead of exposure to organic solvents and dye products. This may explain the difference between our findings and the results from other studies. Nevertheless, one study on the lung cancer risk of painters in the Scandinavian countries ${ }^{29}$ reported statistically significant higher lung cancer risks for painters and lacquerers, with risk estimates varying from 1.3 to 1.4 . 
Studies on PAH's and lung cancer risk show varying results, ${ }^{22,30}$ probably due to differences in study population. In a cohort study among men who worked at least one year in a manual job in a large aluminium production facility in Quebec, ${ }^{30}$ a statistically significant positive association was found between exposure to benzo-a-pyrene (an indicator for PAHs in general) and lung cancer mortality. In a case-control study in Germany ${ }^{22}$ no significant association was found between exposure to PAHs and lung cancer incidence, although in this study certain occupations which are associated with exposure to PAHs (metal producing and processing workers and road construction workers) showed significantly increased odds ratios. Finally, in a cohort study in Norway ${ }^{31}$ among workers in the aluminium industry, it was suggested that the cases could have resulted from exposure to asbestos, rather than from exposure to PAHs. This is partly comparable with our results; the non-significant increased lung cancer risk among men exposed to PAHs disappeared after additional adjustment for exposure to asbestos.

In a review on nickel-related cancer in welders, Langar $d^{32}{ }^{32}$ concluded that there was evidence for an excess lung cancer mortality and incidence in welders with long-term welding experience. There was also evidence that stainless steel welders had a slightly higher lung cancer risk compared with mild steel welders. However, exposure to asbestos and smoking are generally major confounders. In a meta-analysis about exposure to stainless steel welding fumes and lung cancer risk ${ }^{33}$ a statistically significant positive association was reported, after adjustment for smoking habits and exposure to asbestos. Only investigations taking smoking and asbestos exposure into account were included in the meta-analysis, but in two of the five included studies, only assumptions were made about smoking and asbestos exposure. One objective of a case-control study on lung cancer risk and welding in Germany ${ }^{34}$ was to assess confounding by asbestos exposure in what was thought to be a welding-associated risk. The authors concluded that some, if not all, of the excess risk of welders may be due to the exposure of asbestos, which is comparable with our results. Nevertheless, some types of welding processes in the German study still reached borderline significance after adjustment for exposure to asbestos.

In our study the adjusted relative risks for ever exposed versus never exposed persons were used to calculate the population attributable risk due to occupational carcinogens, which was estimated at $13 \%$. The actual proportion due to occupational exposure may be higher since the occupational exposures under investigation were restricted to four relatively common exposures. Other occupational exposures, such as exposure to certain heavy metals and bischloromethylether, were not included, because there was not sufficient evidence for carcinogenity for the human lung or exposure was not estimated to occur frequently in the general population. Unlike the relative risk, the population attributable risk depends not only on the strength of the causal relation but also on the prevalence of the risk factors, giving more importance to common moderately hazardous factors than to rare but strong risk factors. Therefore, the contribution of rare exposures to the proportion of lung cancers in males attributable to occupational exposures is considered to be small. Simonato et $\mathrm{al}^{35}$ investigated the attributable risk of occupational exposure from studies where adjustment was made for smoking. They included 16 case-control studies and found a wide variability of attributable risk estimates. When a list of recognized carcinogenic exposures was used for the selection of relevant occupations, the estimates varied between $2.4 \%$ and $40 \%$. None of the studies were nationwide and consequently no attributable risks could be computed for the general population. 
In our study the population attributable risk of occupational asbestos exposure in the past is $11.6 \%$. Other estimates vary from $6 \%$ in the west of Scotland including Glasgow, ${ }^{36} 14 \%$ in Northeastern Italy (Trieste) for definite asbestos exposure and $20 \%$ for definite and possible asbestos exposure, ${ }^{21} 16 \%$ in Göteborg, Sweden ${ }^{25}$ and $19 \%$ in Helsinki, Finland. ${ }^{24}$ These differences may be due to differences in exposure assessment but it is more likely that differences in levels of exposure in the study areas, partly due to the degree of industrialization, may lead to these differences in attributable risk. In our study $8.8 \%$ of the subcohort was ever exposed to asbestos, whereas the number of exposed controls in the other studies varied from $17 \%{ }^{24}$ to $37 \%$. because of differences in the definition of exposure.

Our cohort study has been performed in a large sample of the general population aged 55-69 years at baseline. The follow-up period of 4.3 years resulted in 677 male lung cancer cases. This number is considered to be sufficient, because in general about 400 cases are needed to detect relevant associations. ${ }^{37}$ The follow-up of person-years was $100 \%$ complete and the completeness of cancer follow-up was also very high, indicating that selection bias due to loss to follow-up is unlikely. The study population originated from 204 municipalities throughout the country. Although the response rate was rather low ( $36 \%)$, data on demographic variables, smoking and dietary habits indicated that the response had not adversely affected determinant distributions in the present cohort. ${ }^{14}$ The number of men aged 55-64 years with a high level of education (higher vocational or university) is somewhat higher in the subcohort $(18 \%)$ compared with men with the same age in the Dutch population ( $14 \%$ ). ${ }^{38}$ However, the number of men with primary school or lower vocational education was also higher in the subcohort compared with the general population ( $48 \%$ versus $37 \%$ ). Therefore, the exposure to occupational carcinogens may be somewhat higher in the cohort and consequently, the actual PAR of the occupational carcinogens may be somewhat lower.

The quality of the exposure assessment strongly affects the outcome of the risk estimate ${ }^{30}$ and ideally includes both intensity and duration of the occupational exposure for each specific study subject. However, in large population-based studles it is almost impossible to obtain this quantitative infonnation. Moreover, in this type of study the range of jobs with potential exposures is large and within given jobs there is a great possible variation of exposures. This makes it even more difficult to identify a clear link between jobs and exposures, compared with industry based studies. ${ }^{40}$ In our study the occupational history of the study subjects was obtained through questionnaires, which did not allow an estimation of the actual exposure concentrations that were experienced in the past. The highest achievable was a retrospective exposure assessment in terms of probability of exposure. In general this can be obtained through a Job Exposure Matrix (JEM) or a case by case expert assessment. The latter was used in this study. The main advantage of this method - compared with the use of a JEM - is that all the available information (job title. type and name of the company, time period) is used for the exposure assessment. ${ }^{40}$ Moreover a JEM may produce greater non-differential misclassification than exposure assessment by experts ${ }^{40,41}$ because information obtained from a JEM is mistakenly taken to relate to individual exposure." ${ }^{41}$ However, a JEM will be more reliable, since it will produce the same exposure information for identical basic data. ${ }^{41}$ Another disadvantage of exposure assessment by experts is the learning phenomenon. However, we used a final review round for re-evaluation of all the jobs for which at least one of both reviewers suspected 
relevant exposure. In this final review round a definitive probability of exposure was assigned to each job title. Finally, with a case by case expert assessment in general, there is no explicit definition of the criteria which are used for the determination of exposure. ${ }^{41}$

In case by case expert assessments different measures for exposures are applied. The highest probability of exposure once experienced is frequently used ${ }^{42}$ and could be directly obtained from our exposure assessment. However, this measure discards the effect of axposure duration which appeared to be essential in evaluation of exposures to carcinogenic agents. ${ }^{30,43,44}$ To incorporate the effect of duration of exposure we calculated a cumulative probability of exposure, for the four carcinogens separately. Besides, we also used highest probability of exposure as measure of exposure instead of the cumulative probability of exposure, with similar results (data not shown). In most studies on occupational exposure and lung cancer, smoking had no strong confounding effect on this association. ${ }^{10.18-21}$ This is comparable with our findings that adjustment for smoking did not substantially change the association between exposure to asbestos and lung cancer risk. We found no studies where also adjustment was made for the intake of vitamin $C$, beta-carotene and retinol. We neither found studies on lung cancer risk in painters where adjustment was made for lifestyle variables. However, it is possible that exposure to paint dust may promote the effect of carcinogens in tobacco smoke. ${ }^{201}$ In that case smoking should be considered as effect modifier instead of confounding factor. Unfortunately, because of the small number of non-smokers among the male lung cancer cases, it is not possible to compare the exposure associated risks between the non-smokers and smokers. The unexpected results for PAH after adjustment for smoking and dietary intake of vitamin $C$, beta-carotene and retinol may also be due to interaction. Further research on this subject will be possible after a longer follow-up period. Besides possible interaction between occupational exposure and lifestyle factors, there may be interaction between different occupational exposures. The PAR was calculated by adding up the four PARs for each specific exposure. Since each rate ratio was adjusted for the influence of the other three exposures, this was regarded as a suitable procedure.

In conclusion, we found a significant positive association between lung cancer risk and lifetime exposure to asbestos or paint dust. These associations were still apparent after adjustment for other occupational exposures and lifestyle factors like smoking and intake of vitamin $\mathrm{C}$, beta-carotene and retinol. The PAR of these exposures was $13 \%$. The main part of the attributable risk was due to exposure to asbestos.

\section{ACKNOWLEDGMENTS}

We want to thank the participants in this study, the regional cancer registries (IKA, IKL, IKMN, $\| K M_{1} \mid K O, I K R, I K S T$, IKW, IKZ), PALGA for providing incidence data; E. Dorant, S. van de Crommert, H. Brants, P. Florax, J. Nelissen and W. van Dijk for assistance in the cohort study, and S. van dien Heuvel from the TNO-PG institute for coding the questions about occupation.

The NLCS was financially supported by the Dutch Cancer Society. 


\section{REFERENCES}

1. Centraal Bureau voor de Statistiek. Atlas van de kankersterfte in Nederiand 1979-1990. Den Haag: SDU Uitgeveriij, 1992.

2. Centraal Bureau voor de Statistiek. Attas van de kankersterte in Nederiand 1969-1978. Den Haag: Staatsuitgeverij, 1980.

3. Netherlands Cancer Registry. Incidence of cancer in the Netherlands. Utrecht, 1991.

4. Doll R, Peto R. The causes of cancer, Oxford: Oxford University Press, 1981.

5. International Agency for Research on Cancer. Overall evaluations of carcinogenicity: An updating of IARC Monographs, Volumes 1 to 42. Lyon: IARC, 1987. (Suppl 7).

6. International Agency for Research on Cancer. Some organic solvents resin monomers and related compounds, pigments and occupational exposure to paint manufacture and painting. Lyon: IARC, 1989. (volume 47).

7. International Agency for Research on Cancer. Chromium, Nickel, and Welding. Lyon: IARC, 1990. (Volume 49).

8. Morabia A, Markowitz S. Garibaldi K, Wynder EL. Lung cancer and occupation: results of a multicentre case-control study. Br J Ind Med 1992;49:721-727.

9. Higginson J, Muir CS. Proportion of cancers due to occupation. Prev Med 1980;9:180-188.

10. Schoenberg JB, Stemhagen $A$, Mason TJ, Patterson J, Bill J, Altman R. Occupation and lung cancer risk among New Jersey white males. J Natl Cancer inst 1987;79:13-21.

11. Schlesseiman JJ. Case-control studies, Design, Conduct, Analysis. New York: Oxford University Press, 1982 .

12. Block G. Vitamin C and cancer prevention: the epidemiologic evidence. Am J Clin Nutr 1991;53: 270s-282s.

13. Graham S. Epidemiology of retinoids and cancer. J Natl Cancer Inst 1984;73:1423-1428.

14. Van den Brandt PA, Goldbohm RA, Van "t Veer $P$, Vollovics $A$, Hermus R.JJ, Sturmans $F$. A large-scale prospective cohort study on diet and cancer in the Netherlands. J Clin Epidemiol 1990;43:285-295.

15. Van den Brandt PA, Schouten LJ, Goldbohm RA, Dorant E, Hunen PMH. Development of a record linkage protocol for use in the Dutch cancer registry for epidemiological research. Int $J$ Epidemiol 1990; 19:553-558.

16. Self $\mathrm{SG}_{n}$ Prentice RL. Asymptotic distribution theory and efficiency results for case-cohort studies. Ann Stat 1988; 16:64-81.

17. Van den Brandt PA, Van "t Veer $P_{n}$ Goldbohm $R A$, et al. A prospective cohort study on dietary fat and the risk of postmenopausal breast cancer. Cancer Res 1993;53:75-82.

18. Baker RJ. Glim 3.77. Relerence Manual. Oxford: Numerical Algorithms Group, 1985.

19. Martischnig KM, Newell DJ, Barnsley WC, Cowan WK, Feinmann EL, Oliver E. Unsuspected exposure to asbestos and bronchogenic carcinoma. Br Med / 1977;1:746-749.

20. Kjuus $H$, Skjaerven $R$, Langärd $S$, Lien JT, Aamodt $T$. A casemreferent study of lung cancer, occupationäl exposures and smoking - 1 . Comparison of title-based and exposure-based occupational information. Scand J Work Environ Health 19a6;12:193-202.

21. Bovenzi $M$, Stanta $G$, Antiga $G$, Peruzzo $P$, Cavallieri $F$. Occupational exposure and lung cancer riskik in a coastal area of Northeastern Italy. Int Arch Occup Environ Health 1993;65:35-41.

22. w lockel $K-H$. Alurens W, Wichmann $H-E$, el all. Occupational and environmental hazards associated with lung cancer. Int J Epidemiol 1992;21:202-213.

23. Ahrens W, Jockel K.H, Brochard $P$, et al. Retrospective assessment of asbestios exposure - I. Case-control analysis in a study of lung cancer: efficiency of job-specific questionnaires and job exposure matrices. Int $J$ Epidemiol 1993; 22(Suppl.2):S83-S95.

24. Karjaliainen $A$, Anttila $S$, Vanhala $E$, Vainio H. Asbestos exposure and the risk of lung cancer in a general urban population. Scand J Work Environ Health 1994;20:243-50.

25. Järvolm B, Larsson S. Hagberg S, Olling S, Ryd W. Torén K. Quantitative importance of asbestos as a cause of lung cancer in a Swedish industrial city: a case-referent study. Eur Respir J 1993;6: 1271-1275.

26. Bethwaite $P B$, Pearce $N$, Fraser J. Cancer risks in painters: study based on the New Zealand cancer registry. Br J Ind Med 1990;47:742-746.

27. Keller JE "Howe HL. Cancer in llinois construction workers: a study. Am J Ind Med 1993;24:223-230.

28. Finkelstein MM. Occupational associations with lung cancer in two Ontario cities. Am J Ind Med 1995:27: 127-136. 
29. Skov T, Weiner J, Pukkala E, Malker H, Anderson A, Lynge E. Risk for cancer of the pharynx and oral cavily among male painters in the Nordic countries. Arch Environ Health 1993;48:176-180.

30. Armstrong B, Tremblay C. Baris D. Thériault G. Lung cancer mortality and polynuclear aromatic hydrocarbons: A case-cohort study of aluminium praduction workers in Arvida, Quebec, Canada. Am J Epidemiol 1994:139:250-262.

31. Langärd S. Prevention of lung cancer through the use of kriowledge on asbestos and ather work-related causes in Norweglan experiences. Scand J Work Enwiron Health 1994;20 speciall issue: 100-107.

32. Langärd S. Nickel-related cancer in welders. Science Tatal Environ 1994:148:303-309.

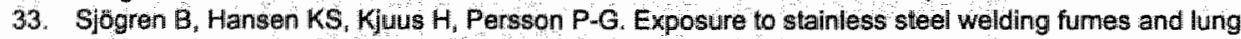
cancer: a meta-analysis, Occupational Environ Med 1994;51:335-336.

34. Jöckell $\mathrm{K}-\mathrm{H}$, Ahrens $\mathrm{W}$; Bolm-Audorff U. Lung cancer risk and weilding - preliminary results from an ongoing case-control study. Am J Ind Med 1994;25:805-812.

35. Simonato $L$, Vineis $P$, Fletcher $A C$, Estimates of the proportion of lung cancer attributable to occupational exposure. Carcinogenesis 1988;9:1159-1165.

36. De Vos Irvine $H$, Lamont DW, Hole DJ, Gillis CR. Asbestos and lung cancer in Gliasgow and the west of Scotsand. Br Med J 1993;306:1503-1506.

37. Phillps AN, Pocock SJ. Sample size requirements for prospective studies, with examples for coronary hearth disease. J Clin Epidemiol 1989;42:639-648.

38. Centraal Bureau voor de Statistiek. Leefsituatie nederlandse bevolking 1986: Kemciffers. Den Haag: Staatsuitgeverij, 1987.

39. Dosemeci $M_{0}$ Cocco $P$, Gomez $M$, Stuart $P A$, Heineman $E F$. Effects on three features of a job exposure matrix on risk estimates. Epidemiology 1994;5:124-127.

40. Bouyer $J_{1}$ Hemon D. Retrospective evaluation of occupational exposures in population-based case control studies: general overview with special attention to job exposure matrices. Int I Epidemiol 1993;22(suppl. 2)" S57-S64.

41. Bouyer $J_{\text {. Hemon }}$. Studying the performance of a job exposure matrix. int J Epidemiol 1993;22 (suppl. 2):\$65-S71.

42. Heineman EF, Olsen JH, Pottern LM, Gomez M, Raffn E, Blair A. Occupational risk factors for multiplle myeloma among Danisch men. Cancer Causes Control 1992;3:555-568.

43. Gomez M, Cocco P. Dosemecil M, Stuart PA. Occupational exposure to chlorinated aliphatic hiydrocarbons: job exposure matrix. Am J Ind Med 1994;26:173-183.

44. Roach $\mathrm{S}$. Health isks from hazardous substances at work, assessment, evaluation and control. New York: Pergamon press, 1992. 
Chapter 8

SOCIOECONOMIC STATUS AND LUNG CANCER INCIDENCE IN MEN

is there a role for occupational exposure?

A. Jeanne M. van Loon, R. Alexandra Goldbohm, IJmert Kant, Gerard M. H. Swaen, Anja M. Kremer, Piet A. van den Brandt. 


\section{ABSTRACT}

Study objective - To evaluate the influence of occupational exposure to carcinogens in explaining the association between socioeconomic status and lung cancer.

Design - A prospective cohort study. Data on diet, other lifestyle factors, sociodemographic characteristics and job history were collected by means of a self-administered questionnaire.

Follow-up for incident cancer was established by record linkage with a national pathology register and with regional cancer registries.

Setting - Population originating from 204 municipalities in the Netherlands.

Participants - 58,279 men aged 55-69 years in September 1986. After 4.3 years of follow-up 470 microscopically confirmed incident lung cancer cases were detected with complete data on dietary habits and job history.

Measurements and main results - Estimation of occupational exposure to asbestos, paint dust, polycyclic aromatic hydrocarbons and welding fumes was carried out by two experts, using information on job history from the basel line questionnaire. Socioeconomic status was measured by means of highest attained level of education and two occupation-based indicators (EGP score and U\&S score). In the initial multivariate analyses of socioeconomic status and lung cancer adjustment was made for age, smoking habits, intake of vitamin $\mathrm{C}$, beta-carotene and retinol and history of chronic obstructive pulmonary disease or asthma. Additional adjustment for occupational exposure to the four carcinogens mentioned above did not change the inverse association between level of education and lung cancer risk (initial model: RR highest/lowest level of education $=0.53$; $95 \% \mathrm{Cl}$ 0.34-0.82; Additional model: RR highest/lowest level of education $=0.53 ; 95 \% \mathrm{Cl} 0.34-0.84)$. The association between the two occupation-based indicators of socioeconomic status and lung cancer risk was also not influenced by occupational exposure to carcinogens. The effect of occupational exposure on the association between level of education and lung cancer risk did not differ between ex-and current smokers.

Conclusions - Occupational exposure to asbestos, paint dust, polycyclic aromatic hydrocarbons and welding fumes could not explain the inverse association between socioeconomic status and lung cancer risk.

Implications - There is more research warranted which explicitly addresses possible explanations for the association between socioeconomic status and lung cancer risk. 


\section{INTRODUCTION}

The risk of lung cancer has very often been found to be inversely related to socioeconomic status (SES). ${ }^{1}$ In studying this association, two possible intermediate factors arise. First, smoking is the most important cause of lung cancer, ${ }^{2}$ which is assoclated with SES. 3,4 Second, occupational exposure to carcinogens is a risk factor for lung cancer, ${ }^{5,5}$, which is also associated with SES. ${ }^{7}$ Occupational categories with a higher risk of lung cancer include metal production and processing workers, road construction workers and chemical workers. ${ }^{8}$ The increased lung cancer risk within these categories is probably due to exposure to asbestos, polycyclic aromatic hydrocarbons and metal fumes. In a previous paper we have reported the findings of our research on the association between SES and lung cancer and the role of smoking habits and other lifestyle characteristics as intermediate factors. ${ }^{9}$ In addition we have examined the role of occupational exposure to carcinogens as an intermediate factor in the association between SES and lung cancer. In defining occupational exposure two criteria were predetermined: the relation between exposure and lung cancer should be substantiated by means of human evidence and the occupational exposure had to occur frequently, by which it was relevant to take into account in a population-based prospective study. Four occupational exposures met these two criteria, i.e. exposure to asbestos, paint dust, polycyclic aromatic hydrocarbons (PAHs) and welding fumes. ${ }^{10-12}$ Thus, we have studied the role of occupational exposure to carcinogens in further explaining the association between SES and lung cancer after adjustment for relevant lifestyle characteristics like smoking and dietary habits.

Furthermore, history of chronic obstructive pulmonary disease (COPD) or asthma was also included in the analyses, because these respiratory disorders are both related to $S E S^{13}$ as well as to the lung cancer risk:

\section{MATERIALS AND METHODS}

\section{The cohort study}

The Netherlands Cohort Study (NLCS) on diet, other lifestyle factors, sociodemographic characteristics, job history and cancer risk, started in 1986. ${ }^{15}$ The cohort included 58,279 men aged 55-69 years at the beginning of the study; originating from 204 municipalities in the Netherlands. Data on diet, various lifestyle variables, job history and other risk factors for cancer were collected by means of a self-administered questionnaire. For data processing and analysis the case-cohort approach was used for reasons of efficiency. In a case-cohort approach cases are derived from the entire cohort, while the person-years at: risk are estimated from a random sample of 1688 subjects (subcohort). The subcohort can be used for studying other tumors than lung cancer as well. ${ }^{15}$ After the baseline exposure measurement the subcohort has been foliowed up biennially for vital status information. Between September 1986 and December 1990 (4.3 years of follow-up) no subcohort members were lost to follow-up. Follow-up for incident cancer has been established by record linkage with a national pathology register (PALGA) and with all regional cancer registries in the Netherlands. The current analysis is restricted to microscopically confirmed lung cancer incidence after 4.3 years of follow-up. In this period completeness of follow-up of the cohort through linkage with the cancer registries and PALGA was estimated to be at least $96 \% .{ }^{17}$ After excluding subjects with self-reported prevalent cancer 
other than skin cancer 677 lung cancer cases were detected. Prevalent cancer cases other than skin cancer were also excluded from the subcohort $(n=58)$. Furthermore, persons with incomplete information about job history or dietary habits were excluded, leaving 1245 subcohort members and 470 lung cancer cases available for analysis.

\section{Sociloeconomic status}

SES was measured by means of highest attained level of education and by means of occupational history, wo of the recommended measures for SES. Educational level was classiffed as primary school, lower vocational school, junior high school, senior high school, higher wocational school, university and other education. Information about occupational history was coded according to the job coding system of the Central Bureau of Statistics (CBS) frequently used in the Netherlands. ${ }^{19}$ For the present analyses, these CBS codes were aggregated according to occupational sector and required training (EGP) and according to social standing (U\&S). The EGP coding scheme is a reconstruction of the scheme developed by Erikson, Goldthorpe and Portocarero, ${ }^{20}$ which is still comparable with the original list. ${ }^{21}$ The U\&S score is based on an ordering of occupational titles according to social standing and is also comparable with international classifications. ${ }^{22}$ Other factors relevant to the association between SES and lung cancer risk that were measured in the

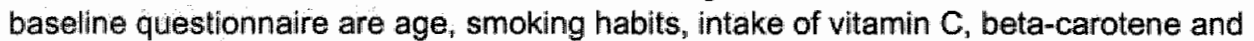
retinol and history of COPD or asthma. For the construction of the smoking variables the following information is used: smoking status (never/ex/current), total years of smoking and the number of cigarettes, cigars and/or pipes smoked per day. For the multivariate analyses smoking status and pack-years of cigarette smoking for current and ex-smokers were used. Mean individual intake of vitamin $\mathrm{C}$, beta carotene and retinol per day was computed by using information about the usual consumption of food and beverages from a 150 item food frequency questionnaire ${ }^{23}$ and information about nutrient contents from the Dutch food composition table of $1986 .^{24}$

\section{Assessment of occupational exposure to carcinogens}

For the exposure assessment by experts information from the baseline questionnaire of the NLCS was used. This information can be best described as a self administered job history, containing data on job title, name of company, type of company, time period and information about what was being produced at the department. The construction of the coding system is described in detail elsewhere (Van Loon et al, submitted). Briefly, an exposure estimate was assigned to each job by an occupational hygienist (IJ.K.) and an occupational epidemiologist (G.M.H.S.), based on information about job title, name of the company, type of company and time period. Each job was scored into one out of four categories: no exposure, possible exposure (<30\% probability), probable exposure ( $30-90 \%$ probability) and nearly certain exposure ( $>90 \%$ probability). Furthermore a weight was assigned to each exposure category: no exposure - weight 0 , possible exposure weight 0.15 , probable exposure - weight 0.6 and nearly certain exposure - weight 0.95 . Next, the cumulative index of exposure was calculated by multiplication of the weight given to each exposure caltegory by the number of years exposed. Subsequently, for each person all exposures were summed up for the four carcinogens separately.

\section{Data analysis}

The prevalence of exposure to the four carcinogens was compared between the case and subcohort group and between SES categories. To study the association between SES and 
ung cancer risk and the role of possible intermediate factors, data were analyzed according to the case-cohort approach, ${ }^{25} ; 26$ using the GLIM statistical package. ${ }^{27}$ In the multivariate analyses, rate ratios and $95 \%$ confidence intervals of lung cancer were computed for the different SES indicators, after adjustment for age, smoking (neverlex/current and pack-years of past and current smokers), intake of beta-carotene, witamin $C$ and retinol (all as continuous variables) and history of COPD or asthma and after additional adjustment for lifetime exposure to asbestos, paint dust, PAHs and welding fumes (also as continuous variables). Finally, the role of occupational exposure to carcinogens in explaining the association between SES and lung cancer was studied more extensively by conducting a multivariate analysis in the different smoking categories.

\section{RESULTS}

The prevalence of occupational exposure to the relevant carcinogens is presented in table 1. A higher proportion of cases was exposed to asbestos, paint dust, PAHs or welding fumes. The distribution of SES indicators and covariates in the case and subcohort group after 3.3 years of follow-up is presented elsewhere. ${ }^{\circ}$ Brielly, cases were on average older than members of the subcohort and current smoking was more prevalent in the case group. Cases had a lower educational level and were more often employed in blue collar occupations than members of the subcohort. Finally, the prevalence of COPD or asthma was higher among cases (13\%) compared with subcohort members (10\%).

Tablle 1: Occupational exposure to carcinogens: number and $\%$ of persons who were ever exposed ${ }^{\prime}$

\begin{tabular}{|c|c|c|c|c|c|c|c|c|}
\hline & \multicolumn{2}{|c|}{ Asbestas } & \multicolumn{2}{|c|}{ Paint dust } & \multicolumn{2}{|c|}{ PAHs } & \multicolumn{2}{|c|}{ Welding fumes } \\
\hline & n & $\%$ & $n$ & $\%$ & $n$ & $\%$ & $n$ & $\%$ \\
\hline Subcohort $(n=1245)$ & 109 & 8.8 & 15 & 1.2 & 66 & 5.3 & 134 & 10.8 \\
\hline Cases ( $(\mathrm{n}=470)$ & 66 & 14.0 & 17 & 3.6 & 31 & 6.6 & 59 & 12.6 \\
\hline
\end{tabular}

Only respondents with complete dielary data and jab history

The prevalence of occupational exposure within each SES category in the subcohort is presented in table 2. Occupational exposure to carcinogens was most prevalent among men with lower vocational school. The prevalence of occupational exposure to asbestos or weiding fumes was also relatively high among men with higher vocational school or university. According to the occupation-based SES indicators the prevalence of exposure to asbestos, paint dust, PAHs or welding fumes was higher among men whose most recent occupation was a blue collar job or a low social standing occupation. The prevalence of exposure to asbestos, PAHs and welding fumes was also high among men within the highest social standing category.

Table 3 shows the results of the multivariate analyses without and with adjustment for lifetime occupational exposure to asbestos, paint dust, PAHs and welding fumes. Initially, adjustment was made for age, smoking habits, intake of beta-carotene, vitamin $C$ and retinol and history of COPD or asthma. The significant inverse association between highest level of education and lung cancer risk (RR highest/lowest level of education $=0.53$; $95 \% \mathrm{Cl} 0.34-0.82$; trend-p $<0.01$ ) did not change after additional adjustment for exposure 
to the four carcinogens (RR highest/lowest level of education $=0.53 ; 95 \% \mathrm{Cl} 0.34-0.84$; trend-p < 0.01). The association between EGP score and lung cancer risk (RR lower white collar/blue collar $=0.76 ; 95 \% \mathrm{Cl} 0.49-1.18$ ) was slightly changed after additionali adjustment (RR lower white collar/blue collar $=0.82 ; 95 \% \mathrm{Cl} 0.52-1.28$ ). There was no association found between U\&S score and lung cancer risk.

Table 2: Association between three different socioeconomic status indicators and occupational exposure to carcinogens: number and $\%$ of persons in the subcohort who were ever exposed ${ }^{\text {s }}$

\begin{tabular}{|c|c|c|c|c|c|c|c|c|}
\hline \multirow[t]{2}{*}{ SES indicator } & \multicolumn{2}{|c|}{ Astbestos } & \multicolumn{2}{|c|}{ Paint dust } & \multicolumn{2}{|c|}{ PAHs } & \multicolumn{2}{|c|}{ Welding fumes } \\
\hline & $\pi$ & $\%$ & $n$ & $\%$ & $n$ & $\%$ & $n$ & 策 \\
\hline \multicolumn{9}{|l|}{ Highest level of education: } \\
\hline Primary sehool & 15 & 5.1 & 7 & 2.4 & 12 & 4.1 & 19 & 6.5 \\
\hline Lower vocational & 49 & 48.8 & 6 & 2.3 & 29 & 11.2 & 65 & 25.0 \\
\hline Junior high school & 20 & 5.8 & 2 & 0.6 & 14 & 4.0 & 23 & 6.6 \\
\hline Senjor high school & 2 & 1.9 & 0 & $a$ & 1 & 1.0 & 4 & 3.8 \\
\hline Higher wocational / university & 23 & 9.6 & 0 & 0 & 10 & 4.2 & 23 & 9.6 \\
\hline \multicolumn{9}{|l|}{ EGP score: ${ }^{2}$ last occupation: } \\
\hline Blue collar & 55 & 12.1 & 12 & 2.6 & 38 & 8.4 & 82 & 18.0 \\
\hline Lower white collar & 12 & 6.7 & 2 & 11 & 8 & 4.5 & 114 & 7.8 \\
\hline Upper whlte collar & 36 & 9.0 & 1 & 0.2 & 17 & 4.2 & 36 & 9.0 \\
\hline Other & 6 & 2.8 & 0 & 0 & 3 & 1.4 & 2 & 0.9 \\
\hline \multicolumn{9}{|l|}{ U\&S sciore: ${ }^{3}$ last occupalion: } \\
\hline 1 (low) & 19 & 8.1 & 12 & 5.1 & 10 & 4.3 & 28 & 11.9 \\
\hline 2 & 40 & 12.7 & 1 & 0.3 & 28 & 8.9 & 48 & 15.2 \\
\hline 3 & 16 & 4.6 & 2 & 0.6 & 13 & 3.7 & 26 & 7.4 \\
\hline 4 & 14 & 7.3 & 0 & 0 & 6 & 3.1 & 16 & 8.4 \\
\hline 5 (high) & 20 & 13.1 & 0 & $a$ & 9 & 5.9 & 16 & 10.5 \\
\hline
\end{tabular}

Only respondents with complete dietary data and job history ( $n=1245)$

2EGP score: an ordering based on occupational sector and required training

${ }^{3}$ UkS score: an ardering based on social standing

In a previous analysis of the NLCS data the inverse association between highest level of education and lung cancer risk was only found among current smokers. ${ }^{9}$ Therefore, we have studied the effect of occupational exposure to carcinogens on the association between SES and lung cancer within the different smoking categories (table 4). Due to the small number of lung cancer cases in the non-smoking group with complete data $(n=3)$, the analysis could not be carried out for the non-smokers only. We found significant inverse associations between highest level of education and lung cancer risk among ex-smokers and among current smokers after adjustment for pack-years, dietary intake of beta-carotene, vitamin $\mathrm{C}$ and retinol and history of COPD or asthma. However, among ex-smokers, only the rate ratio for men with higher vocational school or university was below one. Additional adjustment for occupational exposure to asbestos, paint dust, PAHs and welding fumes showed only marginal changes, both among ex-smokers and current smokers. 
Table 3: Rate ratios for lung cancer according to three different sooloeconomoc status indicators in multivariate analysis '

\begin{tabular}{|c|c|c|c|c|c|c|}
\hline SES indicator & $\begin{array}{l}\text { No. of cases } \\
\text { in cohort }\end{array}$ & $\begin{array}{l}\text { Person-years } \\
\text { in subcohort }\end{array}$ & $\mathrm{RR}^{2}$ & $95 \% \mathrm{Cl}$ & $\mathrm{RR}^{3}$ & $95 \% \mathrm{Cl}$ \\
\hline \multicolumn{7}{|l|}{ Highest level of education: } \\
\hline Primary school & 137 & 1214 & $1^{*}$ & & 1 & \\
\hline Lower vocational & 121 & 1097 & 1.28 & $0.89-1.85$ & 1.27 & $0.87-1.85$ \\
\hline Junior high school & 121 & 1442 & 0.94 & $0.65-1.36$ & 0.97 & $0.67-1: 41$ \\
\hline Sentor high school & 31 & 437 & 0.70 & $0.40-1.24$ & 0.73 & $0.42-1.28$ \\
\hline Higher vocational / university & 57 & 992 & 0.53 & $0.34-0.82$ & 0.53 & $0.34 \cdot 0.84$ \\
\hline $\begin{array}{l}\text { Test for trend } \\
x^{2} \text { (p-value) }\end{array}$ & & & \multicolumn{2}{|c|}{$19.38(<0.01)$} & \multicolumn{2}{|c|}{$16.34(<0.04)$} \\
\hline \multicolumn{7}{|l|}{ EGP score: "last profession: } \\
\hline Blue collar & 198 & 11884 & $1 *$ & & $1^{*}$ & \\
\hline Lower white collar & 55 & 752 & 0.76 & $0.49-1.18$ & 0.82 & $0.52-1.28$ \\
\hline Upper white collar & 144 & $166 \mathrm{~B}$ & 0.91 & $0.66-1.25$ & 0.95 & $0.86-1.31$ \\
\hline Other ${ }^{5}$ & 73 & 891 & 0.75 & $0.51-1.10$ & 0.81 & $0.54=1.20$ \\
\hline $\begin{array}{l}\text { Test for trend } \\
x^{2}(p-v a l u e)\end{array}$ & & & \multicolumn{2}{|c|}{$0.83(0.36)$} & \multicolumn{2}{|c|}{$0.25(0.62)$} \\
\hline \multicolumn{5}{|l|}{ U\&S score: ${ }^{-1}$ last profession; } & & \\
\hline 1 (low) & 102 & 980 & $1 *$ & & 1 & \\
\hline 2 & 129 & 4317 & 1.22 & $0.82-180$ & 1.23 & $0.82-1.86$ \\
\hline 3 & 120 & 1462 & 0.89 & $0.60-1.32$ & 0.97 & $0.65-1.46$ \\
\hline 4 & 61 & 796 & 0.85 & $0.53-1.36$ & 0.91 & $0.56-1.48$ \\
\hline 5 (high) & 58 & 639 & 1.15 & $0.72-1.83$ & 1.18 & $0.73-1.92$ \\
\hline $\begin{array}{l}\text { Test for trend } \\
x^{2} \text { (p-value) }\end{array}$ & & & \multicolumn{2}{|c|}{$0.33(0.56$} & \multicolumn{2}{|c|}{$0.05(0.83)$} \\
\hline
\end{tabular}

\footnotetext{
Reference category

1 Only respondents with complete dietary data and job history

${ }^{2}$ Adjusted for age, smoking behavior (neverfexfcurrent and pack-years), intake of beta-carotene, vitamin $\mathrm{C}$ and retinol, history of COPD and asthma

${ }^{3}$ Adjusted for age, smoking behavior (never/exicurrent and pack-yars), intake of beta-carotene, vitamin C, retinot, history of COPD and athma and exposure to asbestos, paint dust, PAHs and weiding fumes

"EGP' score: an ordering based on occupational section and required training

"Excluded from test for trend

"U\&S score: an ordering based on social standing
}

\section{DISCUSSION}

In a previous paper we have reported an inverse association between SES and lung cancer in the NLCS after adjustment for age and lifestyle variables, after 3.3 years of follow-up. ${ }^{9}$ in addition we have studied the influence of occupational exposure to carcinogens on the association between SES and lung cancer, after 4.3 years of follow-up. The statistically significant inverse association between level of education and lung cancer risk did not change after additional adjustment for occupational exposure to asbestos, paint dust, PAHs and welding fumes. The non-significant inverse association between EGP score and lung cancer risk changed marginally after additional adjustment for occupational exposure to carcinogens. No association was found between social standing and lung cancer risk. The 
effect of occupational exposure on the association between level of education and lung cancer risk was not different between ex-smokers and current smokers.

Table 4: Tate ratios for lung cancer according to highest level of education, by category of smoking in multivariate analysis, whout and wh adfustment for accupational expositres

\begin{tabular}{|c|c|c|c|c|}
\hline & $\mathrm{RR}^{2}$ & $95 \% \mathrm{Cll}$ & $\mathrm{RR}^{*}$ & $95 \% \mathrm{Cl}$ \\
\hline \multicolumn{5}{|l|}{ EX-smokers } \\
\hline \multicolumn{5}{|l|}{ Highest level of education: } \\
\hline Primary school & $1^{*}$ & & $1^{\circ}$ & \\
\hline Lower wocational & 1.12 & $0.61-2.07$ & 1.24 & $0.59-2.60$ \\
\hline Junior thigh school & 1.02 & $0.57 m 1.84$ & 1.13 & $0.58-2.18$ \\
\hline Senior high schoo: & 1.12 & $0.48-2.58$ & 1.25 & $0.5 .2 \cdot 3.03$ \\
\hline Higher wocational / university & 0.37 & $0.17 \cdot 0.82$ & 0.41 & $0.18-0.94$ \\
\hline $\begin{array}{l}\text { Test for trend } \\
X^{2} \text { (p-value) }\end{array}$ & \multicolumn{2}{|c|}{$7.08(<0.01)$} & \multicolumn{2}{|c|}{$5.41(0.02)$} \\
\hline \multicolumn{5}{|l|}{ Current smokers } \\
\hline \multicolumn{5}{|l|}{ Highest level of educalion: } \\
\hline Primary school & $1^{\circ}$ & & $1^{*}$ & \\
\hline Lower wocational & 1.49 & $0.92-2.41$ & 1.48 & $0.90-2.43$ \\
\hline Juniar high school & 0.86 & $0.54-1.37$ & 0.91 & $0.57-1.48$ \\
\hline Senior thigh school & 0.58 & 0.29 .1 .18 & 0.62 & $0.30-1.25$ \\
\hline Higher vocational / university & 0.60 & $0.35-1,03$ & 0.63 & $0.36-1.08$ \\
\hline $\begin{array}{l}\text { Test for trend } \\
X^{2}(p-v a l u e)\end{array}$ & \multicolumn{2}{|c|}{$12.65(<0.01)$} & \multicolumn{2}{|c|}{$9.26(<0.01)$} \\
\hline
\end{tabular}

Reference category

Only respondents with complete delary data and job history

2Adjusted for age, pack-years, dietary intake of beta-carotene, vitamin $\mathrm{C}$ and retinol, history of COPD or asthma

${ }^{3}$ Adjusted for age, pack-years, dietary intake of beta-carolene, witamin $\mathrm{C}$ and retinol, history of COPD or asthma and occupational exposure to asbestos, paint dust. PAHs and welding fumes

Earlier results from the NLCS showed statistically significant positive associations between lung cancer risk and occupational exposure to asbestos or paint dust (Van Loon et al, submitted). Occupations with a high probability of exposure to asbestos in the NLCS were blacksmith, motor mechanic, pipefitter, welder, marine engineer and bargeman. Most of the persons working in these occupations had lower vocational school as highest attained level of education. This might be an explanation for the higher lung cancer risk among men with lower vocational school. However, the proportion of men with higher vocational school or university as highest attained level of education, who were exposed to asbestos was also relatively high, although the majority was found in the lowest exposure tertiles (not presented). This indicates that there is no straightforward association between level of education and occupational exposure to asbestos. Consequently this could be the reason that adjustment for occupational exposure to asbestos did not change the risk estimates, neither when occupational exposure was considered as a continuous variable, nor when categorical variables were used (not presented).

The proportion of men who were ever exposed to asbestos, PAHs or welding fumes and whose last occupation was a white collar profession or a high social standing occupation was rather high. In about half of the instances the probability of exposure to asbestos in the 
White collar profession or high social standing occupation was actually assessed to be greater than zero (marine engineer, management of metal industry or metallurgist): In the other half, people whose last occupation was a white collar profession or a high social standing occupation were exposed to asbestos, PAHs or welding fumes during an earlier episode of their job history, in a blue collar profession or a low social standing occupation. This explains the finding that occupational exposure to asbestos, PAHs or welding fumes was not restricted to men whose last occupation was a blue collar profession or a low social standing occupation. Exposure to paint dust is mainly found among house painters, which appears to be a "lifelong" occupation in the NLCS. Therefore, exposure to paint dust is only found among blue collar workers and within low social standing jobs. However. because there is only a small proportion of house painters in the cohort, this will not explain differences in lung cancer risks among SES categories.

We found only one study that evaluated the association between social class and lung cancer after adjustment for occupational exposure and tobacco." The main goal of that study was to assess the proportion of male lung cancer cases due to occupational exposure. The authors reported that social class (based on the last occupation) was only a minor determinant of lung cancer when occupation and smoking habits were controlled for ( $R R$ high social class/low social class $=0.8$ ). They did not present information about the association between social class and lung cancer without adjustment for occupational exposure.

The NLCS has been performed in a large sample of the general population aged 55-69 years at baseline. The follow-up period of 4.3 years resulted in 470 male lung cancer cases with complete dietary data and job history. The follow-up of person-years was $100 \%$ complete and the completeness of cancer follow-up was also very high, indicating that selection bias due to loss to follow-up is unlikely. Besides, information bias due to random misclassification may have influenced the results. SES is operationalized as highest attained level of education, EGP score (functional level) and social standing (U\&S score), the last two both based on the last accupation. In individuals highest level of education is stable over time and therefore it will avoid the risk of reverse causation "but this stability. can mask important changes in individual circumstances after education is completed. The occupation-based SES indicators reflect the more recent situation. However, it is not clear whether it is relevant to know the SES at older age or the SES at younger age, in studying the association between SES and lung cancer risk.

The lifetime occupational exposure to carcinogens was calculated by multiplying the duration of exposure with the likelihood of exposure. The accuracy of the job histories did not allow an estimation of the actual exposure concentrations that were experienced in the past. This may lead to misclassification of exposure. However, since the associations between occupational exposure and lung cancer risk found in the NLCS are comparable with findings from other studies (Van Loon at al, submitted), it is likely that the exposure assessment reflects the actual exposure to carcinogens to a reasonable extent. Misclassification of smoking habits may lead to residual confounding. We have measured smoking habits very carefully and included smoking status (never/ex/current smokers) and pack-years of cigarette smoking into the model. Therefore, both duration and amount were taken into account. Moreover, we studied the effect of occupational exposure to carcinogens on the association between SES and lung cancer among smokers and ex-smokers separately, with comparable results. Consequently, it is not likely that residual 
confounding of smoking will explain the finding that adjustment for occupational exposure to carcinogens does not influence the association between SES and lung cancer risk.

Although more articles have been published on the association between SES and lung cancer risk, we did not find papers explicitly addressing possible explanations for these associations. Studies on socioeconomic health differences in the Netherlands point to the role of work-related factors like the ability to regulate working conditions ${ }_{i}{ }^{28}$ psychosocial factors ${ }_{i}{ }^{20}$ and differences in social participation and possibilities to control one's fate. ${ }^{30}$ Since these factors are associated with cancer, ${ }^{31,32}$ they may also influence the association between SES and lung cancer. However, it is not possible to investigate these factors in the NLCS, because there were no items about psychosocial characteristics included in the baseline questionnaire. Also, air pollution ${ }^{33,34}$ may play a role in explaining the association between SES and lung cancer. For the same reason mentioned above, it is not possible to investigate this in the NLCS.

In conclusion, after adjustment for smoking, dietary habits and history of lung disease there was still an inverse association between SES and lung cancer risk after 4.3 years of follow-up. Occupational exposure to asbestos, paint dust, $\mathrm{PAHs}$ and welding fumes could not explain this association.

\section{ACKNOWLEDGMENTS}

We want to thank the participants in this study, the regional cancer registries (IKA, IKL, IKMN, $I K N$, IKO, IKR, IKST, IKW, IKZ), PALGA for providing incidence data; E. Dorant, S. van de Crommert, H. Brants ${ }$ P. Florax, J. Nelissen and W. van Dijk for assistance in the cohort study and $S$. van den Heuvel from the TNO-PG institute for coding the questions about occupation.

\section{REFERENCES}

1. Van Loon AJM, Brug J, Goldbohrn RA, Van den Brandt PA. Differences in cancer incidence and mortality among socioeconomic groups. Scand $J$ Soc Med 1995:23:110-120.

2. Tomatis L, ed. Cancer: causes, occumence and control. Lyon: IARC Sclentific Publications 100, 1990.

3. Rosén M, Haning M, Wall S. Changing smoking habits in Sweden: towards better health, but not for all. ImI J Epidemiol 1990;19:316-322.

4. Sterting TD, Weinkam JJ. Smoking patterns by occupation, industry, sex, and race. Arch Environ Health $1978 ; 37: 313-3117$.

5. Simonato L, Vineis P, Fletcher AC. Estimates of the proportion of lung cancer attributable to occupational exposure. Carcinogenesis 1988;9:1159-1165.

6. Coultas DB, Samet JM. Occupational lung cancer. Clinics in Chest Medicine 1992;13:3411-354.

7. Pastorino U, Berrino $F_{\text {n }}$ Gervasio A, Presenti V, Riboli E, Crosignani P. Proportion of lung cancers due to occupational exposure. Int J Cancer 1984;33:231-237.

8. Jockel $\mathrm{KH}_{0}$. Ahrens $W$. Wichmenn $\mathrm{HE}_{n}$ et al. Occupational and environmental hazards associated with lung cancer. Int I Epidamiol 1992;21:202-213.

9. Van Loon AJM, Goldbohm RA, Van den Brandt PA. Lung cancer: is there an association with socioeconomic status in the Netherlands? J Epidemiol Community Health 1995;49:65-69.

10. Intemational Agency for Research on Cancer. Overall evaluations of carcinagenicity: An updating of IARC Monographs, Volumes 1 to 42. Lyon: France, 1987. (Suppl 7). 
11. International Agency for research on cancer. Some onganic solvents resin monomers and rolated compounds, pigments and occupational exposume to paint manufacture and painting. Lyon: IARC 1989. (Volume 47).

12. International Agency for Research on Cancer. Chromium, Nickel, and Welding. Lyon: IARC, 1990. (Volume 49).

13. Bakke PS, Hanoa H, Gulswik A. Educational level and obstructive lung disease given smoking habils and occupational airborne exposure: Nonwegian community study. Am J Epidemiol 1995;141:1080-1088.

14. Wu $\mathrm{AH}$, Fontham $\mathrm{ETH}$, Reynolds $\mathrm{P}$, et al. Previous lung disease and risk of lung cancer among lifetime nonsmoking women in the United States. Am I Epidemiol 1995;141:1023-1032.

15. Van den Brandt PA, Goldbohm RA, Van t Veer P, Volovics A, Hermus RJJ, Sturmans F. A large-scale prospective cohort study on diet and cancer in the Nethertands J Clin Epidemiol 1990;43:285-295.

16 Van dien Brandt PA, Schouten Lل, Goldbohm RA, Dorant E, Hunen PMH. Development af a record linkage protocol for use in the Dutch cancer registry for epidemiological research. Int $J$ Epidemiol 1990 ; 19:553-558.

17. Goldbohm RA, Van den Brandt PA, Dorant E. Estimation of the coverage of Dutch munlcipalities by cancer registries and PALGA based on hospiltal discharge data. Tijdschr Soc Gezondheidsz 1994; 72; $80-84$.

18. Liberatos P. Link BG, Kelsey JL. The measurement of social class in epidemiology. Epidemiol Rev 1988; $10: 87-121$.

19. Centraal Bureau voor de Statistiek. Beroepenclassificatie 1984. Lijst van benamingen per benopencode. Voorburg: CBS, 1985 .

20. Erikson $\mathrm{R}_{\text {, Goldthorpe } \mathrm{JH}}$, Portocarero L. Intergenerational class mobilty in three western countries: England, France and Sweden. Br $J$ Sociol 1979;30:4115-441.

21. Ganzeboom $H_{1}$ Luijkx $R$, Dessens J, el all. lntergenerationele klassenmobliteilt in Nederland tussen 1970 en 1985. Mens en Maatschappij 1987:62:17-43.

22. Van Berkel-Van Schaik AB, Tax B. Naar een standaardoperationalisatie van sociaal-oconomische status voor epidemiologisch en sociaal-medisch onderzoek. Soclaal-ieconomische gezondheidsverschillen nr.6. Den Haag: DOP, 1990.

23. Goldbohm RA, Van den Brandt PA, Brants HAM, et al. Validation of a dietary questionnaire used in a large-scale prospective cohort study on diet and cancer . Eur $/$ Clin Nutr 1994;48:253-265.

24. Stichting NEVO. NEVO-tabel, Nederlands voedingsstoffenbestand 1986-1987. The Hague: Voorlichtingsbureau voor de voeding. 1986.

25. Self SG, Prentice RL. Asymptotic distribution theory and efficiency results for case-cohort studies. Ann Stat $1988 ; 16 ; 64-81$.

26. Van den Brandt PA, Van "t Veer P, Goldbohm RA, et al. A prospective cohort study on dietary fat and the risk of postmenopausal breast cancer. Cancer Res 1993;53:75-82.

27. Baker R.J. Glim 3.77. Reference Manual. Oxford: Numerical Algorithms Group, 1985.

28. Schroer CAP, Bullinga RS. Gezondheidsverschillen tussen sociaal-economische statusgroepen: effect van verschitien in leefwijze of arbeidsbelasting? In: Mackenbach JP (ed). Soclabl-economische gezondheidsverschillen onderzocht. Deel III. Den Haag: DOP. 1991.

29. Ranchor AV. Social class, psychosocial factors and disease. From description towards axplanation. (thesis). Groningen, 1994.

30. Joosten J. De invloed van klasse, status en burgerschap op subjectleve gezondheid. (thesis). Maastricht, 1995.

31. Horne RL, Picard RS. Psychosocial risk factors for lung cancer. Psychosom Med 1979;41:503-514.

32. Jalhn I, Becker U, Jöckel K-H, Pohllabeln H. Occupational life course and lung cancer risk in men. Findings from a socio-epidemiological analysis of job-changing histories in a case-control study. Soc Set Med $1995 ; 40: 961-75$.

33. Hemminki $K_{n}$ Pershagen $G$. Cancer risk of air pollution: epidemiological evidence. Environ Healhh Perspect 1994; 102 (suppl.4):187-192.

34. Barbone $F$, Bovenzi M, Cavallier F, Stanta G. Air pollution and lung cancer in Trieste, Italy. Am $J$ Epidemiol 1995;141:1161-1169. 
Chapter 9

SOCIOECONOMIC STATUS, PHYSICAL ACTIVITY AT WORK AND COLON

CANCER INCIDENCE: results from the Netherlands Cohort Study

A. Jeanne M. van Loon, Plet A. van den Brandt, R. Alexandra Goldbohm 


\section{ABSTRACT}

The role of physical activity at work in explaining the association between socioeconomic status (SES) and colon cancer risk among men was investigated in the Netherlands Cohort study on diet and cancer. This prospective study started in 1986 among 58,279 men aged $55-69$ years. Data on socioeconomic status, job history, diet and other risk factors for colon cancer were collected by means of a self-administered questionnaire.

Information on job title was used for the assessment of physical activity at work (energy expenditure and number of hours sitting per day). Furthermore, subjects were categorized according to their longest occupation ever held and according to their last occupation. For data analysis a case-cohort approach was used, in which the person-years at risk were estimated by means of a randomly selected subcohort of 1688 men. After 4.3 years of follow-up 200 incident colon cancer cases were detected. After adjustment for age, Quetelet index, alcohol intake, prevalence of cholecystectomy and family history of large bowel cancer, we found a positive association between colon cancer risk and highest level of education (RR highest/lowest level of education $=1.54 ; 95 \% \mathrm{Cl} 0.95-2.48$; trend- $\mathrm{p}=0.04$ ), EGP score (RR upper white collar/blue collar $=1.48$; $95 \% \mathrm{Cl} 1.01-2.15$; trend $-\mathrm{p}=0.03$ ) and U\&S score (RR high/low social standing $=2.34 ; 95 \% \mathrm{Cl} 1.37-4.00$; trend $\mathrm{p}<0.01$ ). After additional adjustment for physical activity at work, the association between colon cancer risk and highest level of education or EGP score was not statistically significant anymore. Both for highest level of education and for EGP score, additional adjustment for energy expenditure showed a larger change in rate ratios for colon cancer than additional adjustment for number of hours sitting per day. The rate ratios for colon cancer risk increased in the highest U\&S categories after additional adjustment for both measures of physical activity at work. Additional adjustment for physical activity based on the last occupation showed similar results as additional adjustment for physical activity based on the longest occupation. 


\section{INTRODUCTION}

The association between socioeconomic status (SES) and colon cancer risk has been studied several times. ${ }^{t-9}$ In most studies a positive association has been reported, particularly for men. ${ }^{-9}$. However in almost none of these studies a possible explanation for this positive association was investigated. In only one study adjustment was made for potential risk factors for colon cancer other than age and place of residence. Therefore, we previously studied the association between SES and colon cancer risk in the Netherlands Cohort Study (NLCS) with special attention for the role of lifestyle varlables in explaining this association. A positive age-adjusted association between colon cancer and three different SES indicators was found. ${ }^{10}$ After additional adjustment for relevant covariates like Quetelet Index and physical activity at work, the positive association between colon cancer and social standing remained statistically significant. In these analyses a relatively crude measure for physical activity at work was used, which could have resulted in misclassification. Since physical activity at work and/or leisure time is one of the most consistently observed risk factors for colon cancer; ${ }^{11-13}$ misclassifications may have important consequences for the results. To obviate this problem we have developed a more refined coding system to assess physical activity at work. In this article we describe the re-analysis of the effect of physical activity at work on the association between SES and colon cancer. We have conducted the analyses only for men since there is more job diversity in the studied age category among men than among women, who were mostly housewives.

\section{MATERIALS AND METHODS}

\section{The cohort study}

The Netherlands Cohort Study (NLCS), investigating the associations between various lifestyle variables, sociodemographic indicators and cancer risk, was started in September 1986. At the beginning of the study the cohort included 58,279 men aged 55-69 years, originating from 204 municipalities in the Netherlands. At baseline "data were collected by means of a self-administered questionnaire. A detailed description of the cohort study design has been reported elsewhere. For data analysis the case-cohort approach was used. In short, this means that cases are derived from the entire cohort, whille the person-years at risk are estimated from a random sample of 1688 men (subcohort), which has been followed up biennially for vital status information. Follow-up for incident cancer has been established by record linkage with all regional cancer registries in the Netherlands and with a national pathology register (PALGA). The method of record linkage has been described previously ${ }^{15}$ The analysis is restricted to colon cancer incidence in the period from September 1986 through December 1990. In this period, completeness of follow-up was estimated to be at least $96 \% .{ }^{36}$ After these 4.3 years of follow-up 228 colon cancer cases were detected. We excluded self-reported prevalent cancer cases other than skin cancer $(n=17)$, cases with in situ carcinoma $(n=8)$ and cases without microscopically confirmed diagnosis $(n=3)$. Self-reported prevalent cancer cases other than skin cancer were also excluded at baseline from the subcohort, with the result that 1630 men remained in this group. 


\section{Socioeconomic status}

SES was measured by means of highest level of education attained and by means of occupational history, two of the recommended measures for SES: ${ }^{17}$ Highest level of education was classiffed as primary school "lower vocational school (e.g. technical school, domestic science school), junior high school, senior high school, higher vocational school, university and other education. Information about occupational history was coded according to a job coding system of the Central Bureau of Statistics (CBS), which is frequently used in the Netherlands. ${ }^{18}$ These CBS codes were aggregated according to occupational sector and required training (EGP score) and according to social standing (U\&S score). The EGP coding scheme is a reconstruction of the scheme developed by Erikson, Goldthorpe and Portocarero. ${ }^{10}$ The U\&S coding scheme is developed by Ultee and Sixma. ${ }^{20}$

Educational level was aggregated into five categories: primary school, lower vocational school, junior high school, senior high school and higher vocational school or university. For the occupation-based SES indicators information about the last occupation was used. The EGP score was divided into four categories: blue collar jobs (lower-grade technicians, semi and unskilled manual workers), lower white collar jobs (administrators and non-manual employees), upper white collar jobs (professionals) and other (farmers and self-employed people). The U\&S score was divided into five categories increasing from low (e.g. garbage collector) to high social standing (e.g. lawyer).

\section{Physical activity}

Assessment of physical activity at work was based on job title. All the job codes from the Central Bureau of Statistics were classified according to physical activity by an occupational hygienist. If necessary, information about the different work tasks for each job in the Netherlands was used. ${ }^{21}$ Because it is not yet clear which specific aspect of physical activity is relevant for colon cancer risk, we selected two different measures of physical activity: sitting time and total energy expenditure $(\mathrm{kJ} / \mathrm{min})$. The sitting time scale was divided into three groups: low activity (more than 6 working hours per day spent sitting). moderate activity (2-6 hours per day) and high activity (less than 2 hours per day sitting). The total energy expenditure was based on a rating system developed by Hettinger et al. ${ }^{22}$ Low activity included work with an energy expenditure less than $8 \mathrm{~kJ} / \mathrm{min}$; moderate activity was defined as an energy expenditure between 8 and $12 \mathrm{~kJ} / \mathrm{min}$ and high activity corresponded to an activity level higher than $12 \mathrm{~kJ} / \mathrm{min}$. Since it is not clear whether physical activity at work plays a role in the Initiation of colon cancer or in the promotion of colon cancer ${ }^{12}$ we used information about the longest job ever held as an indicator for the lifetime physical activity at work as well as information about the last occupation.

\section{Data analysis}

The distribution of the different indicators for physical activity was compared between the case group and the subcohort group. Moreover, the distribution of the physical activity indicators among the different SES variables was studied in the subcohort. To investigate the association between SES and colon cancer risk and the role of physical activity at work, data were analyzed according to the case-cohort approach, ${ }^{23,24}$ using the GLIM statistical package. ${ }^{25}$ First, age-adjusted rate ratios of colon cancer were determined for each of the SES indicators. Next, multivariately adjusted rate ratios and $95 \%$ confidence intervals of colon cancer were computed for the different SES indicators, after adjustrnent for relevant covariates but without adjustment for physical activity at work. Finally, additional 
adjustment was made for physical activity at work. In all the multivariate analyses adjustment was made for age (continuous variable), Quetelet index $(<22,23-24,25-26$, $\left.\geq 27 \mathrm{~kg} / \mathrm{m}^{2}\right)$, alcohol intake $(0,0.1-4.9,5.0-14.9,15.0-29.9,30 \mathrm{~g} /$ day $)$, the prevalence of cholecystectomy (yes/no) and family history of large bowel cancer.

\section{RESULTS}

The distribution of the indicators for physical activity at work among colon cancer cases and in the subcohort is presented in table 1. Regarding physical activity in the longest job held, there were proportionally more persons from the case group in the category 6-8 hours sitting compared with the subcohort. There were also proportionally more subjects from the case group in the lowest energy expenditure category. The same pattern was found for physical activity based on the last occupation.

Table 1: Distribution of physical activity indicators in subcohort and colon cancer cases

\begin{tabular}{|c|c|c|c|c|}
\hline \multirow[t]{2}{*}{ Physical activity at work } & \multicolumn{2}{|c|}{ Subcohort } & \multicolumn{2}{|c|}{ Cases } \\
\hline & $n$ & $\%$ & $n$ & $\%$ \\
\hline Total & 1630 & & 200 & \\
\hline Physical activity in langest job held" & 1346 & & 183 & \\
\hline \multicolumn{5}{|l|}{ Mumber of hours sitting } \\
\hline $1(6-8$ hours / day $)$ & 349 & 25.9 & 57 & 31.1 \\
\hline 2 (2-6 hours / day) & 581 & 43.2 & 73 & 39.9 \\
\hline $3(<2$ hours / day) & 416 & 30.9 & 53 & 29.0 \\
\hline \multicolumn{5}{|l|}{ Energy expenditure } \\
\hline$f(<8 \mathrm{~kJ} / \mathrm{min})$ & 773 & 57.4 & 116 & 63.4 \\
\hline $2(8-12 \mathrm{~kJ} / \mathrm{min})$ & 358 & 26.6 & 39 & 21.3 \\
\hline $3(>12 \mathrm{~kJ} / \mathrm{min})$ & 215 & 16.0 & 28 & 15.3 \\
\hline Physical activity in last job & 1464 & & 192 & \\
\hline \multicolumn{5}{|l|}{ Number of hours sitting } \\
\hline 1 (6-8 hours / day $)$ & 382 & 26.1 & 61 & 3*B. B \\
\hline 2 (2-6 hours / day) & 640 & 43.7 & 84 & 42.2 \\
\hline 3 ( $<2$ hours / day $)$ & 442 & 30.2 & 50 & 26.0 \\
\hline \multicolumn{5}{|l|}{ Energy expenditure } \\
\hline $1(<8 \mathrm{~kJ} / \mathrm{min})$ & 854 & 58.3 & 126 & 65.6 \\
\hline $2(8.12 \mathrm{~kJ} / \mathrm{min})$ & 367 & 25.1 & 40 & 20.8 \\
\hline $3(>12 \mathrm{~kJ} / \mathrm{min})$ & 243 & 16.6 & 26 & 13.5 \\
\hline
\end{tabular}

Table 2 shows the association between the indicators for physical activity at work and the three different SES indicators. The number of hours sitting per day was the lowest in the lower SES categories, while the "sitting jobs" (6-8 hours sitting per day) were mostly found among the intermediate SES categories. The association between energy expenditure and SES showed a somewhat different pattern: the lowest energy expenditure was found in the higher SES categories and the highest energy expenditure was found in the lower SES categories. 


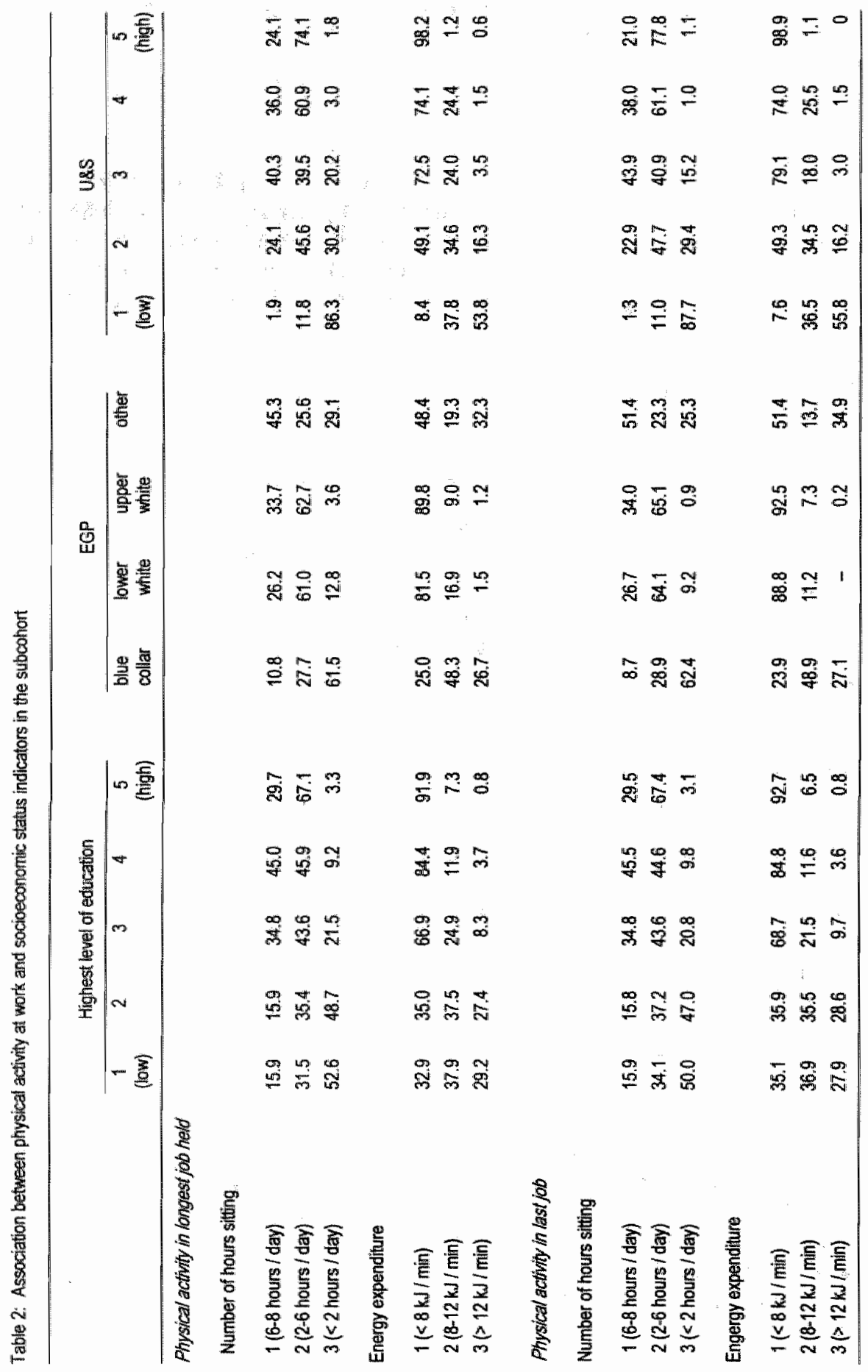


The results of the multivariate analyses are presented in table 3. First, adjustment was made for age. Next, additional adjustment was made for possible other confounders or intermediate factors in the association between SES and colon cancer risk and finally further adjustment was made for the four different indicators for physical activity at work. We found a positive association between the risk for colon cancer and the three different SES indicators after adjustment for age and after additional adjustment for Quetelet index, cholecystectomy, alcohol intake and family history of large bowel cancer. Further adjustment for the indicators for physical activity at work showed different results for the three SES indicators. The association between level of education and colon cancer risk changed somewhat after additional adjustment for hours sitting per day (based on the last occupation as well as based on the longest occupation). Adjustment for energy expenditure showed a larger effect. The greatest difference was found after adjustment for energy expenditure during the last profession. This changed the statistically significant positive association between level of education and colon cancer risk (RR highest/lowest category $=1.54 ; 95 \% \mathrm{Cl} 0.95-2.48$; trend $-\mathrm{p}=0.04$ ) into a non-significant positive association ( $R \mathrm{R}$ highest/lowest category $=1.26 \% 95 \% \mathrm{Cl} 0.75-2.13 ;$ trend $-\mathrm{p}=0.32$ ). The rate ratio for colon cancer in the highest EGP category after adjustment for age, Quetelet index, cholecystectomy, allcohol intake and family history of large bowel cancer (RR upper white collar/blue collar $=1.48 ; 95 \% \mathrm{Cl} 1.01-2.15$; trend-p $=0.03$ ) changed also considerably after additional adjustment for energy expenditure during the last occupation (RR upper white collar/blue collar $=1.17 ; 95 \% \mathrm{Cl} 0.74-1.84$; trend-p $=0.21$ ). Adjustment for hours sitting per day showed a smaller change in rate ratios. Finally, the association between U\&S score and colon cancer risk ( $R R$ highest/lowest category $=2.34 ; 95 \% \mathrm{Cl} 1.37-4.00$; trend-p $<0.01$ ) did not substantially change after additional adjustment for energy expenditure based on the last occupation (RR highest/lowest category $=2.37$ :

$95 \% \mathrm{Cl} 1.19-4.72$; trend-p $<0.01$ ), whereas adjustment for the other indicators for physical activity at work showed an increase in the rate ratios for colon cancer in the highest U\&S categories.

\section{DISCUSSION}

We have found a positive association between SES and colon cancer risk after adjustment for age, Quetelet index, cholecystectomy, alcohol intake and family history of large bowel cancer. The effect of additional adjustment for physical activity at work differed between the three SES indicators. The statistically significant positive association between colon cancer risk and highest level of education or EGP score changed into an non-significant positive association after additional adjustment, while the statistically significant positive association between colon cancer risk and U\&S score remained after additional adjustment for the four indicators for physical activity at work. Additional adjustment for emergy expenditure showed a larger difference in rate ratios for colon cancer and level of education or EGP score than additional adjustment for number of hours sitting at work.

To our knowledge, there are no other studies on SES and colon cancer risk where adjustment is made for physical activity at work. However, there are studies on physical activity and colon cancer risk where adjustment is made for SES. In these studies adjustment for SES did not influence the association between physical activity and colon cancer risk. ${ }^{26-28}$ This implies that if there is an association between SES, physical activity and colon cancer risk, SES is not a confounder in the association between physical activity 


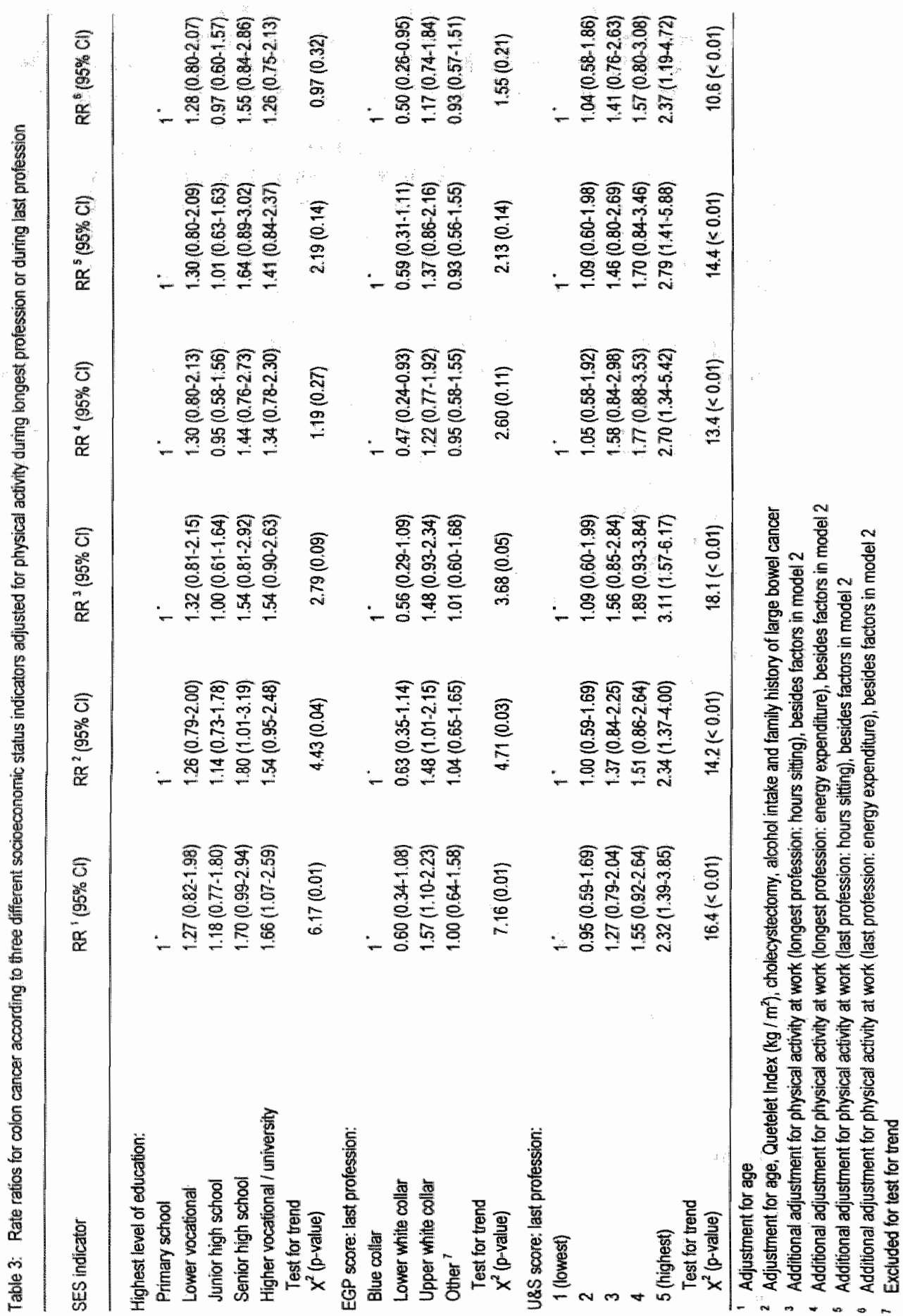


and colon cancer risk. In one descriptive epidemiologic study the suggestion is made that white collar workers have a lower physical activity level than blue collar workers and therefore a higher colon cancer risk. ${ }^{2}$ The conciusion of another study on occupational risks for colon cancer indicates also that the major contribution of occupation in colon cancer etiology is an indirect one via physical activity. ${ }^{30}$ Unfortunately, these assumptions are not further studied.

Physical activity is one of the most consistently observed risk factors for colon cancer. ${ }^{11-13}$ There are several biological mechanisms proposed to explain this association. Physical activity may influence gut motility and bowel transit time. ${ }^{12}$ This reduces the formation of secundairy bile acids, which are cancer promotors. Moreover, the contact between secundairy bile acids and bowel mucosa will be reduced. ${ }^{30}$ Other possible mechanisms concern effects on fat metabolism of hormonal changes which modify colon cancer risk, ${ }^{30}$ or effects on the immune system. ${ }^{12}$

Because it is not known whether physical activity influences colon cancer risk at the initiation phase or whether (lack of) physical activity acts as a promotor for colon cancer. we have considered both physical activity during the last occupation as well as physical activity during the longest occupation and found that additional adjustment for physicall activity based on the last occupation showed similar results as additional adjustment for physical activity based on the longest occupation. Peters et al. ${ }^{31}$ concluded that their results were the same if activity was classified in terms of the individuals most recent job, the job longest held or the lifetime occupational activity. Results from a study conducted by Gerhardsson de Verdier et al. ${ }^{32}$ indicated that the period of interest goes back as far as 20 years before diagnosis. However, iff a reduced bowel transit time plays an important role in explaining the association between physical activity and colon cancer risk by affecting the contact time between colon cancer promotors and bowel mucosa, it would be plausible that physical activity in the last job has a stronger association with colon cancer risk than physical activity in the longest job held. In our study adjustment for energy expenditure or sitting time based on the last occupation showed similar results as adjustment for energy expenditure or sitting time based on the longest occupation. Nevertheless, since the correlation between these measures for physical activity is very high in the NLCS (correlation sitting time last//ongest occupation $=0.90$ and correlation energy expenditure last/longest occupation $=0.93$ ), these findings give no clear indication tor the relevant time period for measuring physical activity.

We found larger changes in the rate ratios for colon cancer risk when adjustment was made for energy expenditure at work compared with adjustment for hours sitting at work. This corresponds with the finding that there was a more consistent association between energy expenditure and SES in the NLCS than between sitting time and SES. Unfortunately, we could not find information on the association between physical activity and SES in other populations.

The significance levels of the age-adjusted associations between the three SES indicators and colon cancer risk after 4.3 years of follow-up are not the same as the significance levels after 3.3 years of follow-up. ${ }^{10}$ This can be due to the increased number of cases after 4.3 years of follow-up. Additional adjustment for confounders and intermediate factors after 3.3 years of follow-up showed also different results compared with the findings after 4.3 years of follow-up. However, also after 4.3 years of follow-up, using the more sophisticated 
coding system for physical activity at work, there is still a statistically significant positive association between colon cancer risk and U\&S score after adjustment for confounders and intermediate factors.

The assessment of physical activity at work was based on job title, with information about jobs from the present. However, there may be large variations in physical activity within one job. This variation could not be included in the assessment of physical activity. Moreover, there may be differences in the level of physical activity at work between the past and the present. This is also not included in the assessment of physical activity. On the other hand, the coding system was based on the Dutch situation. Therefore, it will lead to a better

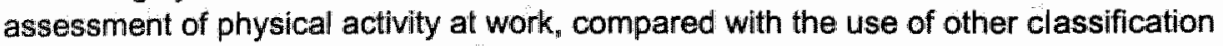
systems developed in other countries. There was no external instrument available to validate our categorization of physical activity at work. To get an indication of the validity, another expert in occupational hygiene has independently coded those occupations that were most frequently reported in the NLCS $(n=109)$. Most differences were found in the coding of energy expenditure (50 out of 109 occupations). For these 50 occupations the differences in the assessment of energy expenditure were rather small, however 38 of the 50 occupations had a score between 8 and $9 \mathrm{~kJ} / \mathrm{min}$ instead of $<8 \mathrm{~kJ} / \mathrm{min}$.

Both energy expenditure and sitting time were categorized into three categories, because these categories are also used in most research on physical activity at work and colon cancer risk. This does not guarantee that these classifications are most appropriate for studying the role of physical activity in the association between SES and colon cancer risk.

Besides misclassification there are other sources of bias, which may influence the results. The most important sources of bias (selection bias, information bias, misclassification of SES and detection bias) are already discussed in our previous article on SES and colon cancer risk. ${ }^{10}$ Therefore, in this paper we will restrict the discussion to residual confounding. In studying the role of physical activity in the association between SES and colon cancer risk, the main omission is the fact that we could only use information on physical activity at work. Nevertheless, since physical activity at leisure time is more common among the higher SES categories, ${ }^{33}$ this will probably not explain the higher colon cancer risk among the higher SES groups.

In one study on SES and colon cancer risk a positive association was only reported for left colon cancer (the distal part of the colon) and not for right colon cancer (the proximal part of the colon). ${ }^{3}$ Moreover, there are indications that the association between physical activity and colon cancer may differ between the proximal and distal part of the colon. ${ }^{11,31,32}$

Although these results are not very consistent, it would be more appropriate to differentiate between left and right colon cancer. Unfortunately, it was not possible to do so, because there was still a limited number of cases.

In conclusion, we found a statistically significant positive association between colon cancer risk and highest level of education or EGP score, that remained after adjustment for age, Quetelet index, alcohol intake, prevalence of cholecystectomy and family history of large bowel cancer. Additional adjustment for physical activity at work changed this statistically significant positive associations into non-significant positive associations. However, the statistically significant positive association between colon cancer risk and U\&S score remained statistically significant after adjustment for these risk factors for colon cancer. Future analyses after a longer follow-up should also study the effect of physical activity at 
leisure time on the association between SES and colon cancer, for the proximal part of the colon and the distal part of the colon separately.

\section{ACKNOWLEDGEMENTS}

We want to thank the participants in this study, the regional cancer registries (IKA, IKL, IKMN, $\mathbb{I K N}, \| K O$, IKR, IKST, IKW, IKZ), PALGA for providing incidence data; $E$. Dorant, $S$. van de Crommert, H. Brants, P. Florax, J. Nelissen and $W$ van Dijk for assistance in the cohort study, S. van den Heuvel from the TNO-PG institute for coding the questions about occupation. J.P. Thissen and D.J.J. Heederik from the Department of Epidemiology and Public Health in Wageningen for coding the job titles to different indicators for physical activity and IJ. Kant for coding a subsample of the job titles to physical activity. The NLCS was financially supported by the Dutch Cancer Society.

\section{REFERENCES}

1. Baquet CR, Horm JW, Gibbs T. Greenwald P. Socioeconomic factors and cancer incidence among blacks and whites. J Natl Cancer /nst 1991;83:551-557.

2. Williams RR. Horm JW. Association of cancer sites with tobacco and alcohol consumption and socioeconomic status of patients: interview study from the third national cancer survey. J Natl Cancer Inst $1977 ; 58: 525-547$.

3. Faivre J, Bedenne L, Boutron MC, Milan C, Collonges R, Arveux P. Epidemiological evidence for distinguishing subsites of colorectal cancer. J Epidemial Community Health 1989;43:356-361.

4. Ferraroni M, Negri E, La Vecchia C, D' Avanzo B, Franceschi S. Socioeconomic indicators, tobacco and alcohol in the aetiology of digestive tract neoplasms. Int J Epidemiol 1989; $18: 556-562$.

5. Bidoli E, Franceschi S, Talamini R, Barra S, La Vecchia C. Food consumption and cancer of the colon and rectum in Northeastern Italy. Int $J$ Cancer 1992;50:223-229.

6. Papadimitriou C, Day N, Tzonou A, Gerovassilis F, Manousos O. Trichopoulos D. Biosocial correlates of colorectal cancer in Greece. Int J Epidemiol 1984;13:155-159.

7. Pukkala E, Teppo L. Socioeconomic status and education as risk determinants of glastrointestinal cancer. Prev Med 1986;15:127-138.

8. Vägerö D, Persson G. Occurrence of cancer in socioeconomic groups in Sweden. Scand J Soc Med $1986 ; 14: 151-160$.

9. Leon DA. Longitudinal study. Social distribution of cancer, 1971.1975 (OPCS Saries LS no 3). London: HMSO, 1988.

10. Van Loon A.JM, Van den Brandt PA, Goldbohm RA. Socioeconomic status and colon cancer incidence: a prospective cohort study. Br J Cancer 1995;71:882-887.

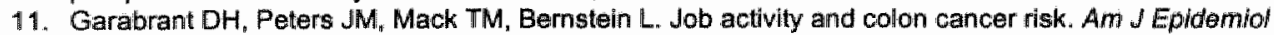
1984;119:1005-1014.

12. Macfarlane GJ, Lowenfels AB. Physical activity and colon cancer. Eur J Cancer Prev 1994;3:393-398.

13. Shephard R.J. Exercise in the prevention and treatment of cancer. An Update. Sports Medicine 1993:15:258-280.

14. Van den Brandt PA, Goldbohm RA, Van 't Veer $P$, Volovics A, Hermus Rul, Sturmans F. A large-scale prospective cohort study on diet and cancer in the Netherlands. J Clin Epidemiol 1990;43:285-295.

15. Van den Brandt PA, Schouten LU, Goldbohm RA, Dorant E, Hunen PMH. Development of a record linkage protocol for use in the Dutch cancer reglstry for epidemiological research. Int J Epidemiol 1990" 19:553-5:58.

16. Goldbohm RA, Van den Brandl PA, Dorant E. Estimation of the coverage of Dulch municipalities by cancer registries and PALGA based on hospiltal discharge data. Tijdschr Soc Gezondheidsz 1994; 72 : $80-84$

17. Liberatos P, Link BG, Kelsey JL. The measurement of social class in epidemiology. Epidemiol Rev 1988; $10: 87-121$.

18. Centraal Bureau voor de Statistiek. Beroepenclassificatie 1984. Lijst van benamingen per beroepencode. Voorburg: CBS, 1985. 
19. Erikson $\mathrm{R}$, Galdthorpe $\mathrm{JH}$, Portocarero L. Intergenerational class mobility in three European societies: England. France and Sweden. Br J Sociol 1979;30:415-441.

20. Sixma H. Uitee W. Een beroepsprestigeschaal voor Nederland in de jaren tachig. Mens en Maatschappij $1983,58: 360-382$.

21. Stichting Landelijk Dienstverienend Centrum. Handleiding voor de venwaardiging van beroependocumenten. Leeuwarden 1992.

22. Hettinger $\mathrm{TH}$, Mueller $\mathrm{BH}$, Gebhard $\mathrm{H}$. Emittlung des Arbeitsenergieumsatzes bei Dynamisch Muskulaerer Arbeit. Schriftenreihe der Bundesarbeit fur Arbeitsschutz. Fa 22 Dortmund, 1989.

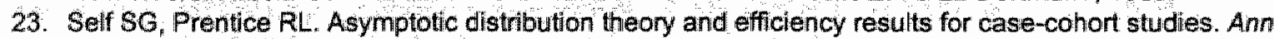
Stat 1968;16:64-81.

24. Van den Brandt PA, Van gt Veer $P$, Goldbohm RA, Dorant $E$, Volovics $A$, Hermus RJJ, Sturnans $F$. A prospective cohort study on dietary fat and the risk of postmenopausal breast cancer. Cancer Res $1993: 53: 75-82$.

25. Baker Ru. Glim 3.77. Reference Manual. Oxfordi: Numerical Algorithms Group, 1985.

26. Desemeci $M$. Hayes RB, Vetter $R$, et al. Occupational physical activity, socioeconomic status, and risk of 15 cancer sites in Turkey. Cancer Causes Control 1993;4:313-321.

27. Ballard-Barbash $R$, Schatzkin A, Albanes D, et al. Physical activity and risk of large bowel cancer in the Framingham study. Cancer Res 1990;50:3610-3613.

28. Gerhardsson M, Norell SE, Kiviranta $H$, Pedersen NL, Ahlbom A. Sedentary jobs and colon cancer. Am J Epidemial 1986:123:750-780.

29. Gerhardsson M, Steineck G. Norell SE. Colorectal cancer in Sweden. A descriptive epidemiologic study, Acta Oncol 1990:29:855-861.

30. Chow W-H, Malker HSR, Hsing AW, et al.Occupational risks for colon cancer in Sweden, J Occ Med $1994 ; 36: 647-651$.

31. Peters RK, Garabrant DH, Yu MC, Mack TM. A case-control study of occupational and dietary factors in colorectal cancer in young men by subsite. Cancer Res 1989;49:5459-546B.

32. Gerhardsson de Verdier M, Steineck G. Hagman U, Rieger A, Norell SE. Physical activity and colon cancer: A case-referent study in Stockholm. Int $J$ Cancer 1990:46:985-989,

33. Mackenbach $\mathrm{JP}$. Ongezonde verschillen. Over sociale stratificatie en gezondheid in Nederland. Assen; Van Gorcum, 1994. 
Chapter 10

GENERAL DISCUSSION 


\subsection{Overview of the findings}

In the prospective cohort study described in this thesis the association between socioeconomic status (SES) and lung, breast, colon and stomach cancer is investigated. Moreover, the role of lifestyle and working conditions in explaining associations between three indicators of SES and cancer risk is studied. The results are summarized in table 1. For women, these results were not presented in the chapters on lung cancer and stomach cancer because of small numbers of cases.

Table 1: Association between socioeconomic status (level of education, occupational group and ifequired trahing (EGP score), social status (ULS score)) and cancer rish

\section{Camcer site Adjustment for confounders (c) and intermediate factors (i)}

Education

ECP

1125

Mert

Lung

age (c)

age (c), pack-yeairs of cigarette smoking (i), Intake of beta-carotene () retino (i) and vitamin: $C$ (i)

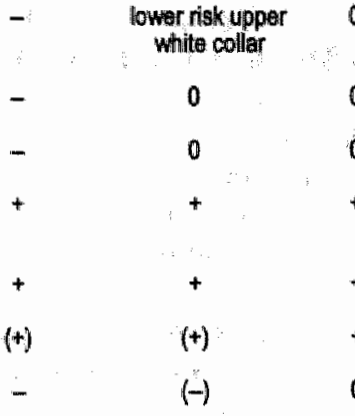

Stomach age |c| additional adjustment for probable exposure to carcinogens at work (1)

Colon age (s)

age (c), alcohol intake (i), Quetelet index (i), family history of large bowel cancer (c), cholecystectomy (c)

additionali adjustment for physicali activity at work (i):

age (c), smoking status (i), intake of alcohol (i), coffee (N), vitamin C (i). beta-carotene (i), family history of stomach cancer (c), prevalence of stomach disorders (c)

Women

Lung age (c)

age (c). pack-years of cigarette smoking (1), intake of beta-carotene (I). retinol (i) and vitamin C (i)

Collon

age (c)

age (c), alcohol inlake (1) "Quetelet index (i), tamily history of large bowel cancer (c), cholecystectomy (c). parity (i), age at first birth (i)

Stomach age $(c)$

\section{0}

$+$

*

$+$

\section{0}

age (c), smoking status (i), intake of alcohol (i), coffee (0), vitamin C. (i). bela-carolene (i), family history of stomach cancer (c), prevalence of stomach disotders (c)

age (c), age at first bitth (1), parity (1), oral contraceptive use (i) alcoholl intake (i), smoking status (j). Quetelet index (i), benign breast disease (c), family histoy of breast cancer (c), ane at menarchio (c), age at menopase (c)

$\begin{array}{ll}\text { (-) not significant inverse assciation } & (+) \text { not significant positive association } \\ - \text { significant inverse association } & + \text { significant positive association }\end{array}$


The comparability of these results with findings from other studies has already been described in the separate chapters. In short, regarding lung cancer the results are partly comparable with other studies. In most studies an association with SES is found, both for educational level and occupation, for men as well as for women, regardless of study design (chapter 3). For colon cancer, the results differed with regard to study design. Although in correlation studies and case-control studies no clear association was found between SES and colon cancer risk, within cohort studies positive age-adjusted associations were reported for highest level of education and occupation for men. For women, the association between SES and colon cancer is less clear than for men (chapter 5 ). In all of seven studies on SES and stomach cancer statistically significant inverse age-adjusted associations were reported with level of education for men. In most studies where occupation was used as SES indicator also significant inverse associations were reported (chapter 6). With respect to breast cancer, almost all studies found a positive association between years of education, educational level, own occupation or highest occupation in the household and breast cancer risk after adjustment for age, regardlless of study design. These findings are not confirmed in our study (chapter 4).

However, it is important to note, that we found only a few studies where the association between SES and different tumour sites was investigated with simultaneous adjustment for lifestyle factors such as smoking habits, ${ }^{1-5}$ coffee consumption, ${ }^{4}$ alcohol consumption, ${ }^{4}$ or vegetable consumption. ${ }^{6}$ The results of these studies are comparable with the results in our study. Briefly, adjustment for lifestyle led only to marginal changes in rate ratios. However, in most studies not all the potentially relevant lifestyle characteristics were considered. Moreover, we found no studies with simultaneous adjustment for working conditions.

A schematic overview of the proposed association between SES and cancer is described in figure 1. Our results will be evaluated in the light of possible explanations for a (llack of) association which are proposed at different steps of this suggested association.

Figure 1: Schematic overvew of the proposed association between SES and cancer and possible explanations for (lack of) association

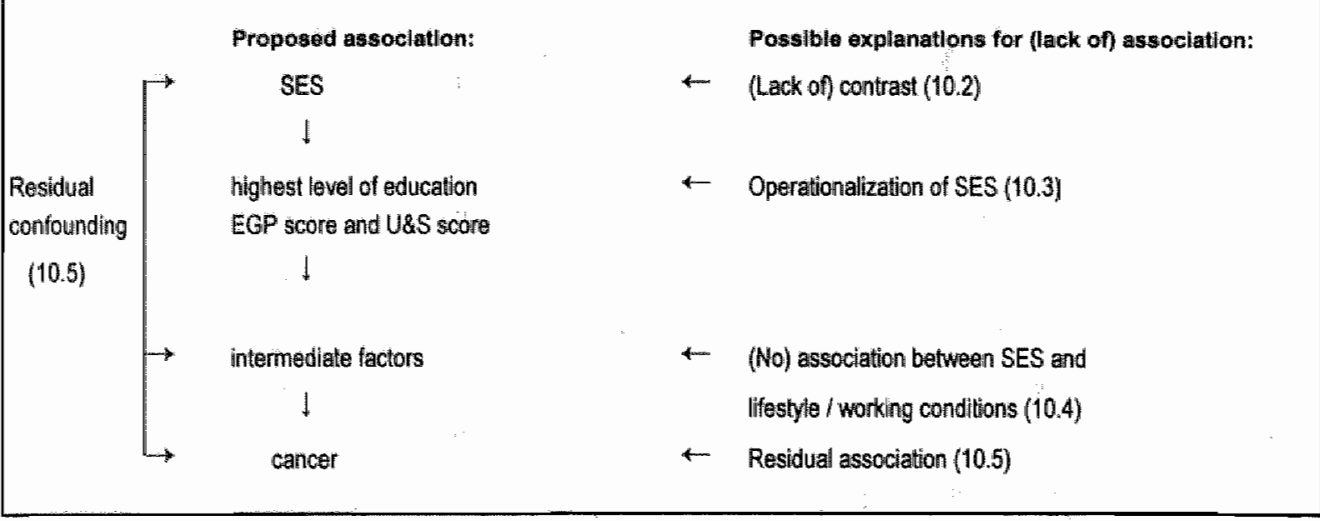




\subsection{Contrast}

Large differences in cancer incidence among SES categories may be due to large differences in SES and/or large effects of SES on cancer incidence. Therefore, it is possible that no differences or small differences in the distribution of SES indicators may lead to no differences or small differences in cancer incidence. To find out whether lack of contrast could have influenced our results, we have compared the distribution of SES indicators between the NLCS with thise distribution in the Netherlands and in other countries respectively. The proportion of men aged 55-64 years with a high level of education (higher vocational or university) is higher in the NLCS (18\%) compared with the proportion of men with the same age in the Dutch population in $1985(13 \%)$, while the proportion of men with primary school as highest level of education is somewhat lower in the NLCS $(27 \%)$ compared with the proportion in the Netherlands $(32 \%)^{7}$. The same is found for women (NLCS: lowest level 33\%; highest level $8 \%$; the Netherlands: lowest level $52 \%$, highest level $5 \%)]^{7}$ As a result, the contrast in level of education is somewhat larger in the NLCS compared with that contrast in the general population. Next, we have compared the distribution of educational level within the Netherlands with the distribution of educational level in other countries (table 2). For that purpose it was necessary to translate the levels of education from several longitudinal studies conducted in ather countries into average number of years of education.

Table 2: Distribution of years of education in affuent countres: \% of the total malle population *

\begin{tabular}{|c|c|c|c|c|c|c|}
\hline \multirow[t]{2}{*}{ Country } & Follows-up period & \multicolumn{4}{|c|}{ Years of education } & \multirow[t]{2}{*}{ age categories } \\
\hline & 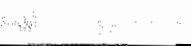 & $\leq 8$ & $9-10$ & $11-14$ & $>14$ & \\
\hline The Netherlands & $1970-1981$ & 48.2 & 21.0 & 17.8 & 12.9 & $38^{2}$ \\
\hline Denmark & $1970-1980$ & $40.4^{3}$ & 40.0 & $13.3^{4}$ & 6.3 & $35-44$ \\
\hline Norway & $1971-1980$ & 38.9 & 20.8 & 27.6 & 12.6 & $30-49$ \\
\hline Sweden & $1971-1980$ & 842 & 6.3 & 9.5 & & $35-59$ \\
\hline Finland & $1970-1980$ & 76.6 & 11.8 & 7.9 & 3.7 & $35-64$ \\
\hline England \& Wales & $1971-1981$ & & $94.6^{\circ}$ & 11.2 & 4.3 & $15+$ \\
\hline France & $1975-1980$ & 31.6 & 46.1 & 8.2 & 14.2 & $35-64$ \\
\hline USA & $1979 \cdot 1981$ & 16.5 & 14.8 & 49.0 & 19.7 & $35-64$ \\
\hline
\end{tabular}

Adapted from Kunst AE, Mackeribach JP. The size of montality differences aseciated with aducational level in nine inctustrialized countries. Am J Public Heallh 1994:64:932-937.

2 Age at beginning of follow-up except for England and Wales and France, where data referred to age al death

3. Includes educational tevel unknown (12.6\%)

- Includes vocational education levell unknown (7.1\%)

5. includes educational level unknown (2.2\%) and no higher qualification (82.1\%)

The distribution of years of education in the Netherlands is comparable with the distribution in Denmark and Norway. Differences in the distribution are smaller in Sweden, Finland and England and Wales and larger in France and in the USA. If differences in cancer incidence are mainly due to inequalities in educational level, the largest differences in cancer incidence within the SES categories should therefore be found in France and the USA and the smallest differences should be found in Sweden and Finland. The position of the Netherlands should be somewhere in between. However, the studies on SES and cancer risk differed so much in study design that it is very difficult to compare the rate ratios or odds ratios in a quantitative way. We could not find a comparison of level of education 
within different countries for women, that also included the Netherlands. Since the contrast in level of education in the NLCS was only a little smaller for women than for men, we can conclude that contrast in level of education in the NLCS is large enough to show differences in cancer incidence between SES categories.

Information about the distribution of occupational groups is presented in table 3. In the first row the distribution in the NLCS is presented. The other information is adapted from Kunst and Mackenbach, ${ }^{9}$ and refers to the male population aged 35-64 years in the early 1970 s. In the NLCS there is a relatively large percentage of professionals, intermediate and upper level employees, while the proportion of unskilled and semi-skilled labourers seems rather low. However, the distribution of occupational groups in the NLCS is not extremely skewed compared with the distribution in other countries. Therefore, differences in cancer incidence In the Netherlands within SES groups should also be comparable with other countries, if these differences are linked with differences in the distribution of occupational groups.

Table 3: Distribution of occupational group among men "

\begin{tabular}{|c|c|c|c|c|c|}
\hline 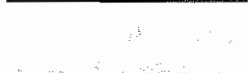 & $\begin{array}{l}\text { Professionals / interm. / } \\
\text { upper level employees }\end{array}$ & $\begin{array}{l}\text { lower level } \\
\text { employees }\end{array}$ & $\begin{array}{l}\text { skilled } \\
\text { labourers }\end{array}$ & $\begin{array}{l}\text { unskilled and } \\
\text { semi-skilled }\end{array}$ & $\begin{array}{l}\text { farmers / self employed } \\
\text { inactive persons }\end{array}$ \\
\hline The Netherlands: NLCS & 30.1 & 11.4 & 26.6 & 10.8 & 17.1 \\
\hline Denmark & $33.4^{2}$ & -3 & 13.3 & 30.2 & 30.3 \\
\hline Sweden & 4.0 & 31.0 & 49.6 & & 25.5 \\
\hline Finland & 7.5 & 13.0 & $36.6^{5}$ & $14.0^{\circ}$ & 30.6 \\
\hline England \& Wales & 25.7 & 10.8 & $37.8^{7}$ & $25.7^{\mathrm{a}}$ & 8.1 \\
\hline
\end{tabular}

'Partly adapted from Kunst AE, Mackenbach JP. Internalional wariation in the size of mortality differences associated with occupational status. Int ل Epidemial 1994:23:742-750.

${ }^{2}$ Inciudes self-employed men level I and II

${ }^{3}$ Combined with other self-employed men or employees

4 Includes unskilled and semi-skilled labourers

"Inctudes semi-skilled labourers

- Only unskilled labourers

"Includes sell-employed men

- Includes agricultural workers

In the NLCS we have found different associations between SES and cancer for men and women. This may be due to the fact that participation of women in the labour force used to be very low in the Netherlands. Among women in the NLCS almost 50\% finished their formal employment 30 years before the start of the study, which was typical for the Netherlands. ${ }^{10}$ The SES of the last occupation will therefore be of limited value. In other studies on SES and cancer risk women are often categorized according to the occupation of their partner. This describes the well-known social gradient in reproductive outcome between SES categories better than a categorization based on their own occupation. ${ }^{11}$ However, this may lead to misclassification because a substantial proportion of the women with a paid job have an occupational status higher than that of their husband ${ }^{12}$ We did not have information about occupational status of the partner but we did have information about level of education of the partner. For breast cancer we used both information about level of education of the study subject and level of education of her partner in the analysis, but this did not lead to different results. 
Our results regarding women are not comparable with the results found in other studles: This may be also due to the participation rate of women in the labour force. In the Netherlands only $18 \%$ of the women who were born between 1917 and 1931 had a paid job in 1960 and in 1971 this percentage was between 17 and $23 \%$. The participation rate was much lower compared with that in other European countries. Therefore, the contrast in the occupation-based SES indicators among women will be much larger in other European countries compared with the Netherlands: Moreover, misclassification will be higher in our study, compared with other studies, since in the NLCS the accupational status of the majority of the women is based on the situation 30 years before our baseline measurement.

We can conclude that in the NLCS the contrast in the distribution of SES indicators is large enough to show differences in cancer incidence between SES categories among men $_{\text {"if }}$ any exists. However, lack of contrast and/or misclassification in the occupation-based SES indicators among women may explain our null findings on the association between SES and cancer risklk.

\subsection{Operationalization of SES}

We used highest level of education and last occupation as measures for SES. Education is easy to measure, it is applicable to every individual and it is stable over time. This stability has the advantage of avoiding the risk of reverse causation. However, it will mask important changes in circumstances after education is completed. ${ }^{4}$ In other studies, number of years at school is the most commonly used measure of education, but certification is found to be more influential in determining prestige. ${ }^{15}$ Therefore, we have chosen to use level of education as measure of SES instead of years of education. The occupation-based SES indicators were derived from the last occupation, no matter what the employment status at baseline was. Because employment status is an independent risk factor for ill-health ${ }^{16}$ this coull have influenced our results. However, because we wanted to compare our findings with other research on SES and cancer, we have chosen to use occupation-based SES indicators instead of including employment status in our analyses. In the subcohort only $4 \%$ of the men and $1 \%$ of the women reported to be unemployed at baseline and the majority of these unemployed people $(67 \%)$ were less than 5 years without a paid job. Therefore, ignoring unemployment in the analyses will not have affected our results to a large extent. However, $16 \%$ of the men and $5 \%$ of the women had no paid job at baseline due to incapacity for work or disability and for $31 \%$ of these persons it was more than 10 years ago since they had had their last occupation. Moreover, incapacity for work was more prevalent among persons with primary school, lower vocational school or junior high school as highest level of education. However it is not clear whether incapacity for work is associated with a higher risk for cancer or not. We did not have information on income, which is one of the three recommended SES indicators. ${ }^{17}$ However, on an international scale income differences in the Netherlands are relatively small. ${ }^{18}$ Notwithstanding, substantial differences in living conditions exist. The frequency of car tenure, having adequate housing and having regular holidays is higher in the higher SES groups. ${ }^{19}$ It has been shown that both housing tenure and car access are associated with cancer risk. ${ }^{20}$ Nevertheless, these two measures of socioeconomic status order risks for different cancer sites similarly to an occupation-based SES indicator or a SES indicator based on education. ${ }^{20}$ 
The categorization of level of education in our study is comparable with that in other studies. The EGP score was categorized into blue collar workers, lower white collar workers, upper white collar workers and others. There are more ways of categorizing this EGP score. Another possibility is distinguishing blue collar workers into unskilled or semi-skilled blue collar workers and skilled blue collar workers. We have also conducted: the analyses on SES and lung cancer using this latter categorization, with hardly any differences in results. There are no straight rules for categorizing the U\&S score either. At the beginning of our study we found only one study in the Netherlands with information about U\&S score, ${ }^{21}$ and we have used the same categorization. There are no indications that a different categorization could result in a better description of the association between U\&S score and cancer risk.

Finally, we found different associations between SES and cancer risk depending on the type of SES indicator. Because most studies on SES and cancer risk did not use information on social standing, we could not compare our findings concerning U\&S score with results from other studies. Also in the Netherlands, there is only limited information about the use of U\&S score in research on socioeconomic health differences. The U\&S score is more often used in research on social stratification and mobility. When studying associations between EGP score and U\&S score a correlation of 0.84 was reported ${ }^{22}$ indicating that there is a fairly high concordance. There are some differences between the U\&S categorization and the EGP categorization (for example salesmen and building contractors have a relatively low score for social standing while salesmen, hodmen and garbage collectors have a relatively high rank in the EGP categorization). However, these differences are too small to explain the differences in associations between cancer risk and EGP score or U\&S score. Moreover, in our categorization these occupations are all categorized as blue collar occupations and the corresponding U\&S score is also within the same U\&S category. In other studies in affluent countries the discrepancies between the results based on education and occupation are less prominent.

Regarding the operationalization of SES $\mathrm{s}_{\mathrm{i}}$ we can conclude that we used appropriate SES indicators, with a suitable categorization. Nevertheless, it would be interesting to include employment status in studying the association between SES and cancer risk . Since different SES indicators show different associations with cancer risk, it is advisable to use several SES indicators in research on socioeconomic health differences.

\subsection{Association between SES and lifestyle or working conditions}

We considered lifestyle factors (smoking habits, dietary habits, alcohol intake) and working conditions (physical activity at work, exposure to carcinogens) as intermediate factors in the association between SES and cancer risk. Adjustment for these lifestyle factors or working conditions did not substantially change the association between SES and cancer. A possible explanation for this finding is the fact that in the study population there was no strong association between socioeconomic status and most of the prominent lifestyle characteristics or working conditions which are related to cancer. To find out whether this relative lack of association was specific for our study population, we have considered the association between SES and lifestyle factors and working conditions in the Netherlands and in other affluent countries. 
In the Netherlands, there was a positive association between SES and smoking status in men untill 1960, which changed into an inverse association after 1960. As a result of these trends, the percentage of Dutch men who never smoked is comparable within the SES categories, whereas the percentage of former smokers is higher within the highest SES categories. Both current smoking habits as well as smoking habits in the past are associated with lung cancer ris $k_{*}{ }^{24,25}$ and there is an interval of several decades between the change in smoking habits in a population and its consequences on lung cancer rates. ${ }^{25}$ In the sixties the prevalence of smoking was not substantially different within the SES categories. Therefore, differences in smoking habits in the distant past will not explain the higher lung cancer risk between the lower SES groups. However; in our study, differences in current smoking habits between SES categories or differences in smoking habits in the recent past neither explained differences in lung cancer risk.

Regarding dietary habits there are only small differences in dietary intake between the SES groups in the Netherlands. In a national food consumption survey conducted in 1987-1988 the intake of fruit and vegetables was found to be somewhat higher among people with a higher level of education. ${ }^{26}$ Moreover, the intake of fat was higher among people within the lowest SES categories, but the composition of the consumed fats was more favorable in the lowest SES categories. ${ }^{28}$

Although we found a positive association between mean individual alcohol intake and SES for both men and women in the NLCS, in the general population in the Netherlands a positive association is only observed in women. ${ }^{27}$ However, because alcohol consumption has shown to be hardly related to colon cancer in our data set, $^{28}$ the positive association between SES and colon cancer may not be explained by alcohol intake.

Furthermore, there is no clear association between physical activity and SES. Physical activity during leisure time is less usual among people within the lower SES categories, but physical activity during work is more prevalent within these SES groups. ${ }^{20}$

Working conditions like physical load and exposure to noise, dirt and dangerous circumstances are generally much less favourable in lower SES groups. ${ }^{18,30}$ Therefore, working conditions may also explain differences in cancer risk within SES categorles. However, within the NLCS no clear association between SES and probable exposure to carcinogens was observed, resulting in only minor changes in lung cancer risk before and after additional adjustment for probable exposure to carcinogens.

Regarding information about the association between lifestyle factors, working conditions and SES indicators in other affluent countries the largest amount of information is availlable on the association between SES and smoking habits. In Western European countries and in the USA the percentage of current smokers is lower within the higher SES categories. ${ }^{3+3 e}$ However, only part of these data were specifically tailored to the middleaged. Since the association between SES and smoking habits differs among the age cattegories, this reduces the comparability of the findings. Moreover, in one study where smoking prevalence rates were presented for different age-categories, the category nonsmokers consisted of people who had never smoked and former smokers. ${ }^{33}$ Since the main differences in smoking habits between SES categories concern in particular the percentage of ex-smokers, at least in the Netherlands, this also reduces the comparability. However, 
those studies that provide information about the association between SES and smoking habits within relevant age categories indicate that also among the elderly the percentage of persons who never smoked was lower within the lower SES categories, ${ }^{39-42}$ although these differences were smaller for the older age categories compared with the younger age groups. ${ }^{40,41}$ Among male current smokers the prevalence of 'heavy smoking' was not substantially different among the SES groups. ${ }^{32,34,41}$ In summary, although the information on SES and smoking habits is not exactly comparable between different countries, the lack of association between SES and smoking habits in the distant past in the Netherlands does not seem to be completely the same as the association found in other affluent countries. However, in most countries differences in smoking status are less clear among the elderly compared with differences in smoking status among other age categories. Moreover, the quantity of cigarettes smoked does not differ considerably between the SES groups.

Several reports have been published on the association between SES and dietary habits, like eating wholegrain bread, a low fat diet, fresh fruits, salads, fried foods or sweets. Although higher social status was generally associated with healthier dietary habits, the differences between the SES categaries were considered to be small compared with the relatively low degree of compliance of all social groups with dietary guidelines. ${ }^{43,44}$ These results are broadly comparable with the Dutch situation. Also in England, Wales and Scotland an inverse association was found between social class and unhealthy diets. ${ }^{33,45}$ Besides, the dietary intake of several vitamins and minerals was reported to be lower among manual workers. ${ }^{34}$ However $_{\text {in }}$ in these studies no comparison was made with dietary guidelines.

No consistent association has been found between SES and alcohol intake. In the UK the association between SES and alcohol intake differed between geographical areas..$^{33}$ Moreover, in two studies different associations between SES and alcohol intake were reported for women..$^{33,45}$ In a study about alcohol consumption patterns in Sweden, only small differences were reported in mean alcohol consumption and the prevalence of high consumers between various SES categories, although for the elderly the mean alcohol consumption was higher among non-manual employees and men with a higher level of education. ${ }^{46}$ The results concerning the elderly in Sweden are comparable with the findings in the NLCS, whereas the other findings, based on broader age-categories, are comparable with the situation in the general population in the Netherlands.

Moderate or vigorous exercise during leisure time was much more likely to be undertaken among people with higher educational qualifications and among those in non-manual occupations ${ }^{33,38}$ and less common among subjects with lower status jobs. ${ }^{45}$ However, physical activity at work is more common among men in manual occupations compared with non-manual occupations. ${ }^{38}$ These findings are also comparable with the Dutch situation. 28

Regarding working conditions, blue collar workers, such as those in the metal industry, asbestos insulators and dye mamufacturers are primarily exposed to occupational carcinogens, although high cancer mortality has also been observed in many non-manual occupations ${ }^{47}$ Exposure to chemicals, dust and noise are also found most among manual workers ${ }_{i}$ who have a relatively low SES. 
We can conclude that associations between SES and lifestyle factors found in the NLCS are not specific for our study population, since these associations are also found among the middle-aged in the general population in the Netherlands and in other affluent countries (apart from alcohol intake). There is a consistent inverse association found between SES and physical activity at work. However, cancer risk is also inversely associated with physical activity at leisure time ${ }^{40,50}$ which is positively associated with SES. ${ }^{29}$ Finally, unhealthy working conditions are more prevalent among the lower SES categories, but they are not restricted to the lower SES category.

\subsection{Residual confounding or residual association}

Another explanation for our findings could be residual confounding or maybe it is more appropriately named 'residual association' when intermediate factors are considered instead of confounders. One aspect of this phenomenon is the possibility that relevant lifestyle variables or working conditions are not accurately measured and therefore, adjustment for these factors does not fully explain the total association between SES and cancer risk.

The validity of self-reported information on current smoking habits can be checked with the measurement of cotinine levels in serum. Studies in different populations showed that the prevalence of self-reported smoking was somewhat lower compared with the prevalence of smoking when defined with cotinine level. The misclassification rate of smokers as non-smokers varied between $2 \%$ and $6 \% \cdot{ }^{51.53}$ One study among young adults aged 18 to 30 years in the United States reported that the misclassification rate was significantly higher among people with a high school education or less. ${ }^{52}$ However, another study among middle-aged persons aged 55 to 74 years in Denmark reported no difference in misclassification rate among the different socioeconomic groups. ${ }^{51}$ The latter study investigated not only the misclassification rate of smokers as non-smokers, but other tobacco habits were also studied between SES categories. Their results showed that the proportion of cigarette smokers was significantly higher in low social class, but among smokers the self-reported amount smoked was quite similar between social classes and the serum cotinine levels were also similar between social classes. Differences in the accuracy of the information on smoking habits among SES groups would lead to different associations between smoking habits and lung cancer risk between the different SES groups. Therefore, we have studled the interaction between SES and smoking habits regarding lung cancer risk. Neither for level of education, nor for the two occupation-based SES indicators the interaction with smoking status was statistically significant, indicating that the association between smoking status and lung cancer risk does not substantially differ between SES groups.

We have used a semi-quantitative food frequency questionnaire to measure the dietary habits of the past year. Information obtained with this questionnaire is validated against a nine-day dietary record among 109 subjects. ${ }^{.4}$ The concordance between the questionnaire and the dietary record was expressed by means of correlation coefficients. For the mean daily energy and nutrient intake the coefficients varied between 0.40 for vitamin $B 1$ to 0.86 for alcohol, with a median of 0.69 . The agreement of a classification in quintiles was also compared, with the conclusion that the questionnaire is able to rank subjects adequately 
according to the intake of food groups and nutrients investigated..$^{54}$ In one study on misclassification of dietary intake among SES groups, the authors reported that people with less education were more likely to give implausible dietary information. ${ }^{53}$ However, this finding has not yet been replicated.

Regarding alcohol intake the main sources of errors are forgetfulness, differences in consumption unit and consumption at public holidays ${ }^{5 \theta}$ There are no studies available where misclassification of alcohol intake is investigated within different SES categories (RA Knibbe, personal communication).

Assessment of physical activity at work was based on job title. Since large variations in physical activity occur within one job, this can also lead to residual confounding. There was no external instrument based on the Dutch situation to validate our scoring system.

Nevertheless, the age-adjusted association between our classification of physical activity at work and colon cancer risk (not presented) is comparable with results found in other studies.

We used all the available information about job history to assess the probability of exposure to established carcinogens, which is not the same as actual exposure. However, associations between occupational exposure and lung cancer risk observed in the NLCS were comparable with findings from other studies, indicating that the exposure assessment reflects the actual exposure to carcinogens to a reasonable extent.

Another aspect of residual confounding or residual association consists of the possibility thal known or unknown confounders or intermediate factors have not been included in the analysis. Regarding lung cancer risk, we operationalized smoking habits by means of smoking status (never/ex/current), pack-years of cigarette smoking and age of starting smoking. However, other characteristics such as specific brands, the part of the cigarette which is usually smoked and whether or not one inhales smoke may influence the association between SES and lung cancer. Besides, exposure to air pollution may explain part of the association between SES and cancer risk. ${ }^{57}$ For stomach cancer, helicobacter pylori infection may be an intermediate between SES and cancer risk. ${ }^{58,59}$ Considering colon cancer risk and breast cancer risk, there may be unknown risk factors which are both associated with SES and cancer risk. Obviously, this applies also for lung cancer and stomach cancer.

We can conclude that residual association or residual confounding may still exist, although in the NLCS most associations between the considered confounders or intermediate factors and cancer risk are in concordance with results reported in other studies. Still, unknown risk factors both related to SES and cancer risk may be responsible for the fact that we cannot explain the associations between SES and cancer risk.

\subsection{Conclusions}

In the NLCS, for men, cancer risk appears to be associated with socioeconomic status. The direction of the association differs between tumour sites. These results are comparable with findings in other affluent countries. There was no association found between SES and 
cancer risk for women. This observation is not in accordance with findings in other countries, which might be due to the exceptionally low participation of women of this age group in the labour force. Until now, possible explanations for the association between SES and cancer had seldom been investigated, although assumptions were often made about the role of lifestyle characteristics like smoking habits, dietary habits or alcohol intake. However, in our study the role of these lifestyle aspects turned out to be less prominent in explaining the association between SES and cancer risk. This lack of explanation might be partly due to a lack of association between SES and several lifestyle factors and it might be partly diue to a lack of association between some lifestyle factors and cancer risk. Also working conditions such as exposure to carcinogens could not explain the association between SES and cancer, although physical activity at work did influence the association between SES and colon cancer risk. Furthermore, although relevant lifestyle factors, working conditions and potential confounders were carefully measured and controlled for in the multivariate analyses, residual confounding or residual association could still have existed. Consequently, it seems that we still do not know all the risk factors for cancer which are associated with SES. Furthermore it may be possible that we still cannot measure these risk factors for cancer adequately. Therefore, SES can still be considered as a proxy for unknown or inadequately measured risk factors for cancer.

\subsection{Implications for further research}

There are some methodological shortcomings in our study which may be prevented in future studies on explaining the association between SES and cancer risk. Further research on SES and cancer risk should pay special attention to the measurement of SES among women. For middle-aged women, especially in the Netherlands, the last occupation gives no indication of their SES. Therefore, it seems necessary not only to collect information for each individual, but also for other adult household members. Moreover, more attention should be paid to other covariates such as different aspects of smoking habits and the prevalence of helicobacter pylori infection. Furthermore, it will be interesting to study the association between SES and cancer and the role of lifestyle factors in explaining this association in a study population, whith a more prominent association between SES and lifestyle factors. Besides, in the USA and other European countries also other cancer sites appear to be associated with SES (for instance esophageal cancer, liver cancer and cervical cancer). It will be interesting to investigate whether these associations also exist in the Netherlands and whether it is possible to find an explanation for these associations.

Further research can also consider clustering of risk factors associated with cancer instead of studying separate lifestyle characteristics or working conditions. Clustering is a phenomenon in which a combination of several risk factors occur more often than one would expect on the basis of probability. ${ }^{6 z}$ Because the presence of more risk factors at the same time may have a greater effect on cancer risk than the presence of a single risk factor, it can be relevant to study the combination of risk factors by means of cluster analyses. This is especially relevant for nutrition-related factors, since it is not the presence or absence of separate food items but the appropriate selection (proper amount and combination) of foods that may be important to health..$^{83}$ Moreover, results from other studies indicate that clustering of lifestyle factors associated with disease (smoking habits, alcohol intake, physical inactivity and unhealthy dietary habits) is more often found among people with a low SES compared with people with a high SES, ${ }^{62-63}$ although in one study 
clustering is restricted to smoking habits and alcohol intake. We could not find information about clustering of lifestyle factors and working conditions.

Besides methodological aspects and further extension to other populations or other cancer sites, other possible explanations for the association between SES and cancer could also be investigated. We started from the assumption that SES is not a direct risk factor for cancer. In our study the hypothesis was tested that lifestyle aspects and working conditions are intermediate factors in the association between SES and cancer. This corresponds with the materialist explanation and/or the cultural explanation, where social class differences in cancer risk are linked to aspects of living and/or differences in lifestyle associated with SES. Nevertheless, there are more possible explanations for an association between SES and cancer.

One of the possible explanations for the association between SES and cancer risk consists of genetic differences within SES categories. This explanation refers to the suggestion that there might be an increased predisposition to cancer related with a lower socioeconomic position. However, against this hypothesis stands the heterogeneity in the associations of socioeconomic conditions and specific cancer sites. ${ }^{66}$ We included family risk for cancer in our analyses as a proxy for genetic differences, which did not explain the association between SES and cancer.

Access to medical care could also be an explanation for differences in cancer risk between SES categorles. Since there are no large differences in access to medical care between SES categories in the Netherlands, ${ }^{67}$ it is not likely that detection bias could influence the results. In addition, at the start of the NLCS, breast cancer screening was not widespread and mass-screening for lung, colon and stomach cancer is not practiced in the Netherlands. Moreover, regarding breast cancer, we have examined the association between tumour stage at time of diagnosis and the different SES indicators and we did not find a clear association with SES.

Differences in living conditions during childhood may be related to the prevalence of certain diseases (e.g. chronic obstructive pulmonary disease, helicobacter pylori infection) or circumstances (for instance dietary intake), which are related to cancer risk (in these examples lung-; stomach- and breast cancer). On the other hand, living conditions during child dhood will be related to the parent's SES and with the SES in adulthood. However, it is often difficult to get information about living conditions during childhood. Another possibility is to collect information on the diseases probably associated with these living conditions and use this information as a proxy for living conditions. In our analyses regarding lung cancer we have adjusted for the prevalence of chronic obstructive pulmonary disease. This did not influence the results.

Finally, psychosocial factors could play a role in the explanation of SES differences in cancer incidence. Psychosocial factors refer both to internal characteristics like personality and attitude as well as external non-physical factors that affect internal characteristics like stressful life events and social support. ${ }^{65}$ Psychosocial factors may affect cancer risk by changing behavior resulting in an increase or decrease in exposure to carcinogens (for instance smoking behavior) and by means of humoral or cellular effects without the intervention of an external carcinogenic. ${ }^{67}$ In this part of the discussion we will focus on the 
latter. There are three major mechanisms by which psychosocial factors may be related to cancer: ${ }^{68}$

1. Influence on factors that lead to cancer (hormonal factors, chromosomal breaks, gene translocations);

2. Influence on factors that protect against carcinogenesis (enzymatic detoxification, DNA repail system, immune system);

3. Influence on nervous system elements interacting with the immune system (for example peptides such as the endorphins).

A wide variety of psychosocial factors have been examined as risk factors for cancer. The most extensivelly studied factors are stress, bereavement, psychosis (especially schizophrenia), depressed mood, suppression of emotion (especially anger), helplessness and hopelessness (as coping mechanisms) and sociall support. ${ }^{66}$ In several articles discussing studies on the association between psychosocial factors and cancer risk different conclusions were drawn. While Fox ${ }^{66,67}$ and Tomatis ${ }^{47}$ conclude that no firm position can be taken in regard to an association between any psychosocial factor and cancer incidence or mortality, Kune ${ }^{69}$ reports an association between stressfull life events and gastric cancer, breast cancer, lung cancer and colorectal cancer. Temoshok and Heller $^{70}$ conclude that even with all the structural differences in design, subjects, type, site and stage of cancer, construct and measurement of psychosocial factors, associations are found between cancer risk and the ability of expressing emotions, personal traits (for example niceness, perfectionism, sociability, defensiveness) and dealing with stressful life events.

At least part of these differences in conclusions seems to be due to the treatment of methodological shortcomings in the reviewed studies. In some studies, patients suffering from other diseases than cancer are used as control group. Since associations have been found between psychosocial factors and, for instance, cardiovascular diseases, ${ }^{71}$ the use of unhealthy controls will influence the results. ${ }^{72}$ In addition, in various studies all different cancer sites are lumped together. Since cancer sites vary considerably with regard to etiology and incidence, this may be another reason for the lack of coherence in results on the association between psychosocial factors and cancer risk. ${ }^{70}$ Finally, the older studies on psychosocial factors and cancer risk were very often correlation studies or case-controll studies. These study designs are subject to recall bias. ${ }^{60,69}$ A patient's psychological state and recall of earlier events could well be influenced by the diagnosis of cancer or by the disease itself. ${ }^{47,66}$ Although Temoshok and Heller ${ }^{70}$ argue that evidence from prospective and retrospective studies converges for the most part, other authors have restricted their conciusions mainly to prospective studies. ${ }^{47,68,66}$ Besides, these reviews are not based on the same studies on psychosocial factors and cancer risk, while it is not clear which criteria are used in selecting research papers. Therefore, it is not clear whether psychosocial factors influence cancer risk. Maybe well designed prospective studies will shed more light on this issue.

Psychosocial factors can only explain differences in cancer risk between SES categorles if there is an association between socioeconomic status and psychosocial factors. This association is investigated in the Longitudinal Study on Socio-Economic Health Differences, ${ }^{73}$ conducted in the southern part of the Netherlands. In this study distinction was made between psychosocial stressors (life events, chronic stress) and stress 
moderators (coping, social support, locus of control). The results indicate that there are no clear associations between SES (based on education) and psychosocial stressors, but unfavourable scores on most of the stress moderators (coping mechanisms, neuroticism, locus of control) were more often reported among respondents with lower levels of education. According to the authors these findings are consistent with results from other studies on SES and psychosocial factors.

So far, we can conclude that it is not clear if there is an association between psychosocial factors and cancer risk. However, there are associations found between SES and psychosocial factors. Therefore, further research on explaining the association between SES and cancer risk may also consider the role of psychosocial factors.

\section{REFERENCES}

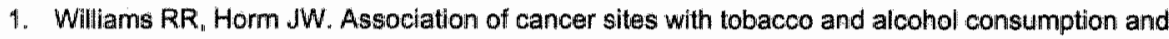
socioeconomic status of patients: interview study from the third national cancer survey. J Nati Cancer inst $1977 \cdot 58: 525-547$

2. Hein $\mathrm{HO}_{\mathrm{B}}$ Suadicani $\mathrm{P}_{\mathrm{H}}$ Gyntelberg $\mathrm{F}$. Lung cancer risk and social class. The Copenhagen male study 17-year follow-up. Dan Med Bull 1992,39:173-176.

3. Dawey Smith $G$, Lean $D$, Shipley MJ, Rose $G$. Socioeconomic differentials in cancer among men. Int $J$ Epidemiol 1991;20:339-345.

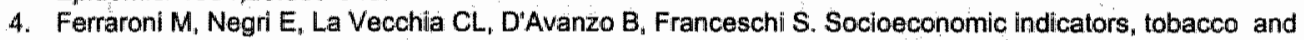
alcohol in the aetiology of digestive tract neoplasms. Int J Epidemiol 1989;18:556-562.

5. Dockerty JD, Marsthall $S_{k}$ Fraser J, Pearce N. Stomach cancer in New Zealand: time trends, ethnic group differences and a cancer registry-based case-control study. Int J Epidemiol 1991;20:45-53.

6 Hansson LE, Baron J, Nyren O, Bergiström R, Wolk A, Adami H-O. Tobacco, alcohol and the risk of gastric cancer. A population-based case-control study in Sweden. Int J Cancer 1994;57:26-31.

7. Centraal Bureau voor de Statistiek. Arbeldskrachtentelling 1985. Den Harag: Staatsuitgeverij; 1987.

8. Kunst AE, Mackenbach. JP. The size of mortality differences associated with educational level in nine industrialized countries. Am J Public Health 1994;84:932-937.

9. Kunst AE, Mackenbach JP. International variation in the size of mortality differences associlated with occupational status. Int $J$ Epidemiol 1994;23:742-750.

10. Hooghiemetra Bil Niphulis.Nell M. Sociale atlas van de wrouw. Deel 2. Arbeid, inkomen en faciliterten om werken en zomg voor kindoren te combineren. Den Hagi: VUGA, 1993.

11. Krieger $N$. Women and social class: a methodological study comparing individual, houselhold, and census measures as predictors of black/white differences in reproductive history. J Epidemial Community Health $1991: 45: 35-42$.

12. Haug MR. Social class measurement and women's occupational roles. Social Forces 1973;52:86-98.

13. Van der Lippe T, Van Doorne-Huiskens. Veranderingen in stratficatie tussen mannen en vrouwen? In: Dronkers J, Ultee WC (Red). Werschuivende ongelijkheid in Nederiand. Sociale gelaagdheild em mobiliteit. Assen: Vart Gorcum, 1995.

14. Zurayk H. Halabi S, Deeb M. Measures of soclal class based on education for use in health studies in deweloping countries. J Epidemiol Community Health 1987,41:173-179.

15. Faia MA. Selection by certification: a neglected variable in stratification research. Am $J$ Sociol $1981 ; 86$ : $1093-11111$.

16. Klein-Hesselink $J$, Spruit IP. The contribution of unemployment to socioeconomic health differences. Int $J$ Epidomiol $1992,21: 329,337$.

17. Van Berkel-Van Schaik AB, Tax B. Naar een standaendoperationalisatie van sociaal-economische status voor epidemiologisch en sodaal-medisch onderzoek. Sociaal-economische gezondheidsverschillen nr. 6 . Den Haag: DOP. 1990.

18. Mackembach JP. Sacio-economic health differences th the Netherlands: a review of recent empirical findings. Soc Sci Mad 1992;34:213-226.

19. Centraal Bureau voor de Statistiek. De feefsituatie van de nedertandse bevolking 1983, kemcijfers. Den Haag: Staatsuitgeveri], 1984 
20. Leon DA. Longitudinal study. Socjal distribution of cancer, 1971-1975 (OPCS Series LS No. 3). London: $\mathrm{HMSO}_{11} 1988$.

21. Thijssen LJM. Sociale stratificatie onder ouderen. Soe Cult Kwartber 1986;8:110-27.

22. Bakker BFM, Blees-Booij A. Verklaren twee meer dan een? In: Dronkers J, Ultee WC (Red). Verschurvende ongelijkheid in Nederland. Socialo gelaagdheild en mobiliteit Assen: Van Gorcum, 1995.

23. Van Reek J. Rookgedrag in Nederland van 1958-1982. Tijdschr Alc Drugs * 983:9:95-103.

24. Engelland $A$, Haldorsen $T$, Andersen $A$, Tretli $S$. The impact of smoking habits on lung cancer risk: 28 years observation of 26,000 Norwegian men and women. Cancer Causes Control, 1996;7:366-376.

25. Boyle P. Maisonneuve P. Lung cancer and tobacco smoking. Review article. Lung Cancer 1995:12: 167-181.

26. Hulshof KFAM, Löwik MRH, Kok FJ, Wedel M, Kistemaker C, Brants HAM. Invloed van sociaal-economische status op voeding en andere levensstijffectoren (Voedselconsumptiepeiling 1987 1988). In: Mackenbach JP (ed). Saciaal-economische gezondheidsverschilen onderzocht. Deellill. Den Haag: DOP, 1991.

27. Knibbe RA, Swinkels $\mathrm{H}$. Alcoholgebruik in Nederland; een analyse van gegevens uit de CBS gezondheidsenquete 1989. Tijdschr Alc Drugs 1992;18:124-138.

28. Goldbohm RA, Van den Brandt PA, Van 't Veer $P$, Dorant $E_{1}$ Sturmans $F$, Hermus RJJ. Prospective study on alcohol consumption and the risk of cancer of the colon and rectum in the Netherlands. Cancer Causes Control 1994; $5: 95-104$

29. Hoeymans $\mathrm{N}_{n}$ Smit $\mathrm{HA}_{\mathrm{n}}$ Verkleij $\mathrm{H}_{1}$ Kromhout $\mathrm{D}$. Sociaal-economische status, lewensstijffaktoren, biologische risicofactoren en hart- en vaatziekten. Bilthoven: RIVM, 1993.

30. Schröer CAP, Bullinga RS. Gezondheidswerschillen tussen sociaal-economische statusgroepen: effect van verschillen in leefwijze of arbeidsbellasting? In: Mackenbach JP (ed). Sociaal-economische gezondheidsverschillen anderzocht. Deel III. Den Haag: DOP, 1991.

31. Berrino $F$, Merletti $F$, Zubiri $A$, et al. A comparative study of smoking, drinking and dietary habits in population samples in France, ${ }_{n}$ taly, Spain and Switzerland. II Tobacco smoking. Rev Epidem et Santé Publ 1988:36:166-176.

32. Covey LS, Zang EA, Wynder EL. Cigaretle smoking and occupational status: 1977 to 1990. Am J Public Health 1992;82:1230-1234.

33. Biaxter M. Health and lifestyles. London / Niew Yark: Tavistock / Routledge, 1990

34. Fehily AM, Philips KM, Yarnell JWG. Diet, smoking, social class and body mass index in the Caerphilly Heart Disease Study. Am J Clin Nutr 1984:40:827-833.

35. Umberson D Gender, marital status and the social control of behavior. Soc Sci Med 1992;34:907-917

36. Weinkam $\mathrm{J} \mathrm{J}_{\mathrm{i}}$ Sterling TD. Changes in smoking characteristics by type of employment from 1970 to 1979/80. Am I Ind Med 1987;11:539-561.

37. Winkleby MA, Jatullis DE, Frank $E_{n}$ Fortmann SP. Socioeconomic status and health: How education, income and occupation contribute to risk factors for cardiovascular disease. Am J Public Health 1992; 82:816-820.

38. Woodward M, Shewry MC, Smith WCS, Tunstall-Padoe H. Social status and coronary heart diseast: Results from the Scottish Heart Health Study. Prow Med 1992;21:136-148.

39. Davey Smith $G$, Shipley MJ, Rose G. Magnitude and causes of socioeconomic differentialls in mortality: Further evidence from the Whitehall Study. J Epidemiol Community Health 1990;44:265-270.

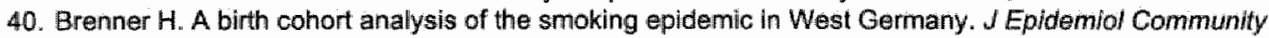
Health 1993;47:54-58.

41. Wynder EL, Covey LS, Mabuchi K. Current smoking habits by selected background variables: their effect on future disease trends. Am J Epidemiol 1974:100:168-177.

42. Winkleby MA, Fortmann SP. Barrett DC. Social class disparities in risk factors for disease: eight-year prevalence patterns by level of education. Prev Med 1990;19:1-12.

43. Baghurst KI, Record SJ, Baghurst PA, Syrette JA, Crawford D, Worsley A. Sociodemographic determinants in Australia of the intake of food and nutrients implicated in cancer aetiology. Med $J$ Australia 1990;153:444-452.

44. Smith AM, Baghurst KI. Public health implications of dietary differences between social status and occupational category groups. J Epidemiol Community Health 1992;46:409-416.

45. Marmot MG, Davey Smith $G$. Stansfeld $S$, et al. Health inequalities among British civil servants: the Whitehall II Study. Lancet 1991,337:1387-1393.

46. Romelsjö $\mathrm{A}$, Leifman $\mathrm{H}_{n}$ Nyström S. A comparative study of two methods for the measurement of alcohol consumption in the general population. Int I Epidemiol 1989;24:929-936.

47. Tomatis $L$ (ed). Cancer: causes, accurence and control. IARC scientific publications. Lyon: IARC, 1990.

48. Blane D. An assessment of the Black report's explanations of health inequalities. Soc Health Iliness 1985: $7: 423-445$. 
49. Longneicker MP, Gertiardssson de Verdler $M_{3}$ Frumkin $H_{1}$ Carpenter $C$. A case-control study of physical activity in relation to risk of cancer of the right colon and rectum in men. Int $J$ Epidemiol 1995;24:42-50.

50. Giovannucd E, Ascherio A, Rimm EB, Colditz GA, Stampler MJ, Willett WC. Physical activity, obesity and risk for colan cancer and adenoma in men. Ann Intem Med 1995;122:327-334.

51. Suadican $P$, Hein $\mathrm{HO}$, Gyntelberg $F$. Serum validated tobacco use and social inequalities in risk of ischaemic heart disease. Int J Epidemiol 1994;23:293-300.

52. Wagenknecht LE, Burke GL, Perkins LL, Haley NJ, Friedman GD. Misclassification of smoking status in the CARDIA study: a comparison of self-report with serum cotinine levells. Am J Public Health 1992; 82: $33-36$.

53. Pérez-Stable Ed, Marin G, Marin BV, Benowitz NL. Misclassification of smoking status by self-reported cigarette consumption. Am Rev Respir Dis 1992;145:53-57.

54. Goldbohm RA, Van den Brandt PA, Brants HAM, et al. Validation of a dietary questionnaire used in a large-scale prospective cohort studly on diet and cancer. Eur J Clin Nutr 1994;48:253-65.

55. Klesges RC, Eck LH, Ray JW: Who underreports dietary intake in a dietary recall? Evidence from the second national health and nutrition examination survey. I Consulting Clinical Res 1995;63:438-444.

56. Lemmens PHHM. Het Ledermann-model nader bezien. Gevolgen van onderschatting voor de verdeling van alcoholconsumptie. Maastricht, RU Limburg, Medische Sacliblogie, 1987.

57. Hemminkil $K_{4}$ Pershagen $G$. Cancer risk of air pollution: epidemiological evidence. Environ Health Perspect 1994;102(suppl:4):187-192.

58. Forman D, Newell DG, Fullerton F, Yarnell JWG, Stacey AR, Wald N, Sitas F. Association between infection with helicobacter pylori and risk of gastric cancer: evidence from a prospective investigation. $\mathrm{Br}$ Med J1991;302:1301-1305.

59. Parsonnet J. Helicobacter pylori and gastric cancer. Gastrcenterol Clin North Am 1993;22:89-105.

60. Kok FJ, Matroos AW, Van der Ban AW, Hautvast JGAJ. Characteristics of individuals with multiple behavioral risk factors for coronary heart disease: the Netherlands. Am J Public Health 1982;72:986-991.

61. Hulshof KFAM, Wedel M, Lowik MRH, et al. Clustering of dietary variables and other lifestyle factors. (Dutch Nutritionall Survellance System). J Epidemiol Community Health 1992,46:417-424.

62. Van Loon AJM. Leefstijl en gezondheld. Resultaten van regionale gezondheildsenquetes vergeleken. Wageningen: LUW, Humanie Epidemiologie en Gezondheidsleer, 1992.

63. Patterson RE, Haines PS, Popkin BM. Health lifestyle patterns of U.S. adults. Prew Med 1994;23:453-460.

64. Tomatis L. Poverty and cancer. Editorial. Cancer Epldemiol Biomarkers Prevention 1992;1:167-175.

65. Mackenbach JP. Ongezonde verschillen. Over stratificatie en gezondheid in Nederland. Assen: Van Gorcum, 1994.

66. Fox BH. The psychological epidemiology of cancer incidence and prognosis. Chronic Diseases in Canada $1995 ; 16:$ s19-s27.

67. Fox BH. Premorbid psychological factors as related to cancer incidence. J Behavioral Med 1978;1: 45-133.

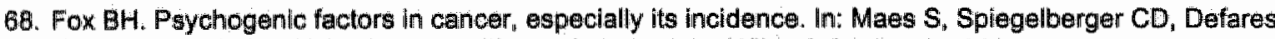
PB, Sarasen IG (eds): Topics in health psychology. John Wiley \& Sons Lid. 1988.

69. Kune S. Stressfull life events and cancer. Epidemiology 1993;4:395-397.

70. Tomoshok $\mathrm{L}$, Helier BW. On comparing apples, oranges and frult salad: a methodological overview of medicall autcome studies in psychosocial oncology. In: Cooper $\mathrm{CL}$ (ed). Psychosocial stress and cancer. John Wiley \& Sons Ltd. 1984.

71. Ranchor AV. Social class, psychosocial factors and disease. From description towards explanantion. (thesis): Groningen, 1994.

72. Timms MWH. Psychology and cancer: an historical review of pre-morbid factors with special reference to breast cancer. Irish J Psychology 1989;10;411-425.

73. Sivera van der Sluijs IJ Van de Mheen H. Stronks K, Mackenbach JP. Blootstelling aam en amgang met psychosociale stressoren: sociaal-economische verschillen. Tijalschr Sac Gezondheidsz 1996;74:71-77. 


\section{SUMMARY}

In this thesis the association between sociaeconomic status (SES) and the risk of cancer of the lung, breast, colon and stomach in the Netherlands is analyzed. Furthermore the role of lifestyle and working conditions in explaining this association is investigated in the Netherlands Cohort Study (NLCS) on diet and cancer. This prospective study started in 1986 among 120,852 subjects aged $55-69$ years at the beginning of the study. SES is operationalized by means of occupation and highest attained level of education. Information about occupational history is scored according to a job coding system of the Central Bureau of Statistics which is frequently used in the Netherlands. Furthermore, these codes are aggregated according to occupational sector and required training (EGP score) and social standing (U\&S score). Follow-up for incident cancer has been established by record linkage with all regional cancer registries in the Netherlands and with a national pathology register. For the first analyses data after 3.3 years of follow-up were used. For latter analyses data after 4.3 years of follow-up were available.

In chapter 2 the literature on SES and cancer risk at different sites is reviewed. In this review only studies conducted since 1970 in affluent countries are included, using education, occupation and/or income as SES indicators. Regarding the four tumour sites explicitly studied in this thesis, consistent positive associations between the three SES indicators and breast cancer risk were reported, and more or less consistent positive associations with SES were reported for colon cancer. Consistent inverse associations between SES and cancer risk were found for lung and stomach cancer. Based on this review it was still unclear whether the reported associations could be (partially) attributed to lifestyle-related risk factors such as smoking, dietary habits and alcohol intake, since in most studies little or no attention was given to the adjustment for lifestyle variables.

The results regarding SES and cancer of lung, breast, colon and stomach are described in chapters 3 to 6 . The role of lifestyle factors in explaining possible associations is also described in these chapters. We found an inverse association between /ung cancer risk and highest level of education for men. This asscciation persisted after adjustment for age,

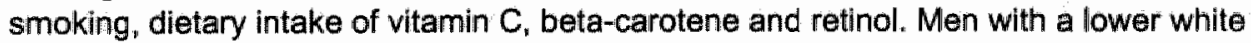
collar profession (for instance clerical workers) had a significantly lower relative rate of lung cancer compared with blue collar workers (for example factory workers) "but after adjustment for smoking habits this difference was reduced (Chapter 3). No association was found between U\&S score and lung cancer risk for men, and we found no associations between the SES indicators and lung cancer risk for women. Neither did we find an ageadjusted association between SES and breast cancer risk. Additional adjustment for traditional risk factors for breast cancer, such as age at first birth, parity, age at menarche and others, did not alter the association between SES and breast cancer risk (Chapter 4). A positive association was found between colon cancer risk and highest level of education or U\&S score for men. Also, male upper white collar workers (for example lawyers, doctors) had a higher colon cancer risk compared with blue collar workers. Only the association between U\&S score and colon cancer risk remained statistically significant after additional adjustment for other risk factors for colon cancer. In women, there were no clear associations found between SES and colon cancer risk (Chapter 5 ). Regarding stomach cancer, we found a lower age-adjusted risk for men with the highest attained level of 
education. This association became less strong after additional adjustment for smoking,

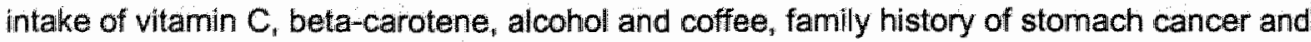
history of stomach disorders. No clear association was found between the occupationbased SES indicators and stomach cancer risk (Chapter 6). No association was found between SES and stomach cancer risk in women.

In chapter 7 the association between lung cancer risk and exposure to fairly common, established carcinogenic occupational exposures (asbestos, paint dust, polycyclic aromatic hydrocarbons and welding fumes) was examined. Therefore, an exposure estimate was assigned to each job by two experts; using information on job history from the baseline questionnaire. Next, for each study subject a probability of occupational exposure was determined. After adjustment for age, each of the other occupational exposures, smoking habits and intake of vitamin $\mathrm{C}$, beta-carotene and retinol, significant associations were found between lung cancer risk and probability of exposure to asbestos or paint dust. Furthermore, the influence of occupational exposure to these four carcinogens in explaining the previously found association between SES and lung cancer risk was evaluated for men. Adjustment for occupational exposure to asbestos, paint dust, polycyclic aromatic hydrocarbons and welding fumes did not change the inverse association between level of education and lung cancer risk. The association between the two occupation-based SES indicators and lung cancer risk was also not strongly influenced by occupational exposure to these carcinogens (Chapter 8 ).

In chapter 9 the role of physical activity at work in explaining the association between SES and colon cancer risk was investigated for men. Information on job title was used for the assessment of two measures of physical activity at work (energy expenditure and number of hours sitting at work). Additional adjustment for physical activity at work changed the statistically significant age- and lifestyle-adjusted positive association between colon cancer risk and highest attained level of education or EGP score into non-significant positive associations. However, the statistically significant positive association between U\&S score and colon cancer risk remained after additional adjustment for physical activity at work.

Finally, these results were evaluated in the light of possible explanations for an association, or lack of one, between SES, lifestyle, working conditions and cancer risk (chapter 10). Distribution of individuals among SES categories, method of operationalization of SES, associations between SES and lifestyle and/or working conditions and residual confounding or residual association are successively discussed. We concluded that for men in the Netherlands Cohort Study cancer risk appears to be associated with SES. The direction of the association differs between tumour sites. For women, no associations were found between SES and cancer risk, which may be due to the fact that the currently used SES indicators are not suitable for women in the studied age range. The SES of the last occupation will be of limited value for these women, because participation of women in the labour force used to be very low in the Netherlands. The role of lifestyle aspects such as smoking, alcohol intake and dietary habits turned out to be less prominent in explaining the associations between SES and cancer risk. Working conditions such as exposure to carcinogens could not explain the association between SES and lung cancer risk. However, adjustment for physical activity at work did alter the association between SES and colon cancer. 
Further research on SES and cancer risk should pay more attention to the measurement of SES among women of middle age or women of older age: Moreover, further research may also consider the clustering of lifestyle factors associated with cancer instead of studying separate lifestyle characteristics or working conditions and it may include the role of psychosocial factors in explaining the association between SES and cancer risk. 


\section{SAMENVATTING}

In dit proefschrift wordt de samenhang tussen sociaal-economische status (SES) en het risico op long-, borst-, colon- en maagkanker in Nederland geanalyseerd. Daarnaast is de rol van leefgewoonten en werkomstandigheden bestudeerd als mogelijke verklaring voor een eventuele samenhang tussen SES en het risico op kanker. Deze vragen zijn onderzocht in de prospectieve Nederlandse Cohort Studie (NLCS) naar voeding en kanker, die in 1986 van start is gegaan met 120.852 deelnemers, in leeftijd varièrend tussen 55 en 69 jaar. Als maten voor sociaal-economische status zijn beroep en hoogst behaalde opleiding gebruikt. Beroep is daarvoor ingedeeld naar beroepssector en benodigde. opleiding (EGP-score) en naar aanzien (U\&S-score). Het opsporen van nleuwe gevallen van kanker, ontstaan na 1986, gebeurde met behulp van informatie van de regionale kankerregistraties en met behulp van PALGA, een landelijke registratie van pathologische gegevens. De eerste resultaten hebben betrekking op gegevens die na 3,3 jaar follow-up verzameld zijn. Voor de latere analyses zijn gegevens na 4,3 jaar follow-up gebruikt.

In hoofdstuk 2 is een overzicht gegeven van de literatuur met betrekking tot SES in relatie tot diverse vormen van kanker. In dit overzicht zijn studies opgenomen die na 1970 zijn verricht, waarin opleiding, beroep en/of inkomen als maat voor SES zijn gebruikt. Uit dit overzicht bleek een consistente positieve samenhang tussen SES en het risico op borstkanker en een min of meer consistente positieve samenhang tussen SES en het risico op colonkanker. Tevens werd een consistent negatieve samenhang tussen SES en het risico op long- en maagkanker gevonden. Uit dit literatuuroverzicht bieek dat het onduidelijk was of deze associaties (deels) te wijten zijn aan leefgewoonten, zoals roken, voedingsgewoonten en alcoholgebruik ${ }_{\llcorner}$aangezien daar zeer weinig onderzoek naar verricht was.

De resultaten met betrekking tot SES en de samenhang met long-, borst-, colon- en maagkanker zijn beschreven in hoofdstuk 3 tot en met 6 . In eerste instantie is alleen gecorrigeerd voor eventuele verschillen in leeftijd. Vervolgens is de rol van leefgewoonten als verklaring voor gevonden associaties in de analyses betrokken.

We vonden een inverse samenhang tussen het risico op longkanker en thet hoogst behaalde opleidingsniveau bij mannen. Deze samenhang bleef bestaan na correctie voor rookgewoonten en inname van vitamine $C$, beta-caroteen en retinol. Mannen met een lager "witte boorden beroep" (bijvoorbeeld kantoorpersoneel) hadden een statistisch significant lager relatief risico op longkanker dan mannen met een "blauwe boorden beroep" (bijvoorbeeld fabrieksarbeiders), maar na correctie voor rookgewoonten was dit verschil verminderd (Hoofdstuk 3). We vonden geen samenhang tussen U\&S-score en longkankerrisico voor mannen en geen samenhang tussen de drie SES indicatoren en het risico op longkanker bij vrouwen.

Tussen de drie indicatoren voor SES en het risico op borstkanker werd eveneens geen verband gevonden. Correctie voor traditionele risicofactoren voor borstkanker zoals leeftijd waarop een vrouw haar eerste kind krijgt, het aantal kinderen, leeftijd waarop de menarche optreedt, zorgde niet voor een verandering in de samenhang tussen SES en borstkanker (Hoofdstuk 4).

Er werd in de NLCS bij mannen een positieve samenhang gevonden tussen het risico op colonkanker enerzijds en de hoogst behaalde opleiding of de U\&S-score anderzijds. 
Bovendien hadden mannen met een hoger witte boorden beroep (bijvoorbeeld artsen, advocaten) een hoger risico op colonkanker vergeleken met mannen met een blauwe boorden beroep. Echter, alleen de samenhang tussen U\&S-score en het risico op colonkanker bleef statistisch significant na correctie voor andere risicofactoren voor colonkanker. Bil vrouwen werden geen duidelijke assoclaties gevonden tussen SES en het risico op colonkanker (Hoofdstuk 5).

Ten aanzien van maagkanker vonden we een lager risico voor mannen in de hoogste opleidingscategorie. Deze samenhang werd minder sterk na correctie voor roken, inname van vitamine $C$, beta-caroteen, alcohol en koffie, het voorkomen van maagkanker in de familie en de prevalentie van maagaandoeningen. Er was geen duidelijke samenhang tussen het risico op maagkanker en de twee op beroep gebaseerde indicatoren voor SES (Hoofdstuk 6). Er werd geen samenhang gevonden tussen SES en het risico op maagkanker bij vrouwen.

In hoofdstuk 7 wordt de samenhang beschreven tuissen het risico op longkanker en eventuele blootstelling aan een aantal carcinogene stoffen in de arbeidssituatie (asbest, verfstof, polycyclisch aromatische koolwaterstoffen en lasdamp). Daarvoor is door twee deskundigen aan elk beroep een kans op blootstelling toegekend, gebaseerd op de beroepsinformatie uit de vragenlijst. Vervolgens is per persoon een kans op blootstelling aan kankerverwekkende stoffen tijdens werk vastgesteld. We vonden een statistisch significante samenhang tussen het risico op longkanker en de geschatte blootstelling aan asbest of verfstof, na correctie voor leeftijd, elk van de andere blootstellingen, rookgewoonten en de inname van vitamine $\mathrm{C}$, beta-caroteen en retinol. Vervolgens is bij mannen onderzocht of blootstelling aan de bovengenoemde carcinogenen de eerder geconstateerde samenhang tussen SES en longkanker kon verklaren

(hoofdstuk 8). Daaruit bleek dat noch de associatie tussen het risico op opleidingsniveau en longkanker, noch de associatie tussen de twee op beroep gebaseerde maten voor SES en het risico op longkanker sterk beînvloed werd door blootstelling aan de onderzochte carcinogene stoffen tijdens werk.

In hoofdstuk 9 is nagegaan of lichamelijke arbeid tijdens werk een mogelijke verklaring vormde voor de samenhang tussen SES en het risico op colonkanker bij mannen. Voor het inschatten van de twee maten voor lichamelijke activiteit tijdens werk (energieverbruik en aantal uren zitten per dag) werd gebruilk gemaakt van de beroepsinformatie. De voor leeftijd en leefstill gecorrigeerde statistisch significante samenhang tussen het risico op colonkanker en het opleidingsniveau c.q. de EGP-score, veranderde in een niet statistisch significante samenhang na correctie voor lichamelljke activiteit tijdens werk. De statistisch significante samenhang tussen het risico op colonkanker en de U\&S-score bleef echter bestaan na additionele correctie voor lichamelijke activiteit tijdens werk.

Tenslotte zijn deze bevindingen bekeken in het licht van mogelijke verklaringen voor een (gebrek aan) samenhang tussen SES, leefgewoonten, werkomstandigheden en het risico op kanker (hoofdstuk 10). Achtereenvolgens werden daarvoor het contrast in SES, de operationalisatie van SES, associaties tussen SES en leefgewoonten of werkomstandigheden en residuele confounding of residuele associatie bediscussieerd. Uit dit onderzoek kunnen we concluderen dat het risico op kanker voor mannen in de NLCS samenhangt met SES. De richting van de associaties varieert per tumorsoort. Voor vrouwen vonden we geen associaties tussen SES en het risico op kanker. Dit is wellicht te 
wijten aan de ongeschiktheid van de gehanteerde SES maten voor de generatie vrouwen die aan het onderzoek deelneemt. Aangezien deze vrouwen in Nederland in veel mindere mate deelnemen aan het arbeidsproces dan vrouwen in andere West-Europese landen en in Noord-Amerika, is het aannemelijk dat het laatste beroep geen goede indicator is voor SES. De rol van leefgewoonten als roken, alcoholgebruik en voedingsgewoonten bleken slechts een gering deel van de associaties tussen SES en het risico op kanker te verklaren. Werkomstandigheden als blootstelling aan kankerverwekkende stoffen tijdens werk vormden geen verklaring voor de samenhang tussen SES en het risico op longkanker. Correctie voor lichamelijke activiteit tijdens werk veranderde echter well de associatie tussen SES en het risico op colonkanker.

Verder onderzoek naar de samenhang tussen SES en kanker zou aandacht moeten besteden aan het op andere manieren meten van SES bij vrouwen uit de door ons bestudeerde leeftijdsgroep. Daarnaast zou het bestuderen van clusters van risicofactoren voor kanker in plaats van afzonderlijke leefstijl-kenmerken tot andere inzichten kunnen leiden. Tenslotte kan onderzoek naar psychosociale factoren mogelijk verklaringen bieden voor de samenhang tussen SES en het risico op kanker. 


\section{DANKWOORD}

Met veel plezier heb ik het onderzoek naar de samenhang tussen sociaal-economische status en kanker uitgevoerd. Dit plezier heb ik aan heel veel mensen te danken, want ik heb de gegevens van duizenden mensen mogen gebruiken. Een deel van deze personen wordt nog met zekere regelmaat bestookt met nieuwe vragenlijsten en gelukkig worden deze lijsten door vrijwel iedereen steeds weer ingevuld.

Naast de anonieme dankzegging will ik ook diverse mensen persoonlijk noemen; te beginnen met mijn promotoren Piet van den Brandt en Ferd Sturmans en mijn co-promotor Sandra Bausch. Beste Piet, ik had tijdens mijn stageperiode al van je geleerd dat epidemiologisch onderzoek veel leuker was dan ik daarvoor dacht. Dat en ook veel inhoudelijk zaken heb ik de afgelopen jaren wederom van je meegekregen. Als co-promotor heb je heel veel meegedacht en meegeschreven. Je enthousiasme en betrokkenheid zorgde ervoor dat ik na besprekingen steeds weer met nieuwe ideeën en frisse moed aan het werk ging en ik ben heel blij dat je uiteindelijk zelfs mijn promotor bent geworden. Beste Sandra, ook jouw enthousiasme en gedrevenheid was voor mij een stimulans tijdens de afgelopen jaren. Bovendien ben je voor mij het bewijs dat je goed meerdere of zelfs veel bezigheden naast elkaar kunt verrichten. Daarnaast zorgde je ervoor dat ik aan het begin van mijn aanstelling op maandag bij TNO in Zeist kon zitten werken en sinds kort kan ik daar op vrijdag weer terecht. $\mathrm{k}$ hoop dat we daardoor nog meer dingen samen kunnen doen. Beste Ferd; jjj begon als één van de eersten over promoveren, toen er na mijn aanstelling van anderhalf jaar mogelijkheden kwamen om langer bij de vakgroep Epidemiologie te blijven werken. Dit heeft er echter toe geleid dat ik in die mate een onderzoeker ben geworden, dat ik het moeilijk vind om zeer stellige, beleidsgerichte uitspraken te doen over onderzoek.

De leden van het "NLCS-team" leverden ieder hun eigen bijdrage aan het tot stand komen van het proefschrift. Elisabeth Dorant, ijj bent altijd aanspreekbaar voor vragen, onduidelijkheden enzovoort. Patricia Florax en Jolanda Nelissen, de vragenlijsten die door jullie ingevoerd zijn vormen de basis van al mijn computerwerk, bovendien kon ik bij] topdrukte bij jullie terecht voor typewerk of voor invoer in cardbox. Voor een praatje (en soms een koekje...) kan ik ook altijd de "cohortkamer" binnenlopen. Sacha van de Crommert, door jouw adequate beheer van de data blijft het overzicht altijd behouden. Bovendien weet je heel veel van SPSS en andere relevante computerpakketten. Marijke Moll, ook op jou kon ik vaker een beroep doen als er snel iets opgezocht of getypt moest worden. Anita Botterweck, Agnes Schuurman en Miranda Dirx, jullie leveren eveneens een belangrijke bijdrage aan de goede sfeer, waarin gezelligheid op zijn tijd afgewisseld kan worden met het delen van frustraties over GLIM, geweigerde manuscripten en onderzoek doen in het algemeen. Harry van Montfort, ik hoef het maar te vragen en je komt kijken waarom mijn computer weer niet doet wat ik will (ook al zijn de computer ins en outs niet aan mij besteed). Willy van Dijk, Henny Brants, Arthur van Aken en Carla Sloot dragen vanuit TNO in Zeist eveneens bij aan het tot stand komen en op peil houden van de gegevens waar ik mee in de weer ben geweest. 
IJmert Kant, Gerard Swaen, Anja Kremer en Hans Brug wil ik bedanken voor hun hulp bij het schrijven van één of meer hoofdstukken in dit proefschrift. Met Jan Joosten en Sandra Beurskens heb ik met name over de introductie en algemene discussie van gedachten gewisseld. Swenneke van den Heuvel van TNO-PG wil ik bedanken voor het coderen van de beroepenvraag; waar twee maten van sociaal-economische status op gebaseerd zijn. Joost Thissen en Dick Heederik van de vakgroep Humane Epídemiologie en Gezondheidsleer worden bedankt voor het coderen van de beroepsinformatie naar lichamelijke activiteit. Verder wil ik alle mensen bedanken die al "voor mijn tijd" een bijdrage geleverd hebben aan de Nederlandse Cohort Studie, waar ik voor mijn proefschrift gretig gebruilk van heb gemaakt.

Mijn collega's van de vakgroep Epidemiologie wil ik bedanken voor een zeer plezierige werksfeer, waar het gezellig samen koffie drinken en lunchen hand in hand gaat met een kritische kijk op het vakgebied. Ook zijn er vele collega's betrokken geweest bij de laatste bewerking van het proefschrift. Zij hebben ervoor gezorgd dat ik met een gerust hart met zwangerschapsverlof kon gaan. Cobie Martens en Ria Franke wil ik met name bedanken voor hun aanzienlijke hulp bij het camera-klaar maken van het proefschrift en Riekie de Vet wil ik bedanken voor het opsporen van typefouten, scanfouten en inconsistente zaken in de "bijna laatste" versie.

Harry Wijnhoven heeft er tenslotte voor gezorgd dat de tekst bedekt kon worden met een mooie kaft. Heel veel dank woor dit cadeau.

Verder wil ik mijn vrienden en familieleden bedanken voor de betrokkenheid bij mijn werk en voor de afwisseling buiten mijn werk. Voor velen was Maastricht een heel eind weg, maar gelukkig wisten ze het wel te vinden. Mijn ouders wil ik bedanken voor de steun en voor het vertrouwen wat ze in mij stelden toen ik ging studeren. Zij hebben zelf nooit de kans daarvoor gehad, ik hoop dat ze via mij lets van het plezier, de uitdaging en de voldoening mee hebben gekregen. Diederik, tenslotte wil ik jou bedanken voor een zeer plezierig en afwisselend leven. Gelukkig vond je het geen probleem om enkele jaren in Maastricht te wonen, want zonder jouw inschikkelijkheid was ik daar nooit gaan werken. De laatste fase van het promotieonderzoek was niet makkelijk te combineren met een zwangerschap, maar gelukkig kon ik altijd op je terugvallen als het teveel werd. Ik ben erg blij dat onze Tjitse net op tijd geboren is om de afronding van mijn proefschrift mee te maken. 


\section{AUTHORS}

P.A. van den Brandt M.Sc. Ph.D., Department of Epidemiology, University of Maastricht

J. Brug M.Sc. Ph.D., Department of Health Education, University of Maastricht

R.A. Goldbohm M.Sc. Ph.D., Department of Consumer Research and Epidemiology, TNO-Nutrition and Food Research Institute, Zeist

IJ. Kant B.Sc. Ph.D., Department of Epidemiology, University of Maastricht

A.M. Kremer M.D. Ph.D., Innovation of work, Organisation and Technology, Amsterdam

G.M.H. Swaen Ph.D., Department of Epidemiology, University of Maastricht 


\section{CURRICULUM VITAE}

Jeanne van Loon werd geboren op 29 juni 1963 te Oss. In 1981 behaalde zij het Atheneum-B diploma aan het Maaslandcollege te Oss. Van 1981 tot 1988 studeerde zij Humane Voeding aan de Landbouwuniversiteit te Wageningen. Naast het hoofdvak Humane Voeding, volgde zij doctoraalvakken bij de vakgroepen Epidemiologie, Psychologie, Voorlichtingskunde en Vrouwenstudies. Na haar afstuderen was zij achtereenvolgens werkzaam voor de Voedingsraad (verwerken van ziekte- en sterftecijfers met betrekking tot aan voeding gerelateerde aandoeningen), het Rijksinstituut voor Landen Tuinbouwprodukten (bepalen van de nitraatinname van de Nederlandse bevolking) en de vakgroep Humane Epidemiologie en Gezondheidsleer te Wageningen (onderzoek naar regionale verschillen in gezondheid). Vanaf februari 1992 tot heden is zij als Universitair Docent werkzaam bij de vakgroep Epidemiologie van de Universiteit Maastricht. In deze periode werd het in dit proefschrift beschreven onderzoek verricht. 
